\title{
Axillary and internal mammary sentinel node biopsy in breast cancer : studies on technical aspects, clinical implications and outcome
}

Citation for published version (APA):

Heuts, E. M. (2009). Axillary and internal mammary sentinel node biopsy in breast cancer : studies on technical aspects, clinical implications and outcome. [Doctoral Thesis, Maastricht University]. Maastricht University. https://doi.org/10.26481/dis.20090702eh

Document status and date:

Published: 01/01/2009

DOI:

10.26481/dis.20090702eh

Document Version:

Publisher's PDF, also known as Version of record

Please check the document version of this publication:

- A submitted manuscript is the version of the article upon submission and before peer-review. There can be important differences between the submitted version and the official published version of record.

People interested in the research are advised to contact the author for the final version of the publication, or visit the DOI to the publisher's website.

- The final author version and the galley proof are versions of the publication after peer review.

- The final published version features the final layout of the paper including the volume, issue and page numbers.

Link to publication

\footnotetext{
General rights rights.

- You may freely distribute the URL identifying the publication in the public portal. please follow below link for the End User Agreement:

www.umlib.nl/taverne-license

Take down policy

If you believe that this document breaches copyright please contact us at:

repository@maastrichtuniversity.nl

providing details and we will investigate your claim.
}

Copyright and moral rights for the publications made accessible in the public portal are retained by the authors and/or other copyright owners and it is a condition of accessing publications that users recognise and abide by the legal requirements associated with these

- Users may download and print one copy of any publication from the public portal for the purpose of private study or research.

- You may not further distribute the material or use it for any profit-making activity or commercial gain

If the publication is distributed under the terms of Article 25fa of the Dutch Copyright Act, indicated by the "Taverne" license above, 


\section{Axillary and internal mammary sentinel node biopsy in breast cancer \\ Studies on technical aspects, clinical implications and outcome.}




\section{Axillary and internal mammary sentinel node biopsy in breast cancer}

Studies on technical aspects, clinical implications and outcome.

\section{Proefschrift}

ter verkrijging van de graad van doctor aan de Universiteit Maastricht

op gezag van Rector Magnificus, Prof mr. G.P.M.F. Mols

volgens het besluit van het College van Decanen

in het openbaar te verdedigen

op donderdag 2 juli 2009 om 10.00 uur

$$
\text { door }
$$

Esther Maria Heuts 
Promotor:

Prof. dr. M.F. von Meyenfeldt

\section{Co-promotores:}

Dr. F.W.C. van der Ent, Orbis Medisch Centrum, Sittard

Dr. A.C. Voogd

Beoordelingscommissie:

Prof. dr. V.C.G. Tjan-Heijnen (voorzitter)

Dr. L.J. Boersma

Prof. dr. G. Cserni (Bacs-Kiskun County Teaching Hospital, Hungary)

Prof. dr. E.J.Th. Rutgers (NKI-AVL Amsterdam)

Prof. dr. G.J.). Teule

Layout \& Design:

www.dlgraphics.nl

Illustration cover:

Dana Hamers

Eric Lemmens

Print:

Drukkerij Schrijen-Lippertz Voerendaal/Stein

ISBN/EAN: $978-90-8590-036-8$

The publication of this thesis was financially sponsored by

AstraZeneca BV

Novartis Pharma BV

Pfizer BV

GlaxoSmithKline BV

Maatschap Heelkunde MUMC+ 


\section{CONTENTS}

Chapter 1 Introduction and outline of the thesis

Studies on technical aspects, clinical implications and outcome of axillary SN biopsy

Chapter 2 Additional tracer injection to improve the technical success rate of lymphoscintigraphy for sentinel node biopsy in breast cancer Ann Surg Oncol 2009; 16:1156-1163

Chapter 3 Results of sentinel node biopsy not affected by previous excisional biopsy Eur I Surg Oncol 2006; 32:278-281

Chapter 4 Incidence of axillary recurrence in 344 sentinel node negative breast cancer patients after intermediate follow-up Acta Chir Belg 2007; 107:279-283

Studies on technical aspects, clinical implications and outcome of internal mammary SN biopsy

Chapter 5 Internal mammary lymph drainage and sentinel node biopsy in breast cancer- a study on 1008 patients Eur I Surg Oncol 2009; 35:252-257

Chapter 6 Results of tailored treatment for breast cancer patients with internal mammary lymph node metastases The Breast, in press

Chapter 7 Evaluation of early versus delayed lymphoscintigraphic imaging in detecting internal mammary sentinel lymph nodes in breast cancer.

Nucl Med Commun 2006: 27:677-681

Chapter 8 The role of preoperative SPECT/CT for internal mammary sentinel node biopsy in patients with breast cancer Submitted

Chapter 9 General Discussion 129

Chapter 10 Summary 143

Chapter 11 Samenvatting 151

Dankwoord 159 


\section{Chapter 1}

Introduction and

Outline of the Thesis 
Chapter 1

8 


\section{INTRODUCTION}

Breast cancer is by far the most common form of cancer and, together with carcinoma of the lung, the leading cause of cancer-related deaths in European women today'. In the Netherlands, over 12,000 new patients with breast cancer were diagnosed in 2005 while 3322 patients died of this disease 2 .

In recent years breast cancer treatment has gradually shifted from aggressive surgical treatment to minimally invasive surgical procedures. The introduction of mass screening programs resulted in the earlier detection of breast cancers, which brought about a change in stage distribution. These smaller breast lesions made room for less aggressive treatment options. Besides this rearrangement in stage distribution, the addition of adjuvant chemotherapy and radiotherapy have made less invasive treatment possible ${ }^{3}$. An excellent example of this shift in treatment is the sentinel node ( $\mathrm{SN}$ ) technique as an alternative for axillary fymph node dissection (ALND) for staging in breast cancer. An overview of the history, technique, validation and indications of the SN procedure will be given in this chapter, as well as the aims of this thesis, following from this overview.

\section{History}

In the early 1900's Halsted formulated the theory that a tumour gradually metastasizes through lymphatic channels to regional lymph nodes before hematogenic dissemination takes place. Since then regional lymph node dissection has always been an integral part of breast cancer treatment. In accordance with Halsted's concept, breast cancer was treated with radical mastectomy, in which the breast, axillary lymph nodes and the pectoral muscle were dissected, followed by the supra-radical mastectomy, whereby, in addition to the axillary lymph nodes, the internal mammary nodes were removed. After a period of several decades during which this radical surgery was advocated, a new era of less invasive treatment emerged, as randomized clinical trials had failed to demonstrate survival benefit of the supra-radical surgical procedure.

In 1948 Patey introduced the modified radical mastectomy in which the pectoral muscle was spared. In 1981 breast conserving treatment was advocated by Veronesi. All along, axillary lymph node dissection remained an essential part of the treatment: for staging, local regional control and an indicator of the need for adjuvant therapy.

In $30 \%$ to $40 \%$ of patients with curable breast cancer metastases in the axilla are found. Axillary clearance in this group provides regional tumour control. However, the morbidity of ALND is considerable: high percentages of 
chronic lymphedema (6-56\%), pain (16-55\%), sensibility disorders (58-81\%) and dysfunction of the shoulder and arm (14-32\%) are reported, depending on the definitions used ${ }^{4}$. In patients with a tumour negative axilla, who make up $60-70 \%$ of all patients, lymph node dissection has no additional value. With SN biopsy it is now possible to offer this group of patients an accurate staging without the morbidity of axillary clearance.

In $1993 \mathrm{Krag}$ was the first to describe the SN biopsy technique in breas cancer ${ }^{5}$. He injected a radioactive tracer around the tumour. The sentinel lymph node was localized during surgery by measuring the radioactivity with a gamma probe. Based on the intradermal injection technique used by Morton for melanomas, Giuliano introduced a peritumoural injection technique with blue dye $e^{6-8}$. Albertini advocated the combination of both techniques. Borgstein simplified the sentinel lymph node technique by showing that the intracutaneous blue dye injection identified the same axillary lymph nodes as the peritumoural radioactive tracer injection ${ }^{9}$.

The concept

The sentinel lymph node is the first lymph node upon which the primary tumour drains. This lymph node will be the first lymph node to harbour metastases. In case of a tumour negative SN, lymphatic metastasizing has not (yet) occurred.

\section{The technique}

In a one or two day protocol a radioactive tracer is injected in the breast. Preoperative lymphoscintigraphy is helpful by visualizing location and number of axillary and non-axillary SNs. Under general or local anaesthesia according to the preoperative lymphoscintigraphic images and after injecting a blue dye as a second tracer, the radioactive and/or blue SN can be found and removed. Both "isosulfan blue" and "patent blue V" can be used for lymphatic mapping, depending on local availability. Moreover, occasional reports about the use of other blue dyes have been published.

Several studies have shown that the combination of a preoperative lymphoscintigraphy and the intra operative use of blue dye and a gamma probe gives the best results ${ }^{10}$.

However, sometimes the lymphatic mapping procedure fails, because of insufficient or absent radioactive tracer uptake in the lymph nodes. Because a negative preoperative lymphoscintigraphy is predictive for failure of intraoperative SN identification, faint- or non-visualization of hotspots on lymphoscintigraphic imaging frequently results in the need to perform ALND ${ }^{11}$. 
Chapter 2 provides the results of a study which explored the value of additiona tracer injection to increase the technical success rate of the SN procedure in case of a vague or negative lymphoscintigraphy. In addition factors were identified that are associated with inadequate visualization of hotspots.

There is still debate concerning the location of the tracer injection. Based on the anatomic embryology of the breast, the skin overlying the breast and the breast parenchyma share the same lymphatic drainage to the axillary nodes 9 . Therefore, the site of tracer injection does not influence the detection of the axillary SN. Various injection sites for the radiocolloid are described with good results, such as intracutaneous, subareolar, peritumoural, intratumoural, subtumoural and periareolar injection sites. Advocates of the intracutaneous injection technique emphasize the simplicity of the technique and the rapid flow through the lymphatic channels, which make the one day protocol short and simple.

Advocates of the peritumoural and intratumoural injection site stipulate that this technique provides a more precise image of the drainage pathways of the tumour.

Lymph drainage to the internal mammary chain is virtually absent afte intradermal injections. But lymphoscintigraphy can visualize internal mammary nodes after peri-, intra- or subtumoural tracer injection, enabling internal mammary SN biopsy ${ }^{12-14}$.

There is ongoing debate concerning the particle size of the different radioactive tracers. Smaller particles flow more easily through the lymphatics and are retained in the macrophages of the lymph node for a relative short period, as compared to larger colloids. In the Netherlands Tc-99m nanocolloid is used. This tracer combines easy gamma detection with rapid accumulation in the sentinel lymph node.

There is also discussion concerning the amount of radioactivity used. The amount of radioactivity in the literature varies from $37-370 \mathrm{MBq}(1-10 \mathrm{mCi})^{15}$. Radiation safety for the medical staff versus optimal detection of the radioactive lymph nodes and logistic reasons influence the amount of tracer used. The radiation exposure for the patient is negligible as compared to adjuvant radiotherapy for breast conserving therapy and irrelevant in case of a mastectomy. Pijpers et al. proved that the radiation exposure for the surgeon and the staff, using $37 \mathrm{MBq}(1 \mathrm{mCi})$, stays within the limit of $1 \mathrm{mSv}$ per year ${ }^{16}$. If we extrapolate the knowledge from this study to our own technique, using $370 \mathrm{MBq}$, a surgeon can perform over $650 \mathrm{SN}$ procedures per year and stay well within the legal limit of $1000 \mu \mathrm{Sv}$. 
Histopathological examination of the SN consists of hematoxylin/eosin staining, serial sectioning and immunohistochemical (IHC) staining ${ }^{17}$. Compared to ALND, the SN procedure enables improved staging, because the pathologist can focus on one node or a few at the most, instead of up to twenty nodes. By means of specific techniques, e.g. IHC, micrometastases can now be detected, which previously remained undetected and have resulted in stage migration ${ }^{18}$. The prognostic relevance of micrometastases in breast cancer is subject of ongoing studies.

Indication and exclusion criteria for SN biopsy

Indications and exclusion criteria for the use of SN biopsy have not fully crystallized yet. Currently, SN biopsy is applied to $>70 \%$ of breast cancer patients in The Netherlands ${ }^{19}$. Before performing a SN procedure, a preoperative clinical and ultrasound examination of the axilla and fine needle aspiration of suspect nodes should be performed. This will reduce the risk of false negative results due to massive tumour infiltration in the lymph node.

Groups for which the use of SN biopsy is debated are patients with ductal carcinoma in situ (DCIS), patients with a previous excisional biopsy, patients with recurrent breast cancer and patients who received neo-adjuvant chemotherapy.

- DCIS is a non-invasive cancer which does not metastasize. However, in approximately $17 \%$ of the resected DCIS specimens an invasive component is found, which necessitates staging. The Dutch guideline for breast cancer (NABON richtlijn) does not recommend SN biopsy in case of grade I DCIS. In case of extended and/or high grade DCIS (grade II and III) a SN biopsy should be considered ${ }^{20}$.

- Previous excisional biopsy is also considered an exclusion criterion due to potential disruption of lymphatic tracts. In Chapter 3, the results are presented of 88 patients undergoing a SN procedure after previous excisional biopsy.

- Until now, preoperative radiotherapy to the breast is considered to be an absolute exclusion criterion for SN biopsy.

- There is still debate considering $S N$ biopsy following neo-adjuvant chemotherapy. In patients with T3/T4 tumours, for whom neo-adjuvant chemotherapy is most often considered, the sentinel node procedure may be less reliable because of the risk of massive tumour infiltration. In addition, chemotherapy induces cellular necrosis, which complicates pathological examination. However, recent studies have shown good results in patients receiving neo-adjuvant chemotherapy ${ }^{21}$

- Mastitis carcinomatosa remains an exclusion criterion ${ }^{22}$. 


\section{Validation and long term results}

Many studies concerning the concept, validation and feasibility of the $\mathrm{SN}$ procedure in breast cancer have been performed ${ }^{6,8-10,23-27}$

Validation studies confirm that SN biopsy, independent of the technique used, accurately predicts the nodal status of the axilla. After validation of the institution and the surgeon axillary clearance can be omitted in case of a tumour negative SN. To do so, the aforementioned studies recommend an identification rate and a sensitivity of more than $95 \%$, resulting in a false negative rate of less than $5 \%$

The first long term results in this group of patients are currently available. Chapter 4 describes the follow-up results of $\mathrm{SN}$ negative patients who did no receive elective ALND. Special attention was paid to axillary recurrence and possible reasons for this relapse.

\section{Internal mammary SN biopsy}

The technique of lymphatic mapping inevitably confronts us with the visualization of SNs outside the axilla. This has renewed the interest in internal mammary lymph drainage and the question of its clinical relevance. Surgical series from the 1950s showed that one third of breast cancer patients had IMN involvement, with a higher risk in patients with medial tumours and/or positive axillary nodes. The presence of internal mammary metastases has similar prognostic importance as axillary nodal involvement ${ }^{28}$. However, after three randomized trials, which showed no survival benefit from extended mastectomy compared with radical or modified radical mastectomy, IMN dissection was largely abandoned. Given the prognostic significance of nodal positivity in the internal mammary chain, harvesting of the internal mammary nodes, based on lymphoscintigraphy, will have implications for staging and adjuvant treatment ${ }^{12,29}$. Nevertheless, when lymphatic mapping reveals IM drainage, staging of these nodes is not performed routinely, thus discarding additional staging information.

The experience in a 9 years period, in which IMSN biopsy was performed on a routine basis in patients with primary breast cancer is presented in Chapter 5 .

The clinical relevance of IMSN biopsy, in terms of survival, is questionable. Whether radiotherapy to the IM chain or adjuvant systemic therapy is beneficial to high risk subgroups of breast cancer patients with IM metastases is unclear In an attempt to answer this question, treatment outcome of patients with $\mathbb{I}$ lymph node metastases, who received tailored adjuvant treatment regimens were evaluated, of which the results are presented and discussed in Chapter 6 The next two chapters deal with technical aspects and refinement of IMSN 
biopsy. As discussed above, intraparenchymal tracer injection is essential to visualize drainage to the $\mathrm{IM}$ lymph nodes. In addition to the injection site, other factors can influence IM drainge. In Chapter 7 the effect of different time intervals between radioactive tracer injection and lymphoscintigraphy on visualization of IMSNs is evaluated.

The retrieval of IMSNs is often technically more challenging as compared to axillary SN biopsy and is associated with lower identification rates ${ }^{5}$. Failure in harvesting IM SNs is correlated with their small size, difficult anatomical localization, or limited radioactive tracer uptake ${ }^{4}$. SPECT/CT (Single-Photon Emission Computed Tomography/Computed Tomography) is a recent noninvasive technique that combines the functional information of SPECT with the anatomical information provided by CT. Chapter 8 gives the results of a study, in which it was investigated whether this new technique is beneficial compared to lymphoscintigraphy alone, in patients with IM hotspots.

\section{AIMS OF THE THESIS AND DATA COLLECTION}

In summary, the aims addressed in this thesis are to:

Chapter 2: ascertain the value of additional tracer injection to increase the technical success rate of the SN procedure in case of a vague or negative lymphoscintigraphy.

Chapter 3: determine whether patients with previous excisional biopsy are eligible for $\mathrm{SN}$ biopsy.

Chapter 4: evaluate the accuracy of the $\mathrm{SN}$ procedure by focusing on the outcome of SN negative patients who did not receive elective ALND

Chapter 5: demonstrate the risk of IM lymph node metastases in case of IM hotspots on lymphoscintigraphy and evaluate the relevance of IMSN biopsy as a method to improve staging.

Chapter 6: assess treatment outcome of patients with IM lymph node metastases, who received tailored adjuvant treatment regimens

Chapter 7: establish the effect of different time intervals between radioactive tracer injection and lymphoscintigraphy on visualization of IMSNs.

Chapter 8: investigate whether SPECT/CT has a significant influence on the surgical decision making, as compared to conventional lymphoscintigraphy alone, in patients with breast cancer with $I M$ hotspots on lymphoscintigraphy. 
1997 . PW

Chapter 2: 1208 patients, 93 with additional tracer injection, 1997-August 2007. Aim: to evaluate the value of additional tracer injection.

Chapter 3: 138 patients SN with ALND, 1997.jan 2000. Aim: to determine the validity of SN after excision biopsy.

Chapter 4: 656 patients, 343 with negative SN, 1998-May 2004. Aim: to determine the number of axillay recurrences in case of a negative SN.

Chapter 5: 1008 patents, 1997-may 2006. Aim: evaluate the clinical relevance of IMSN biopsy to improve staging.

Chapter 6: 764 patients, 1997-july 2004. Aim: assess outcome of patients with IM metastases

Chapter 7: 1997-august 2001, 682 patients, Aim: establish the effect of different time intervals on visuallzzation of IMSNs

Chapter 8: jan 2006-jan 2008, 42 patients. Aims.investigate the additional rolc of SPECT/CT for IMSNs.

With the exception of the multicenter study described in chapter 7 , all studies described in this thesis are based on the data from the Maasland Hospital (as of February $1^{\text {st }} 2009$ Orbis Medical Center) in Sittard-Geleen, The Netherlands. This prospective, standardized ongoing database was created at the introduction of the SN procedure in 1997 in the Maasland Hospital, and presently consists of over 1400 patients. All consecutive patients with clinically node-negative operable primary breasl cancer undergoing SN biopsy were included in the database. Except for pregnant women and patients with $\mathrm{T}_{4-}$ tumours, no patients were excluded. Data with regard to patient and tumour characteristics, and staging and treatment procedures were documented and complete disease-specific follow-up data were obtained.

The SN technique consisted of an injection of $370 \mathrm{MBq}(10 \mathrm{mCi}){ }^{99 \mathrm{~m}} \mathrm{TC}$ nanocolloid, either peritumourally or into the breast tissue adjacent to the cavity of the previous excisional biopsy. All patients underwent preoperative lymphatic mapping following a mean interval of 16 hours (range: 12-18). During surgery in all patients attempts were made to harvest both axillary and non-axillary SNs, as visualized on lymphoscintigraphy. In phase I of this study (137 patients) SN biopsy was followed by completion axillary lymph node dissection in all cases. In phase II, after validation of the SN technique in our institute, completion axillary lymph node dissection was performed only in cases of a tumour-positive axillary $\mathrm{SN}$ or non-successful $\mathrm{SN}$ procedure. 


\section{RefERENCES}

1. Ferlay I, Autier P, Boniol M, Heanue $M$, Colombet $M$, Boyle P. Estimates of the cancer incidence and mortality in Europe in 2006. Ann Oncol 2007; 18:581-592.

2. Netherlands Cancer Registry (2005).

http://www.ikcnet.nl/page.php?id=1865\&nav_id=41. accessed 16-12-08.

3. Louwman WJ, Voogd AC, van Dijck JA, Nieuwenhuijzen GA, Ribot J, Pruijt JF, et al. On the rising trends of incidence and prognosis for broast cancer patients diagnosed 19752004: a long-term population-based study in southeastern Neherlands. Cancer Causes Conlrol 2008; 19:97-106.

4. Schijven $M$, Rutten $H$, Roumen R. Implementation of the sentinel node biopsy: a survey among surgeons in the Netherlands. Eur I Surg Oncol 2000; 26:431-4.32.

5. Krag DN, Weaver DL, Alex JC, Fairbank IT. Surgical resection and radiolocalization of the sentinel lymph node in breast cancer using a gamma probe. Surg Oncol 1993; 2:335-339.

6. Giuliano AE, Kirgan DM, Guenther IM, Morlon DL. Lymphatic mapping and sentinel lymphadenectomy for breast cancer. Ann Surg 1994; 220:391-398.

7. Morton DL, Wen DR, Wong JH, Economou IS, Cagle LA, Storm FK, et al. Technical details of intraoperative lymphatic mapping for early stage melanoma. Arch Surg 1992; 127:392-399.

8. Albertini J), Lyman $\mathrm{GH}, \mathrm{Cox} \mathrm{C}$, Yeatman T, Balducci L., Ku N, et al. Lymphatic mapping and sentinel node biopsy in the palient with breast cancer. JAMA 1996; 276:18181822.

9. Borgstein PI, Meijer S, Pijpors R. Intradermal blue dye to identify sentinel lymph-nude in breast cancer Hetter| [sece comments]. I.ancel 1997; 349:1668-1609.

10. Tafra L, Lannin DR, Swanson MS, Van Eyk J\}, Verbanac KM, Chua AN, et al. Multicenter Trial of Sentinel Node Biopsy for Breast Cancer Using Both Technetium Sulfur Colloid and Isosulfan Bluc. Dye. Ann Surg 2001; 233:51-59.

11. Goyal A, Mansel RE. Recent advancess in sentinel lymph node biopsy for breasl cancer. Curr Opin Oncol 2008; 20:621-626.

12. van der Ent FW, Kengen RA, van der l'ol HA, Povel IA, Stroeken HJ, Hoofwijk AG. Halsted revisited: internal mammary sentinel lymph node biopsy in breast cancer. Ann Surg 2001; 234:79-84.

13. Jansen L, Nieweg OE, Valdes OR, Rutgers B], Peterse LL, de Vries J, el al. Improved staging of breast cancer through lymphatic mapping and sentinel node biopsy. Eur I Surg Oncol 1998; 24:445-446.

14. Shimazu K, Tamaki Y, Taguchi T, Motomura K, Inaji H, Koyama $H$, el al. Lymphoscintigraphic visualization of internal mammary nodes with subtumoral injection of radlocolloid in patients with breast cancer. Ann Surg 2003; 237:390-398. 
15. van der Ent FWC, Kengen RAM, van der Pol HAG, Hoofwijk AGM. Sentinel node biopsy in 70 unselected patients with breast cancer: increased feasibility by using $10 \mathrm{mCl}$ radiocolloid in combination with a blue dye tracer. Eur I Surg Oncol 1999; 25:24-29.

16. Pijpers R, Meijer $S$, Dignum P, Bosma A, van Lingen A, Borgstein PI. The sentinel node procedure: aspects of radiation safely of a new surgical technique. Tijdschrift voor Nucleaire Geneeskunde 1997; 19:144-147.

17. Richtlijn behandeling van het mammacarcinoom, Nationaal Borstkanker Overleg Nederland (NABON). Alphen aan den Rijn: van Zuiden Communications; 2002.

18. Maaskant AJ, van de Poll-Franse IV, Voogd AC, Coebergh JW, Tutein NoltheniusPuylaert MC, Nieuwenhuijzen GA. Stage migration due to introduction of the sentinel node procedure: a population-based study. Breast Cancer Res Treat 2009; 113:173179

19. Ho VK, van der Heiden-van der Loo, Rutgers EJ, Van Diest Pl, Hobbelink MG, TjanHeijnen VC, et al. Implementation of sentinel node biopsy in breast cancer patients in the Netherlands. Eur J Cancer 2008; 44:683-691.

20. Richtlijn Behandeling Mammacarcinoom (NABON richtlijn). http://www.oncoline.nl/index.php?pagina=/richtlijn/item/pagina.php\&richtlijn_id=593. 2008, accessed 16-4-0009.

21. Xing $Y$, Foy $M$, Cox DD, Kuerer HM, Hunt KK, Cormier JN. Meta-analysis of sentinel lymph node biopsy after preoperative chemotherapy in patients with breast cancer. $\mathrm{Br}$ J Surg 2006; 93:539-546.

22. Stearns V, Ewing CA, Slack R, Penannen MF, Hayes DF, Tsangaris TN. Sentinel lymphadenectomy after neoadjuvant chemotherapy for breast cancer may reliably represent the axilla except for inflammatory breast cancer. Ann Surg Oncol 2002; 9:235-242.

23. Giuliano $A E$, Jones $R C$, Brennan $M$, Statman $R$. Sentinel lymphadenectomy in breast cancer. J Clin Oncol 1997; 15:2345-2350.

24. Veronesi U, Paganelli G, Galimberti V, Viale G, Zurrida S, Bedoni $M$, et al. Sentinelnode biopsy to avoid axillary dissection in breast cancer with clinically negative lymph-nodes. Lancet 1997; 349:1864-1867.

25. Roumen RMH, Valkenburg JGM, Geuskens LM. Lymphoscintigraphy and feasibility of sentinel node biopsy in 83 patients with primary breast cancer. Eur J Surg Oncol 1997; 23:495-502.

26. Borgstein PJ, Pijpers R, Comans EF, Van Diest PJ, Boom RP, Meijer S. Sentinel lymph node biopsy in breast cancer: guidelines and pitfalls of lymphoscintigraphy and gamma probe detection. J Am Coll Surg 1998; 186:275-283.

27. Krag D, Weaver D, Ashikaga T, Moffat F, Klimberg VS, Shriver $C$, et al. The sentinel node in breast cancer--a multicenter validation study. N Engl I Med 1998; 339:941-946. 
28. Veronesi U, Cascinelli N, Bufalino R, Morabito A, Greco M, Galluzzo D, et al. Risk of internal manmmary lymph node metastases and its relevance on prognosis of breast cancer patients. Ann Surg 1983; 198:681-684.

29. Jansen L, Doting $M H$, Rutgers EJ, de Vries J, Olmos RA, Nieweg OE. Clinical relevance of sentinel lymph nodes outside the axilla in patients with breast cancer. Br I Surg 2000; 87:920-925. 


\section{ChAPTER 2}

Additional tracer injection to improve the technical success rate of lymphoscintigraphy for sentinel node biopsy in breast cancer 
Chapter 2

\section{ABSTRACT}

Background

Sentinel node (SN) biopsy has become the standard of care in the treatment of breast cancer. The aim of this study is to determine the value of additional tracer injection to increase the technical success rate of the SN procedure and to identify factors that influence the ability to visualize hotspots.

\section{Methods}

From February 1997 to August 2007, 1208 clinically node-negative breast cancer patients underwent lymphatic mapping for SN biopsy. The technique involved the injection of $370 \mathrm{MBq}(10 \mathrm{mCi}) \mathrm{Tc}-99 \mathrm{~m}$-nanocolloid peritumorally. In case of insufficient or absent visualization of hotspots $37 \mathrm{MBq}(1 \mathrm{mCi})$ of additional tracer was given intracutaneously above the tumour.

\section{Results}

In 93 patients $(7.7 \%)$ visualization of hotspots on initial lymphoscintigraphy was insufficient (41 patients) or absent (52 patients). The first 14 patients did not receive additional tracer injection. In 5 patients, additional tracer did not result in successful lymphoscintigraphy, which is correlated with massive nodal tumour infiltration. In 33 patients with negative initial lymphoscintigraphy, additional tracer injection resulted in secondary SN visualization.

In 41 patients with faint hotspots on initial lymphoscintigraphy, additional tracer injection, by increasing nodal uptake, simplified an accurate SN biopsy. Decreased radiotracer uptake in this group was associated with older age and high BMI.

\section{Conclusions}

Additional tracer injection following initial scan failure increases the success rate of lymphoscintigraphy during lymphatic mapping in breast cancer, without compromising the accuracy. If additional tracer injection does not result in secondary SN visualization, gross nodal tumour involvement is often present and ALND is mandatory.

\section{Synopsis}

Faint- or non-visualization of hotspots on lymphoscintigraphy frequently results in failure of SN identification. We determined the value of additional tracer injection to increase the identification rate of the SN procedure and identified factors that influence the visualization of hotspots. 


\section{INTRODUCTION}

Since the introduction of the sentinel node (SN) procedure in breast cancer, many validation studies confirmed the accuracy of the SN biopsy in predicting the axillary node status ${ }^{1-6}$. As compared to axillary lymph node dissection (ALND), SN biopsy causes less morbidity and provides the same staging information. As a consequence, ALND is nowadays abandoned in case of a negative SN biopsy, thereby avoiding unnecessary morbidity and costs associated with ALND.

However, sometimes the lymphatic mapping procedure fails, because of insufficient or absent radioactive tracer uptake in the lymph nodes. Because a negative preoperative lymphoscintigraphy is predictive for failure of intraoperative SN identification, faint- or non-visualization of hotspots on lymphoscintigraphy ('initial scan failure') frequently results in the need to perform ALND7.

After having experienced 14 patients with a negative preoperative lymphoscintigraphy in the first three years of our study, we started to use additional radiocolloid tracer injections as of May 2000, to avoid technical failure of the lymphatic mapping procedure.

The aim of this study is to determine the value of additional trace injection to increase the technical success rate of the sentinel node procedure in case of a vague or negative lymphoscintigraphy and to identify factors that influence non-visualization of hotspots.

\section{PATIENTS AND METHOdS}

From April 1997 to August 2007, after having received approval of the Local Ethical Committee, and after informed consent, a total of 1208 consecutive patients with clinically node-negative operable primary breast cancer were included in a prospective study on SN biopsy. In Phase I of this study (137 patients) SN biopsy was followed by completion axillary lymph node dissection in all cases. In Phase II, after validation of the SN technique in our institute, completion axillary lymph node dissection was performed only in cases of a tumour-positive axillary SN or a non-successful SN procedure. From this ongoing prospective study we analysed all consecutive patients who showed inadequate or absent visualization of hotspots on the initial lymphoscintigraphic images (Figures $1-3$ ).

Our technique of SN biopsy has been described in detail elsewhere ${ }^{2}$. The lymphatic mapping procedure consists of $370 \mathrm{MBq}(10 \mathrm{mCi}) \mathrm{TC}-99 \mathrm{~m}$ - 
nanocolloid injected peritumorally or in the breast parenchyma surrounding the cavity of a previous excisional biopsy. All patients underwent preoperative lymphoscintigraphy following a mean interval of 16 hours (range: 12-18). In case of initial scan failure, additional radiocolloid tracer injections of $37 \mathrm{MBC}$ (1 $\mathrm{mCi})$ Tc-99m-nanocolloid intracutaneously above the tumour were used as of May 2000, in order to increase the technical success rate of lymphoscintigraphy by obtaining secondary $\mathrm{SN}$ visualization. A second lymphoscintigraphy was performed 10-15 minutes after the additional tracer injection was given.

In relation to the mapping procedure, radiation exposure guidelines and doses were considered for both patients and personnel and were found to be well within legal safety limits, as was published previously ${ }^{2}$.

In 2002 preoperative ultrasonography of the axilla was introduced in our hospital and became standard procedure in combination with FNA cytology in case of clinically or radiologically suspicious axillary lymph nodes. Thus, patients treated before 2002 did not receive routine ultrasound investigation of the axilla.

During surgery, all axillary and non-axillary SNs were pursued, as visualized by lymphoscintigraphy. Intraoperative identification of the SNs was based both on blue dye mapping and gamma probe detection. In all cases of a failed SN procedure, whether based on secondary scan failure or based on intraoperative SN identification failure, ALND was performed, which involved at least removal of all level I and II lymph nodes.

Histopathologic examination of the SN consisted of routine serial sectioning with hematoxylin and eosin (H\&E) staining, followed by immunohistochemical (IHC) staining, whenever routine H\&E staining did not reveal metastases.

Depending on the type of the variable, the Chi-square test or t-test was used to compare the characteristics of patients with successful lymphoscintigraphy and with initial scan failure.

\section{RESULTS}

In all, 1208 consecutive patients with clinically node-negative breast cancer were included in this study. Patient and tunour characteristics are listed in Table 1.

\section{Initial scan failure}

In 93 patients, the results of preoperative lymphoscintigraphy were classified as initial scan failure: 
in 52 patients, because lymphoscintigraphy showed no axillary hotspots at all (negative lymphoscintigraphy) and in 41 patients, because the initial SN visualization was considered inadequate (i.e., too faint to allow successful intraoperative $\mathrm{SN}$ retrieval). The mean age of these 93 patients was 65.8 years, as compared to 58.5 years for the remaining group of 1115 patients with clear hotspots on initial lymphoscintigraphy $(p<0.0001)$.

Within the first three years of the study 14 patients (group A, Table 2) with a negative initial lymphoscintigraphy did not receive additional tracer injection and consequently ALND was performed in all cases. Of these 14 patients, 10 were found to have positive lymph nodes, with five of them having more than ten involved nodes. The remaining four patients had a negative SN procedure, using the blue dye technique, which was confirmed by completion ALND. No axillary recurrences were seen in these four patients within a median follow up of 80 months.

As of May 2000, in case of initial scan failure, an additional tracer injection of $1 \mathrm{mCi}$ Tc-99m-nanocolloid intracutaneously was routinely used.
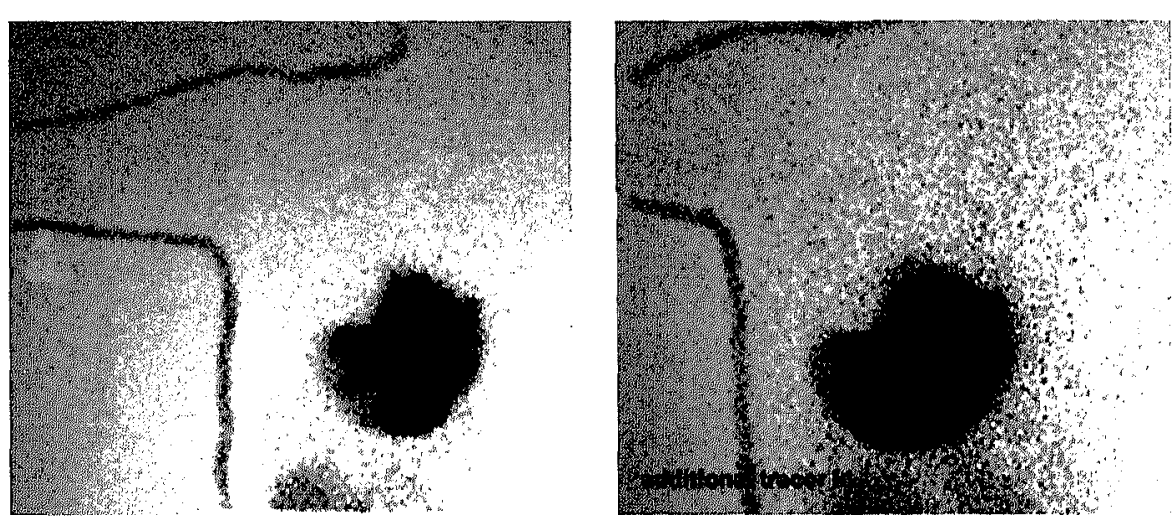

Figure 1a

Figure 1b

Figure 1 Lymphoscintigraphy of patient with initial scan failure (1a) and secondary scan failure atter additional tracer injection (1b)

\section{Secondary scan failure}

In 5 patients (group B, Table 2) with initial scan failure, following additional tracer injection, repeated lymphoscintigraphy still did not show hotspots (Figures $1 \mathrm{a}$ and $1 \mathrm{~b}$ ). Mean age of these patients was 66.2 years. Successful SN harvesting was possible in only one patient, because a (tumour-positive) palpable lymph node was found intra-operatively. 
Table 1 Comparison of characteristics of patients ( $N=1208)$ with successful lymphoscintigraphy and with initial scan failure

\begin{tabular}{|c|c|c|c|c|c|}
\hline \multirow[t]{3}{*}{ Characteristic } & \multicolumn{2}{|c|}{$\begin{array}{c}\text { Surcessful } \\
\text { lymphoscintigraphy }\end{array}$} & \multicolumn{2}{|c|}{$\begin{array}{l}\text { Initial scan } \\
\text { failure }\end{array}$} & \multirow[t]{3}{*}{ P-value } \\
\hline & \multicolumn{2}{|c|}{$(n=1115)$} & \multicolumn{2}{|c|}{$(n=93)$} & \\
\hline & $\mathrm{N}$ & $(\%)$ & $n$ & $(\%)$ & \\
\hline \multicolumn{6}{|l|}{ Age } \\
\hline$\leq 50$ & 346 & $31 \%$ & 10 & $11 \%$ & $<0.0001$ \\
\hline $51 \cdot 70$ & 544 & $49 \%$ & 52 & $56 \%$ & \\
\hline$>70$ & 225 & $20 \%$ & 31 & $33 \%$ & \\
\hline \multicolumn{6}{|l|}{ Tumour localization } \\
\hline Lateral & 615 & $55 \%$ & 43 & $46 \%$ & 0.23 \\
\hline Medial & 395 & $36 \%$ & 40 & $43 \%$ & \\
\hline Central & 105 & $9 \%$ & 10 & $11 \%$ & \\
\hline \multicolumn{6}{|l|}{ Tumour size } \\
\hline DCIS/Paget & 37 & $3 \%$ & 1 & $1 \%$ & $<0.0001$ \\
\hline $\mathrm{T} 1$ & 653 & $59 \%$ & 46 & $49 \%$ & \\
\hline $\mathrm{T} 2$ & 398 & $36 \%$ & 34 & $37 \%$ & \\
\hline T3 & 27 & $2 \%$ & 12 & $13 \%$ & \\
\hline \multicolumn{6}{|c|}{ Number of positive lymph nodes } \\
\hline 0 & 676 & $61 \%$ & 46 & $49 \%$ & $<0.0001$ \\
\hline $1-3$ & 351 & $31 \%$ & 24 & $26 \%$ & \\
\hline$>3$ & 88 & $8 \%$ & 23 & $25 \%$ & \\
\hline \multicolumn{6}{|l|}{ Tumour grade } \\
\hline Good & 286 & $26 \%$ & 29 & $31 \%$ & 0,43 \\
\hline Moderate & 478 & $43 \%$ & 39 & $42 \%$ & \\
\hline Poor & 351 & $31 \%$ & 25 & $27 \%$ & \\
\hline \multicolumn{6}{|l|}{ Surgery } \\
\hline Core biopsy & 932 & $84 \%$ & 77 & $83 \%$ & 0.84 \\
\hline Previous excisional biopsy & 183 & $16 \%$ & 16 & $17 \%$ & \\
\hline \multicolumn{6}{|c|}{ Estrogen receptor status } \\
\hline Negative & 215 & $21 \%$ & 19 & $22 \%$ & 0.80 \\
\hline Positive & 823 & $79 \%$ & 68 & $78 \%$ & \\
\hline Missing values & 77 & & 6 & & \\
\hline \multicolumn{6}{|l|}{ Progesterone receptor } \\
\hline Negative & 367 & $35 \%$ & 24 & $28 \%$ & 0.14 \\
\hline Positive & 670 & $65 \%$ & 63 & $72 \%$ & \\
\hline Missing values & 78 & & 6 & & \\
\hline $\begin{array}{l}\text { M hotspots on } \\
\text { lymphoscintigraphy }\end{array}$ & 236 & $21 \%$ & 5 & $5 \%$ & $<0.0001$ \\
\hline$B M I$ & $100^{*}$ & $25.5^{\star *}$ & 93 & $29.0^{* *}$ & $<0.0001$ \\
\hline
\end{tabular}

${ }^{*}$ sample of 100 patients ${ }^{* *}$ mean BMI (Body Mass Index) 
Axillary dissection was done in all 5 patients and showed a tumour-positive axilla in four $(80 \%)$ of which three patients showed massive tumour infiltration of almost all axillary lymph nodes. The only node negative patient in this subgroup had no axillary recurrence during a follow up period of 49 months.

Secondary SN visualization

In 33 patients (group C, Table 2) with initial scan failure, we noted secondary $\mathrm{SN}$ visualization on repeated lymphoscintigraphy as a direct result of additional tracer injection (Figures $2 \mathrm{a}$ and $2 \mathrm{~b}$ ). In these patients mean age was 64.7 years. Secondary lymphoscintigraphy clearly showed one or more axillary hotspots, which subsequently could be harvesled in all cases, showing a positive SN in 17 patients (52\%), all of whom underwent ALND. Massive nodal tumour burden, with ten or more tumour-positive nodes, was present in 3 patients only $(9 \%)$. In 15 patients the SN was found to be tumour-negative and no ALND was performed. No axillary recurrences were noted during a median follow up of 27 months in these patients. One patient $(5.5 \%=1 / 18)$ in this subgroup had a

Table 2 Patient and tumour characleristics of patients with initial scan failure $(N=93)$ group A: initial scan failure, no additional tracer given group B: initial and secondary scan failure

group C: initial scan failure, successful secondary scan

group D: enhanced scan after addilional tracer injeclion

\begin{tabular}{|c|c|c|c|c|c|}
\hline & A & $B$ & $c$ & $D$ & P-value \\
\hline Number of patients & 14 & 5 & 33 & 41 & \\
\hline Age (mean) & 64.7 & 66.2 & 64.7 & 67.0 & \\
\hline BMI (mean) & 29.3 & 29.1 & 28.9 & 28.9 & \\
\hline \multirow[t]{2}{*}{ Tumour size $>2 \mathrm{~cm}$} & 9 & 5 & 15 & 17 & 0.06 \\
\hline & $(64 \%)$ & $(100 \%)$ & $(45 \%)$ & $(41 \%)$ & \\
\hline \multirow{2}{*}{ Uttrasound axilla $(n)$} & 1 & 2 & 17 & 23 & 0.007 \\
\hline & $(7 \%)$ & $(40 \%)$ & $(52 \%)$ & $(56 \%)$ & \\
\hline \multirow[t]{2}{*}{ Axillary metastases $(\%)$} & 10 & 4 & 17 & 16 & 0.10 \\
\hline & $(71 \%)$ & $(80 \%)$ & $(52 \%)$ & $(39 \%)$ & \\
\hline \multirow[t]{2}{*}{ Massive nodallymphatic tract infiltration } & 8 & 3 & 3 & 1 & $<0.0001$ \\
\hline & $(57 \%)$ & $(60 \%)$ & $(9 \%)$ & $(2 \%)$ & \\
\hline Axillary recurrence in node-negative patients & $\cdot$ & - & 0 & 0 & \\
\hline $\begin{array}{l}\text { Median follow up node-negative } \\
\text { patients (months) }\end{array}$ & $80^{*}$ & $49^{*}$ & 27 & 41 & \\
\hline
\end{tabular}


false-negative SN procedure. A tumour-positive lymph node was found during subsequent simple mastectomy. She was given axillary radiotherapy. No axillary recurrence was seen thereafter within a 60 months follow up period.

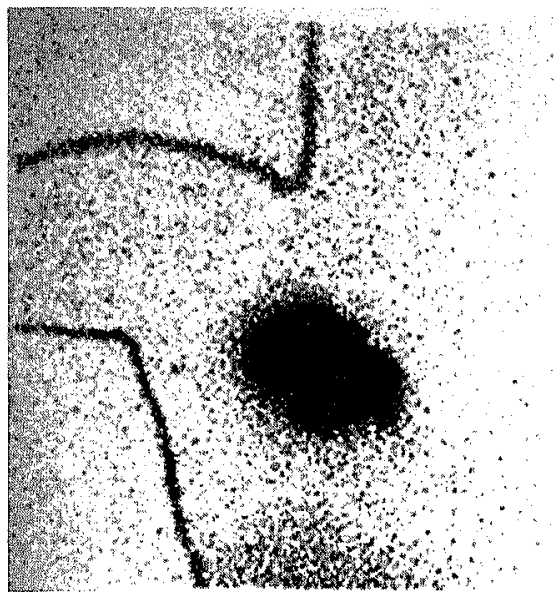

Figure 2a

Figure 2 Lymphoscintigraphy of patient with initial scan failure (2a), but secondary SN visualization after additional tracer injection (2b)

\section{Enhanced lymphoscintigraphy}

In 41 patients (group D, Table 2) with initial scan failure, in which initial lymphoscintigraphy showed only a faint hotspot, judged to be insufficient to allow successful SN harvesting, additional tracer injection led to increased radioactive uptake in the same hotspot (Figures $3 \mathrm{a}$ and $3 \mathrm{~b}$ ), rather then visualizing additional holspots. The mean age of these patients was 67.0 years. Additional hotspots as a result of additional tracer injection were seen in only 5 patients $(12 \%)$. The increased radioactive uptake facilitated SN harvesting, which was successful in all cases. A tumour-positive SN was found in 16 patients $(39 \%)$, which was not different from the group of 1115 patients with clear hotspots on initial lymphoscintigraphy (39\%). Only one patient $(2.4 \%)$ had massive tumour infiltration in the axilla, showing all axillary lymph nodes to be tumour-positive. No completion ALND was performed in the remaining 25 patients with a negative SN biopsy. Among these 25 patients again no axillary recurrences were found during a median follow up of 41 months. 


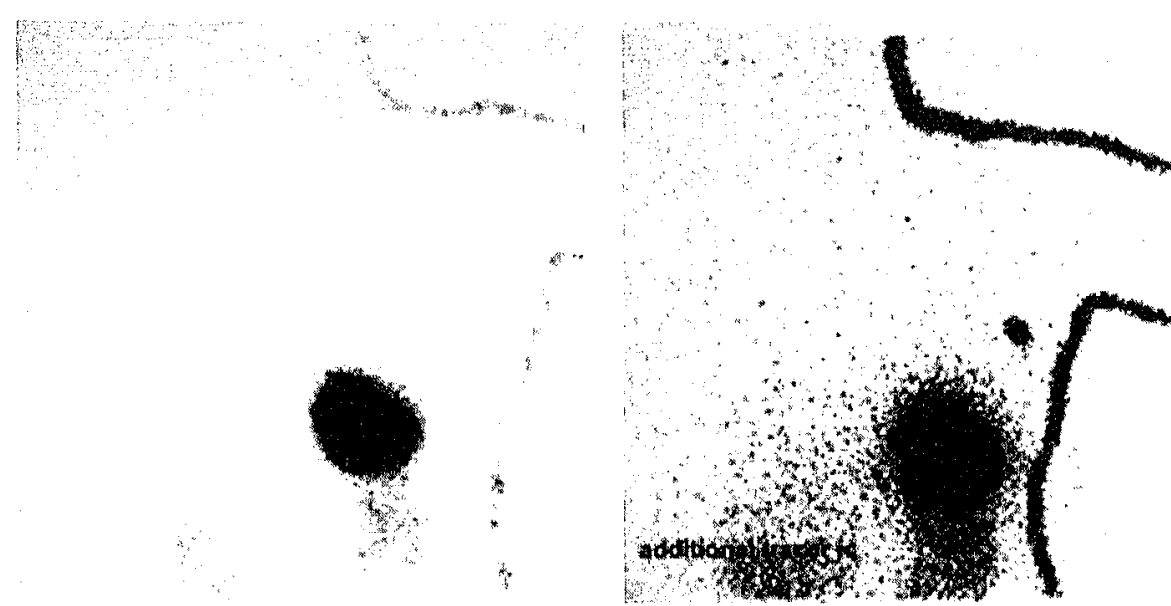

Figure 3a

Figure 3 h

Figure 3 Lymphoscintigraphy of patient with faint hotspot (3a), but clear hotspot after additional tracer injection (3b)

\section{Discussion}

Because of its high sensitivity to detect nodal metastatic disease and its minimally invasive nature, $\mathrm{SN}$ biopsy has become the standard of care for staging early invasive breast cancer, thereby limiting axillary dissection to patients with axillary metastases and sparing node-negative patients the morbidity of axillary dissection. However, sometimes the lymphatic mapping procedure tends to fail, because of inadequate or even absent radioisotope uptake in the SN. This urges the surgeon to perform a complete axillary lymph node dissection, which might have been avoided, had the lymphatic mapping been successful.

After having experienced 14 patients with a negative preoperative lymphoscintigraphy in the first three years of our study, we started to use additional radiocolloid tracer injections as of May 2000, to avoid technical failure of the lymphatic mapping procedure. The use of additional tracer injection has been previously reported by Cserni et al, in 20 patients.

Several factors have been identified to influence lymphatic mapping. Besides technical factors, like tracer volume, tracer dose, site of tracer injection and timing of lymphoscintigraphic imaging, other factors like prior breast surgery and upper lateral lumour location, which might hamper lymphatic mapping due to shine through, have been reported to influence lymphatic 
drainage patterns. However, there are three major reasons for initial scan failure: extensive nodal tumour infiltration, increased age and increased Body Mass Index (BMI)

\section{Extensive nodal tumour infiltration}

Axillary hotspot visualization is negatively influenced by extensive nodal involvement $t^{2,9-14}$. This can be explained by nodal tracer uptake physiology: the radioactive tracer is bound to colloid, which is phagocytosed by macrophages within the normal lymph tissue of the $\mathrm{SN}$. If the $\mathrm{SN}$, or the afferent lymph tracts, show massive tumour infiltration and/or extranodal growth, the lymph flow might be blocked, or there might be not enough functional lymph tissue left to phagocytose the radiocolloid. Thus, if a $\mathrm{SN}$ is completely replaced by tumour or the afferent lymph tract is blocked by extensive lymphatic tract infiltration, initial lymphoscintigraphy can fail to show any hotspot. Additional tracer injection under these circumstances might result in secondary scan failure, in which case ALND is mandatory.

Lymphatic tumour burden does not seem to affect blue dye uptake because, in contrast to the uptake of radiocolloid, which is based on sufficient functional lymph tissue, blue dye uptake is a process of passive diffusion through the lymphatic system ${ }^{11}$.

Massive nodal tumour and/or lymphatic tract infiltration was present in $57.1 \%$ of 14 patients (group A) early in our study, in which a negative initial lymphoscintigraphy was not followed by additional tracer injection, and in $60 \%$ of 5 patients (group B), in which additional tracer injection, after initial scan failure, did not result in secondary SN visualization.

If additional tracer injection does result in secondary $\mathrm{SN}$ visualization, as was seen in 33 patients (group C) in our study, it can be argued whether this visualized hotspot in fact is the true $\mathrm{SN}$, or might be an alternative lymph node which, based on rerouting of lymph flow, is erroneously considered to be the true $\mathrm{SN}^{13,15,16}$

If so, rerouting of lymph flow during lymphatic mapping would ultimately result in increased false-negative rates ${ }^{17}$.

However, in 33 patients with secondary SN visualization resulting from additional tracer injection, only one patient $(5.5 \%)$ had a false-negative SN biopsy, whereas 15 patients with a negative $\mathrm{SN}$ after additional tracer injection, who consequently had no ALND, showed no axillary recurrences within 29 months of follow up. These results suggest that SN biopsy after additional tracer injection does not compromise its accuracy, as was also pointed out by others $^{18}$, 


\section{Internal mammary (IM) basin drainage}

The incidence of IM metastasis is correlated with axillary nodal involvement ${ }^{19}$. It seems intuitive, that a large axillary tumour burden can result in blockage of lymph flow to the axilla, consequently leading to re-direction of lymph flow to the $1 \mathrm{M}$-chain ${ }^{13}$. However our results, like those of other investigators ${ }^{11}$, show that extensive nodal infiltration of the axilla is not correlated with increased lymph drainage to the $\mathrm{IM}$ lymph nodes, since IM hotspots were noted in only $5.4 \%(5 / 93)$ of patients with initial scan failure, versus $21.2 \%$ in patients with a successful initial lymphoscintigraphy (Table 1). This seemingly unexpected result is probably explained by the fact that patients with initial scan failure had a significantly increased mean age and $\mathrm{BMI}$, whereby both factors are inversely correlated to IM lymph drainage.

\section{Palpable lymph nodes}

An axillary lymph node with gross tumour involvement, might consequently be enlarged, thus is more likely be detected by routine physical examination and/or axillary ultrasound.

However, because a tumour-loaded lymph node also can be the same size as a tumour-negative lymph node, physical examination of the axillary lymph nodes in order to detect nodal metastases, has shown to be inaccurate ${ }^{20,21}$. Lymph nodes that can be palpated intraoperatively through the incision of the SN biopsy and are felt to be suspicious, should be harvested and regarded as $S N^{2,22,23}$

\section{Axillary ultrasound}

Routine preoperative axillary ultrasound is advocated by several investigators $9,20,24$. Combined with ultrasound-guided FNA of enlarged or suspicious lymph nodes, preoperative ultrasound can detect metastatic disease, hence avoiding an unnecessary or potentially unsuccessful SN biopsy.

In this study, routine preoperative ultrasonography of the axilla, which was introduced in our institute in 2002, was performed in only 43 of the 93 patients with initial scan failure. Moreover, of 48 patients with a tumour-positive axilla in this subgroup, only 15 patients had a preoperative ultrasound examination of the axilla. In one of these patients, ultrasound showed a suspicious lymph node, which was tumour-negative on FNA. Among 15 patients, who showed extensive nodal involvement or extra nodal tract invasion in relation to initia scan failure (Table 2), preoperative axillary ultrasound was performed in only two patients.

Thus, within this study we were not able to define the diagnostic yield of preoperative axillary ultrasound in relation to initial scan failure. 
However, in retrospect, it seems clear, that a substantial number of our patients with initial scan failure would not have needed a lymphatic mapping procedure, had routine preoperative axillary ultrasonography been introduced earlier in our institute.

\section{Increased age}

With the loss of oestrogen levels in postmenopausal women, the breast parenchyma is partially replaced by fatty tissue. This process of fatty degeneration results in a substantial decrease of lymphatic capillaries, normally confined to the breast parenchyma, which in turn is correlated with decreased radioactive uptake in the $\mathrm{SN}$. Thus, increased age is inversely correlated with the ability to visualize axillary hotspots and internal mammary hotspots ${ }^{13,25-29}$.

Likewise, our study showed that the mean age of patients with initial scan failure was significantly higher when compared to patients with a successful initial lymphoscintigraphy. (65.8 ys versus 58.5 ys, $p<0.0001$ ).

The inverse effect of increased age on the technical success rate of lymphoscintigraphy becomes even more obvious when looking at the results of 41 patients (group D) in our study with initial scan failure showing only very faint hotspots (Figure 3), necessitating additional tracer injection for successful $\mathrm{SN}$ retrieval. In this subgroup, in which massive nodal tumour infiltration as a causal factor was nearly absent (one patient), the mean age was 67 years, besides $\mathrm{BMI}$ accounting for the main factor to result in initial scan failure (Table 2).

\section{Body Mass Index (BMI)}

BMl is also recognized as a factor that affects the lymphoscintigraphic visualization of sentinel nodes ${ }^{26,27,30}$. As is true for increased age, patients with a high BMI might have sparse lymphatic capillaries and more fatty tissue in their breast parenchyma.

In our study, the mean BMI was 29.0 for the patients with initial scan failure and 25.5 for a random sample of 100 patients with clearly visible hotspots on the initial scan.

The difference was highly significant $(\mathrm{P}<0.0001)$.

This result confirms the findings from other investigators regarding the effect of BMI on the success rate of lymphoscintigraphy.

\section{Previous excisional biopsy}

Previous excisional biopsy is reported to result in changing of lymphatic drainage patterns and scan failure $e^{4,13,31,32}$. In a previous study, we reported the results of 88 patients, in which SN biopsy with completion ALND was 
performed following previous excisional biopsy ${ }^{33}$. Initial scan failure was seen in only 4 patients $(4.5 \%)$ and no false-negative SN procedures were noted. In the present sludy 199 patients had a previous excisional biopsy. Of these, $8.0 \%$ showed initial scan failure as compared to $7.6 \%$ in patients, in which breast cancer was diagnosed by core biopsy (Table1). Therefore, in our opinion, excisional biopsy prior to $\mathrm{SN}$ biopsy is not correlated with scan failure.

\section{CONCLUSION}

Sentinel node ( $\mathrm{SN}$ ) biopsy has become the standard of care in the treatment of breast cancer. To prevent unnecessary ALND, the results of preoperative lymphoscintigraphy should be optimal. To avoid technical failure of lymphatic mapping, we evaluated the results and accuracy of additional intracutaneous radiocolloid tracer injections of $37 \mathrm{MBq}(1 \mathrm{mCi})$ in patients with initial scan failure. A negative initial lymphoscintigraphy, if followed by additional tracer injection, resulted in secondary SN visualization in $87 \%$ of these patients, thus enabling an accurate (false-negative rate $5.5 \%$ ) SN biopsy. Both age and extensive nodal tumour infiltration as well as BMI adversely affect SN visualization.

In case additional tracer injection does not result in (secondary) SN visualization, ALND is mandatory, because of the high risk of positive lymph nodes, many times with massive tumour infiltration of the axilla.

If initial SN visualization is faint, this is mainly correlated with increased age and high BMI, rather than a large tumour burden. In these patients additional tracer injection facilitates an accurate SN procedure. 


\section{RefERENCES}

1. Krag DN, Weaver DL, Alex JC, Fairbank IT. Surgical resection and radiolocalization of the sentinel lymph node in breast cancer using a gamma probe. Surg Oncol 1993; 2:335-339.

2. van der Ent IWC, Kengen RAM, van der Pol HAG, Hoofwijk AGM. Sentinel node biopsy in 70 unselected patients with breast cancer: increased feasibility by using $10 \mathrm{mCl}$ radiocolloid in combination with a blue dye tracer. Eur I Surg Oncol 1999; 25:24-29.

3. Giuliano AE, Kirgan DM, Guenther IM, Morton DL. Lymphatic mapping and sentinel lymphadenectomy for breast cancer. Ann Surg 1994; 220:391-398.

4. Albertini Jl, lyman $\mathrm{CH}$, Cox C et al. Lymphatic mapping and sentinel node biopsy in the palient with breast cancer. JAMA 1996; 276:1818-1822.

5. Borgstein PJ, Meijer S, Pijpers R. Intradermal blue dye to identify sentinel lymph-node in breast cancer. L.ancet 1997; 349:1668-1669.

6. Tafra L, Lannin DR, Swanson MS et al. Multicenter Trial of Sentinel Norle Biopsy for Breast Cancer Using Both Technetium Sulfur Colloid and Isosulfan Blue Dye. Ann Surg 2001; 233:51-59.

7. Goyal A, Mansel RE. Recent advances in sentinel lympl node biopsy for breast cancer. Curr Opin Oncol 2008; 20:621-626.

8. Cserni $G$, Rajlar $M$, Boross $G$, Sinko $M$, Svebis $M$, Baltas B. Comparison of vital dycguided lymphatic mapping and dye plus gamma probe-guided sentinel node biopsy in breast cancer. World ) Surg 2002; 26:592-597.

9. De Kanter AY, Menke-Pluijmers MB, Henzen-Logmans SC, Van Geel AN, van Eijck C, Wiggers T, Eggermont AM. Reasons for failure to identify positive sentinel nodes in breast cancer patients with significant nodal involvement. Fur I Surg Oncol 2006; 32:498-501.

10. Wong SL, Edwards MJ, Chao C, Simpson D, MCMasters KM. The elfect of lymphatic tumor burden on sentinel lymph node biopsy results. Breast I 2002; 8:192-198.

11. Goyal A, Douglas-Jones AG, Newcombe RG, Mansel RE. Effecl of lymplatic lumor burden on sentinel lymph node biopsy in breast cancer. Breast f 2005; 11:188-194.

12. Noguchi $M$, Michigishi T, Nakajima K, Koyasaki N, Taniya T, Ohta N, Miyazaki I. The diagnosis of internal mammary node melastases of breast cancer. Int Surg 1993. 78:171-175.

13. Borgstein PJ, Pijpers R, Contans EF, Van Diest PJ, Boom RP, Meijer S. Sentinel lympl node biopsy in breast cancer: guidelines and pilfalls of lymphoscintigraphy and gamma probe detection. I Am Coll Surg 1998; 186:27.5-283.

14. Guenther IM. Axillary dissection after unsuccessful sentinel lymphadenectomy for breast cancer. Am Surg 1999 Ocl 65:991-994. 
15. Kapteijn BA, Nieweg OE, Petersen JL, Rutgers E), Hart AA, van Dongen JA, Kroon BB. Identification and biopsy of the sentinel lymph node in breast cancer. Eur / Surg Oncol 1998; 24:427-430.

16. Noguchi $M$. Sentinel lymph node biopsy as an alternative to routine axillary lymph node disseclion in breast cancer patients. I Surg Oncol 2001; 76:144-156.

17. Gulec SA, Moffal FL, Carroll RG, Krag DN. Gamma probe guided sentinel node biopsy in breast cancer. Q J Nucl Med 1997; 41:251-261.

18. Bajen MT, Benitez A, Mora J et al. Subdermal re-injection: a method to increase surgical delection of the sentinel node in breast cancer without increasing the falsenegative rale. Eur I Nucl Med Mol Imaging 2006; 33:338-343.

19. Cserni G, Szekeres JP. Internal mammary lymph nodes and sentinel node biopsy in breast cancer. Surg Oncol 2001; 10:25-33.

20. Lanng C, Hoffmann J, Galatius H, Engel U. Assessment of clinical palpation of the axilla as a criterion for performing the sentinel node procedure in breast cancer. Eur J Surg Oncol 2007; 33:281-284.

21. Noguchi M, Katev N, Miyazaki 1. Diagnosis of axillary lymph node metastases in patients with breast cancer. Breast Cancer Res Treat 1996; 40:283-293.

22. Tanis PJ, Nieweg OE, Merkus JW, Peterse JL, Kroon BB. False negalive sentinel nodo procedure established through palpation of the biopsy wound. Eur I Surg Oncol 2000; 26:714-715.

23. Gui GP, Joubert DJ, Reichert $R$ et al. Continued axillary sampling is unnecessary and provides no further information to sentinel node biopsy in staging breast cancer. Eur ] Surg Oncol 2005; 31:707-714.

24. van Rijk MC, Deurloo EE, Nieweg OE et al. Ultrasonography and fine-necdle aspiration cytology can spare breast cancer patients unnecessary sentinel lymph node biopsy. Ann Surg Oncol 2006; 13:31-35.

25. Heuts EM, van der Ent FW, van der Pol HA et al. Evaluation of early versus delayed lymphoscintigraphic imaging in detecting internal mammary sentinel lymph nodes in breast cancer: a multicenter study to establish an optimal lymphatic mapping protocol. Nucl Med Commun 2006; 27:677-681.

26. Chakera AH, Friis E, Hesse U, Al Suliman N, Zerahn B, Hesse B. Factors of imporlance for scinligraphic non-visualisation of sentinel nodes in breast cancer. Eur I Nucl Med Mol Imaging 2005; 32:286-293.

27. Cox CE, Dupont E, Whitehead GF et al. Age and body mass index may increase the chance of failure in sentinel lymph node biopsy for women with breast cancer. Breast J 2002; 8:88-91.

28. Valdes-Olmos RA, Jansen L, Hoefnagel CA, Nieweg OE, Muller SH, Rutgers EJ, Kroon BB. Evaluation of mammary lymphoscintigraphy by a single intratumoral injeclion for sentinel node identification. J Nucl Med 2000; 41:1500-1506. 
29. McMasters KM, Tutrle TM, Carlson D) et al. Sentinel lymph node biopsy for breast cancer: a suitable alternative to routine axillary dissection in multi-institutional practice when optimal technique is used. I Clin Oncol 2000; 18:2560-2566.

30. Derossis AM, Fey JV, Cody HS, III, Borgen PI. Ohesity influences outcome of sentinel lymph node biopsy in early-stage breast cancer. I Am Coll Surg 2003; 197:896-901.

31. Estourgie $S H$, Valdes Olmos RA, Nieweg $O E$, Hocfnagel CA, Rutgers EJ, Kroon BB. Excision biopsy of breast lesions changes the pattern of lymphatic drainage. Br I Surg 2007; 94:1088-1091.

32. Glass EC, Essner R, Giuliano AE. Sentinel node localization in breast cancer. Senin Nucl Med 1999; 29:57-68.

33. Heuts EM, van der Ent FW, Kengen RA, van der Pol HA, Hulsewe KW, Hoofwijk AG. Rosults of sentinel node biopsy not affected by previous excisional biopsy. Eur I Surg Oncol 2006; 32:278-281. 


\section{Chapter 3}

Results of sentinel node biopsy not affected by previous

excisional biopsy

EM Heuts, FWC van der Ent, RAM Kengen, HAG van der Pol, KWE Hulsewé AGM Hoofwijk

Eur / Surg Oncol 2006; 32:278-281. 


\section{ABSTRACT}

\section{Background}

Sentinel lymph node (SN) biopsy has been validated in the treatment of breast carcinoma and is considered to stage the axilla adequately in this disease. However, patients with previous excisional biopsy are regarded not eligible for $\mathrm{SN}$ biopsy. We evaluated the results of SN biopsy for this group of patients based on confirmatory axillary lymph node dissection.

\section{Patients and methods}

As of April 1997 all consecutive patients with stage $T_{1-3}$ breast cancer were enrolled into a prospective study on SN biopsy. As part of this study, a total of 88 patients, who had previously undergone diagnostic excisional biopsy followed by complete axillary lymph node dissection, were reviewed to determine the validity of the sentinel node procedure.

\section{Results}

Lymphoscintigraphy visualized one or more axillary hot spots in 84/88 patients A successful SN biopsy was performed in 87 patients. Complete axillary lymphnode dissection showed no false-negative SN biopsy among the $87 \mathrm{SN}$ procedures.

\section{Conclusion}

SN biopsy is a reliable and safe method following excisional biopsy as is confirmed by completion axillary lymph node dissection. Therefore, patients with previous excisional biopsy are eligible for sentinel node procedure and can be spared unnecessary axillary lymph node dissection. 


\section{INTRODUCTION}

In the last decade sentinel node (SN) biopsy was introduced as a new technique for nodal staging in breast cancer ${ }^{1,2,3}$. As compared to axillary lymph node dissection (ALND), it provides similar staging information, yet with the advantage of generating only minimal morbidity. When performed by an experienced surgeon, sensitivity of SN biopsy is in excess of $95 \% \%, 4,5,7,8,9,10$. Therefore, a negative SN biopsy accurately predicts the absence of nodal tumour involvement in the axilla and justifies avoidance of complete AIND.

However, controversy persists about the accuracy of SN biopsy following previous excisional biopsy. It is assumed that the lymphatic drainage pattern is altered in these patients, resulting in less accurate lymphatic mapping and unreliable results of the SN biops $\gamma^{3,11}$. If this hypothesis is correct, then a number of breast cancer patients will be deprived of the advantages of the $\mathrm{SN}$ technique.

To date there are no published validalion studies in which the reliability of the $S \mathrm{~N}$ procedure in breast cancer patients following previous diagnostic excisional biopsy is investigated by performing a completion axillary lymph node dissection. For this study we reviewed the relevant data in our large prospective database on SN biopsy, to determine the accuracy of the procedure in this selected group of patients.

\section{Patients and Methods}

From an ongoing prospective study on SN biopsy we analysed all consecutive patients with stage $T_{1-3}$ breast cancer, who had undergone diagnostic excisional biopsy prior to SN biopsy (group A). In this group a total of 88 patients were operated in a period from April 1997 until January 2000. After having received approval of the local ethical committee and after obtaining informed consent, all group $A$ patients underwent SN biopsy followed by a completion axillary lymph node dissection. All operative procedures were performed by two surgeons experienced in $\mathrm{SN}$ biopsies. In the same time period a total number of 49 patients (group B) underwent SN biopsy and completion ALND following diagnostic core biopsy. This group was used for comparison.

The lymphatic mapping procedure in both groups consisted of a dualtracer technique. The day before surgery, at the Department of Nuclear Medicine, a radioactive tracer was injected peritumorally (group $B$ ) or into the breast tissue adjacent to the biopsy cavity (group $\mathrm{A}$ ), carefully avoiding injection 
into the biopsy cavity itself. All patients received $10 \mathrm{mCi}(370 \mathrm{MBq})^{99 m}$ Technetium nanocolloid (Nanocoll, Nycomed Amersham Sorin, Saluggia, Italy) in $4 \mathrm{ml}$ saline. Lymphoscintigraphic images were obtained the next day, after a mean period of 16 hours after tracer injection, in three standard projections: an anterior and anterolateral view (arm in 90 degrees abduction) and a lateral view (arm raised above the head). Focal accumulation of radioactivity was registered as the localization, number and intensity of "hot spots" in and outside the axilla. The position of axillary and non-axillary SNs was marked on the skin preoperatively, with the help of a gamma camera and a hand-held gamma probe. In the operating room, shortly after induction of general anaesthesia, a dye tracer $(0.8-1 \mathrm{ml}$ Patent Blue V, Laboratoire Guerbet, Aulnay-sous -Bois, France) was injected intradermally in the skin above the tumour (group $B$ ) or in the skin surrounding the excisional biopsy scar (group A).

During surgery, in all patients, attempts were made to harvest both axillary and non-axillary SNs, as visualized by lymphoscintigraphy. Intraoperative identification of the SNs was based both on blue dye mapping and gamma probe detection. A SN was defined as any node that was hot and/or blue. The $\mathrm{SN}$ procedure aimed at complete removal of all axillary $\mathrm{SNs}$, as was confirmed by a reduction of background activity in the remaining axillary tissue to less then $10 \%$ of the ex vivo activity of the most active $\mathrm{SN}$ (ex vivo ratio $10: 1$ ). Completion axillary lymph node dissection involved at least removal of all level I and II lymph nodes.

Histopathologic examination of the $\mathrm{SN}$ consisted of routine serial sectioning with hematoxylin and eosin (H\&E) staining, followed by immunohistochemical (IHC) staining, whenever routine H\&E staining did not reveal metastases.

In relation to the mapping procedure, radiation exposure guidelines and doses were considered for both patients and personnel and were found to be well within legal safety limits, as was published previously ${ }^{12}$.

\section{RESULTS}

In all, 88 consecutive patients with previous excisional biopsy (group A) were included in this study. Patient characteristics are listed in Table 1. Tumour size was $\mathrm{pT}_{1}$ in 58 patients, $\mathrm{pT}_{2}$ in 27 patients and $\mathrm{pT}_{3}$ in 3 patients. The average tumour size was $15 \mathrm{~mm}$ (range $3-70 \mathrm{~mm}$ ). The primary tumour was located in the lateral quadrants in 55 patients, of which 26 tumours were in the upperouter quadrant. 
SN biopsy after previous excisional biopsy

Table 1 Patient characteristics of the excisional biopsy group (A) and the core biopsy group (B)

\begin{tabular}{lcc} 
& A & B \\
\hline Number of patients & 88 & 49 \\
Mean age (y) & 56 & 64 \\
Range & $36-80$ & $39-94$ \\
\hline Tumour localization & & \\
$\quad$ Lateral & 55 & 28 \\
Medial & 27 & 19 \\
$\quad$ Central & 6 & 2 \\
\hline Tumour size (mm) & & \\
$T_{1}$ & 58 & 11 \\
$T_{2}$ & 27 & 32 \\
$T_{3}$ & 3 & 6 \\
Mean & 15 & 28 \\
Range & $3-70$ & $10-60$ \\
Histology & -75 \\
Ductal carcinoma & 55 & 34 \\
Lobular carcinoma & 16 & 8 \\
Ductal/lobular carcinoma & 6 & 6 \\
Other & 11 & 1 \\
\hline
\end{tabular}

Table 2 Results of lymphoscintigraphy for the excisional biopsy group (A) and the core biopsy group (B)

\begin{tabular}{lcc} 
& A & B \\
Number of patients & 88 & 49 \\
Axillary hotspots & 84 & 47 \\
Axillary SN biopsy & 87 & 49 \\
ALND & 88 & 49 \\
Axillary metastases & 35 & 20 \\
False negative SN & 0 & 1 \\
IM hotspots & 24 & 22 \\
IM SN biopsy & 17 & 13 \\
IM metastases & 5 & 2 \\
\hline
\end{tabular}


Lymphoscintigraphy visualized one or more axillary hot spots in $84 / 88$ (Table 2). A successful SN biopsy was performed in all of these patients patients no visible SNs were seen on the lymphoscintigraphic images. of these a SN could still be identified during operation by using the $\mathrm{b}_{\mathrm{J}}$ mapping technique, following a blue lymphatic duct leading to a blue $\mathrm{SN}$. Overall successful axillary SN identification therefore was $\operatorname{pos}_{S i}$ 87/88 patients.

In the remaining patient, who underwent previous excisional bi two different locations in the same breast, none of the two techniques $w_{\text {. }}$ to identify a sentinel node. A complete axillary lymph node dissectio performed in this patient, revealing two metastatic nodes within a basin lymph nodes.

In 68 patients the removed axillary nodes were both blue-stained ar In 16 patients the SNs could be localized only by the radiocolloid an patients only by the blue tracer, as was mentioned. The median ex vivo ratio (ex vivo SN activity against background) of the axillary SNs was 25

The mean interval between the previous excisional biopsy ar sentinel node procedure was 19 days (range 10-85). A median of 2 axilla (range 1-12) per patient was removed.

Following SN biopsy, all group A patients underwent complete a lymph node dissection. A median of 16 lymph nodes (range 4-32) was re during ALND (inclusive of the number of removed SNs). Overall a metastatic involvement was found in 35 patients. Axillary SN biopsy co predicted the positive nodal status of the axilla in 34/35 patients. As ment in one axillary node-positive patient, $\mathrm{SN}$ identification was not succ. There was no false-negative SN biopsy among the 87 successful SN proce Consequently, the sensitivity of $\mathrm{SN}$ biopsy following previous excisional in this study was $100 \%$. The SN was the only involved axillary node patients with axillary metastases.

Non-axillary SNs were seen predominantly in the internal mar nodal basin, in all cases concomitant with axillary SNs. Lymphoscinti showed additional internal mammary SNs (IM-SN) in 24 patients. Atten harvest these IM-SNs were successful in 17 patients. Metatastatic involvement of the IM-SNs was seen in 5 patients, in all cases in combi with a tumour-positive axilla (Table 2). 


\section{Discussion}

Because of its high sensitivity and its minimally invasive nature, SN biopsy has replaced ALND as the primary procedure for axillary staging in breast cancer in many centers. However, various exclusion criteria have been formulated by different investigators. One of these exclusion criteria is a previous excisional biopsy $3,6,13$. Prior surgery is assumed to alter the lymphatic drainage patterns by disrupting the lymphatic channels, thus preventing the surgeon from performing accurate lymphatic mapping and SN biopsy. Estourgie for example, by using repeated lymphoscintigraphy before and after excisional biopsy in a group of 20 breast cancer patients, found post-excisional differences in lymph drainage in $45 \%$ of patients with axillary drainage and in $80 \%$ of patients with internal mammary drainage, suggesting that SN biopsy is not valid when performed after previous excisional biopsy ${ }^{14}$

However, although in recent years ultrasound-guided and stereotactic core biopsy have emerged as a more efficient alternative preoperative techniques in diagnosing invasive breast cancer in both palpable and non palpable breast lesions, diagnostic excisional biopsy remains necessary in those cases in which core biopsy is inconclusive. Inconclusive core biopsy will be more frequent in patients with early-stage breast cancer and moreover, in these patients the likelihood of nodal involvement is low. Thus, by excluding patients with previous excisional biopsy for $\mathrm{SN}$ staging on the assumption of unreliability, a substantial number of presumably node negative early-stage breast cancer patients, i.e. those who would benefit most from a SN biopsy, will be denied the advantages of the $\mathrm{SN}$ technique.

investigators, who do not exclude previous excisional biopsy in their studies, monitor their accuracy of SN biopsy by determining the incidence of axillary relapse at follow up, since confirmatory axillary dissection usually is no longer performed routinely. Recently, such a large study was published concerning 543 patients who had undergone an open breast biopsy before SN biopsy. After a median follow-up of two years 3 nodal recurrences were observed in $383 \mathrm{SN}$ negative patients ${ }^{15}$. These results confirm, without completion ALND, the accuracy of the SN procedure after prior breast surgery.

The best way, however, to validate the accuracy of SN biopsy following previous breast surgery is to study the results of prospective studies comparing $\mathrm{SN}$ biopsy with the results of routine completion axillary dissection. After searching the literature we found no relevant studies. In our analysis of 88 such patients, we found no false negative results in 87 successful SN procedures, resulting in both a sensitivity and an accuracy of $100 \%$. 
Assuming there is a single lymphatic trunk that conveys lymph from the subareolar plexus toward the axillary lymph nodes ${ }^{16-18}$, large excisional biopsies in the upper lateral quadrant of the breast might distort this main lymphatic trunk, making the procedure less accurate. We, however, did not find such an influence in this relatively small subgroup of 26 patients with previous open biopsy in the upper outer quadrant. This might be explained by a relatively small tissue volume of the excisional biopsy, but this was not measured routinely in our series.

We compared our findings in patients with previous excisional biopsy (group A) with 49 patients in which SN biopsy was performed after diagnostic core biopsy (group B). These patients, as for group A, were also operated in our learning phase, and therefore underwent a confirmatory ALND too. Patient characteristics of both groups are shown in Table 1. T1 tumours were more frequent in the previous excisional biopsy group, as can be expected, since small tumour size more often will result in inconclusive core biopsy. Lymphoscintigraphy showed axillary hotspots in $47 / 49$ patients in group B, compared to $84 / 88$ patients in group A. SN biopsy was successful in all patients in group $B$, but completion ALND revealed one false negative SN procedure after core biopsy (sensitivity $95 \%$ ), compared to a sensitivity of $100 \%$ in the excisional biopsy group (Table 2). These comparable results support our opinion that previous excisional biopsy does not decrease the accuracy of the SN procedure.

Prior breast surgery also might disrupt lymph drainage patterns to the internal mammary nodal basin. In comparing both groups, more IM hotspots were visualized in group B as compared to group A (45\% versus $27 \%$ ) (Table 2). However, after re-evaluating our previously published data on IM SN biopsy, in which 256 patients with both diagnostic core biopsy (160 patients) and excisional biopsy (96 patients) were included ${ }^{19}$, no differences between both groups are found: IM SN's were successfully imaged by lymphoscintigraphy in $26 \%$ in patients with diagnostic core biopsy, compared to $25 \%$ in the previous excisional biopsy group. The IM-SN identification rate in the core biopsy group was $59 \%$, patients with previous excisional biopsy showed identification rates of $71 \%$. These data demonstrate that previous excisional biopsy neither affects the visualization nor the identification of internal mammary sentinel nodes. 
SN biopsy after previous excisional biopsy

\section{CONCLUSION}

Sentinel node biopsy for breast cancer following previous excisional biopsy is accurate for axillary lymph node staging, as is confirmed by completion axillary lymph node dissection in this study. Localisation of the biopsy, even in the upper outer quadrant, does not affect identification of the axillary sentinel node. Moreover, visualization and identification of internal mammary sentinel nodes is not impaired. Therefore, patients with previous excisional biopsy are eligible for the sentinel node procedure and can be spared an unnecessary axillary lymph node dissection. 
Chapter 3

48 


\section{REFERENCE List}

1. Krag DN, Weaver DL, Alex JC, Fairbank JT. Surgical resection and radiolocalization of the sentinel lymph node in breast cancer using a gamma probe. Surg Oncol 1993; 2:335-339.

2. Giuliano AE, Kirgan DM, Guenther JM, Morton DL. Lymphatic mapping and sentinel lymphadeneclomy for breasl cancer. Ann Surg 1994; 220:391-398.

3. Albertini IJ, Lyman GH, Cox C, Yeatman T, Balducci L, Ku N, et al. Lymphatic mapping and sentinel node biopsy in the patient with breast cancer. JAMA 1996; 276:1818-1822.

4. Giuliano AE, Jones $R C$, Brennan $M$, Statman R. Sentinel lymphadenectomy in breast cancer. J Clin Oncol 1997; 15:2345-2350.

5. Roumen RMH, Valkenburg JGM, Geuskens LM. Lymphoscintigraphy and feasibility of sentinel node biopsy in 83 patients with primary breast cancer. Eur I Surg Oncol 1997; 23:495-502.

6. Veronesi U, Paganelli $G$, Galimberti V, Viale $G$, Zurrida S, Bedoni $M$, et al. Sentinelnode biopsy to avoid axillary dissection in breast cancer with clinically negative lymph-nodes. Lancet 1997; 349:1864-1867.

7. Turner RR, Ollila DW, Krasne DL, Giuliano AE. Histopathologic validalion of the sentinel lymph node hypothesis for breast carcinoma. Ann Surg 1997; 226:271-276.

8. Borgstein PJ, Pijpers R, Comans EF, van Diest PJ, Boom RP, Meijer S. Sentinel lymph node biopsy in breast cancer: guidelines and pilfalls of lymphoscintigraphy ancl gamma probe detection. I Am Coll Surg 1998; 186:275-283.

9. Krag D, Weaver D, Ashikaga T, Moffat F, Klimberg VS, Shriver C, et al. The sentinel node in breast cancer: a multicenter validation studly. N Engl / Mod 1998; 339:941-946.

10. Cox CE, Pendas S, Cox JM, Joseph E, Shons AR, Yeatman T, ct al. Guidelines for sentinel node biopsy and lymphalic mapping of patients with breast cancer. Ann Surg 1998; 227:64:5-653.

11. Glass EC, Essner R, Giuliano AE. Sentinel node localization in breast cancer. Semin NuCl Med 1999; 29:57-68.

12. van der Ent FWC, Kengen RAM, van der Pol HAG, Hoorwijk AGM. Sentinel node biopsy in 70 unselected patients with breast cancer: increased feasibility by using $10 \mathrm{mC}$ radiocoltoil in combination with a blue dye tracer. Eur / Surg Oncol 1999; 25:24-69.

13. Pijpers R, Moijer S, Hoekstra OS, Collet Gl, Comans EF, Boon RP, et al. Impact of lymphoscintigraphy on sentinel node identification with technetium-99m-colloidal albumin in breast cancer. I Nucl Med 1997; 38:366-368.

14. Estourgie SH, Valdes Olmos RA, Nieweg OE, Hoefnagel CA, Rutgers EJTh, and Kronn BBR. Reproducibility study of lymphoscintigraphy: excisional biopsy of breast lesions changes drainage patterns. Eur J Cancer 2004; 2:79. 
15. Luini A, Galimberti V, Gatti G, Arnone P, Vento AR, Trifiro G, et al. The sentinel node biopsy after previous breast surgery: preliminary results on 543 patients treated at the European Institute of Oncology. Breast Cancer Res Treat 2005; 89:159-163.

16. Borgstein PI, Meijer S, Pijpers RI, Van Diest PJ. Functional Iymphatic anatomy for sentinel node biopsy in breast cancer: echoes from the past and the periareolar bluc method. Ann Surg 2000; 232:81-89,

17. Tanis PI, Nieweg OE, Valdes Olmos RA, Kroon BB. Anatomy and physiology of lymphatic drainage of the breast from the perspective of sentinel node biopsy. I Am Coll Surg 2001; 192:399-409.

18. Zavagno G, Rubello D, Franchini Z, Meggiolaro F, Ballarin A, Casara D, et al. Axillary sentinel lymph nodes in breast cancer: a single lymphatic pathway drains the entire mammary gland. Eur J Surg Oncol 2005; 31:479-484

19. van der Ent FWC, Kengen RAM, van der Pol HAG, Povel IA, Stroeken HJ, Hoofwijk AGM. Halsted revisited: internal mammary sentinel lymph node biopsy in breast cancer. Ann Surg 2001; 234:79-84. 


\section{Chapter 4}

Incidence of axillary recurrence in 344 sentinel node negative breast cancer patients after intermediate follow-up

A prospective study into the accuracy of sentinel node biopsy in breast cancer patients 


\section{Abstract}

Sentinel lymph node biopsy (SLNB) has been validated in the treatment of breast carcinoma and is considered to stage the axilla adequately in this disease. However, long term follow-up data are only scarcely available. We evaluated the results of SLNB with respect to locoregional failures in the axilla in SN-negative patients with invasive breast carcinoma and analysed their causal factors.

Between 1997 and May 2004, 656 patients without clinically palpable lymph nodes entered our study. Data with regard to demographics, diagnostics, therapy and follow up were gathered prospectively from all patients. Patients treated after May 2004 were excluded from this study to permit at least one year of follow-up.

Out of the 656 patients, 344 patients with a negative sentinel lymph node biopsy did not undergo axillary dissection and were followed up clinically. Median follow up was 43 months. In 3 patients $(0.9 \%)$ axillary recurrences developed. All three patients subsequently underwent a completion axillary dissection, chemotherapy and radiotherapy.

The low rate of clinical axillary recurrence after an intermediate follow up period suggests that a negative $\mathrm{SN}$ biopsy accurately reflects the nodal stage in patients with breast cancer. 


\section{INTRODUCTION}

For decades axillary lymph node dissection (ALND) has been part of the standard procedure in surgical treatment of breast cancer. Axillary lymph node status, as the most important prognostic indicator for recurrence and survival and determinant for subsequent adjuvant therapy, is still an essential element in the rreatment of breast cancer ${ }^{1,2}$. Since the introduction of the sentinel lymph node biopsy (SLNB) as a new technique for nodal staging in breast cancer it has evolved to a generally accepted procedure ${ }^{3,4}$. As compared to ALND, SN biopsy causes less morbidity and is considered to provide the same staging information. When performed by an experienced surgeon, it has shown to be reliable ${ }^{5,6}$ as based on validation studies that determined the accuracy of the $\mathrm{SN}$ in predicting the status of the remaining axillary lymph nodes in a "back-up" ALND. However, little is known regarding intermediate follow-up results and no long-term clata are currently available.

In the present prospective study we describe our results of the follow-up of sentinel node negative patients who did not receive elective ALND. Special attention was paid to axillary recurrence and possible reasons for this relapse.

\section{Materials AND Methods}

As of 1998, after validation of the sentinel node technique in our institute by performing confirmatory ALND in 138 patients (false negative rate $2 \%$, sensitivity $98 \%$ ), completion axillary lymph node dissection was omitted in case of a negative SLNB. Subsequently, from July 1998 until May 2004, 656 consecutive patients with clinically node-negative operable primary breast cancer, who underwent SLNB, entered a prospective database. Exclusion criteria included pregnancy and T4 tumours. To allow at least one year of potential follow-up, patients treated after May 2004 were excluded from this analysis. At least one sentinel node (SN) could be identified in 639 out of 656 patients $(97,4 \%)$. In the remaining 17 patients no $\mathrm{SN}$ could be identified and a primary axillary clearance was performed. In 344 of 639 patients, the sentinel lymph node did not reveal metastases. Of these 344 patients, diagnosis of invasive breast cancer was obtained by core needle biopsy in $288(84 \%)$ and by excisional biopsy in $56(16 \%)$ patients.

Our technique of SN biopsy has previously been described in detail ${ }^{7}$. The lymphatic mapping procedure consisted of a dual-tracer technique. All patients received peritumoural injection of $10 \mathrm{mCi}\left(370 \mathrm{MBq}\right.$ ) ${ }^{99 m}$ Technetium nanocolloid (Nanocoll, Nycomed Amersham Sorin, Saluggia, Italy) in $4 \mathrm{~m}$ saline. Lymphoscintigraphic images were obtained in all patients. Additionally, 0,8-1 $\mathrm{ml}$ Patent Blue $\mathrm{V}$. 
(Laboratoire Guerbet, Aulnay-sous-Bois, France) was injected intradermally above the tumour or alongside the excisional biopsy scar. During surgery in all patients attempts were made to harvest both axillary and non-axillary SNs, as visualized by lymphoscintigraphy.

Histopathologic examination consisted of routine haematoxylin and eosin (H\&E) staining and serial sectioning, followed by immunohistochemical staining whenever routine $\mathrm{H} \& \mathrm{E}$ staining did not reveal metastases. Micrometastases were defined based on a size greater than $0.2 \mathrm{~mm}$ and less than or equal to $2 \mathrm{~mm}$ in diameter according to the Dutch national guidelines. Patients with solitary tumour cells in the sentinel node (equal to or smaller than $0.2 \mathrm{~mm}$ ) were considered to be node-negative.

After breast conserving surgery patients received post-operative adjuvant radiation therapy with 50 Gy for the whole breast in 5 weeks with an additional boost of 16 Gy to the tumour site for patients under the age of 60 years. No radiation was given to the axilla. SN negative patients received adjuvant systemic treatment according to the Dutch national guidelines within the study period, as described in Table 1.

All patients were seen for follow up every 3 months during the first year

Table 1 Adjuvant systemic treatment regimens for $S N$ negative breast cancer patients, guidelines 1999-2003

*Starting 2003 all patients $<35$ years received adjuvant therapy independent of tumour characteristics.

**Adjuvant treatment: -ER-/PR- patients receive chemotherapy without hormonal therapy -Patients $<60$ yrs and ER/PR+ receive chemotherapy in combination with hormonal therapy - Patients 60-70 yrs and ER/PR+ receive hormonal therapy and chemotherapy based on patient and tumour characteristics.

*** Grade III and ER/PR+ : adjuvant hormonal therapy

****ER/PR+ hormonal therapy, ER/PR- : consider chemotherapy

\begin{tabular}{cccc}
$\begin{array}{l}\text { Tumour size } \\
\text { Premenopausal } \\
\text { Gr IIII }\end{array}$ & $<1 \mathrm{~cm}$ & $1-3 \mathrm{~cm}$ & $>3 \mathrm{~cm}$ \\
\hline Gr III & No & No & Yes $^{* *}$ \\
\hline $\begin{array}{l}\text { Postmenopausal } \\
\text { Yes* }\end{array}$ & No & Yes $^{* *}$ & Yes $^{* *}$ \\
\hline Gr IIII & No & No \\
\hline Gr III & No & Yes $^{* *}$ & Yes $^{* *}$ \\
\hline$>70$ years & No & No $^{* \star *}$ & Yes $^{* * *}$
\end{tabular}


and every 6 months in the second year following surgery. Thereafter follow up was once a year. Follow up consisted of physical examination and a yearly bilateral or contralateral mammography. Special attention was paid to axillary and locoregional recurrence by clinical examination only. No screening tests were carried out to exclude the presence of distant metastases.

\section{RESULTS}

Patient and tumour characteristics are listed in Table 2. All 344 patients without metastases were included in the study.

Preoperative lymphoscintigraphy was performed in all patients and axillary hotspots were visualised in 343 patients. In one patient no visible SNs were seen on the lymphoscintigraphic images. A sentinel lymph node could still be identified during operation by using the blue dye mapping technique. Additional lymph drainage to the internal mammary nodes was seen in 53 of the 343 patients $(15 \%)$. Axillary sentinel nodes were identified and removed in all cases. The mean number of axillary sentinel nodes removed was 2.1 (range 1-7). Internal mammary SNs were harvested in $34(64 \%)$ of relevant patients.

After a median follow-up of 43 months (mean 45 months, range 1-7 years) three axillary relapses occurred. The first patient, aged 52 years was found to have an axillary recurrence 21 months after the initial sentinel node procedure. A core biopsy was performed in 2000 in this patient and a grade 2 invasive ductal carcinoma with a diameter of $22 \mathrm{~mm}$ was diagnosed. A standard $\mathrm{SN}$ procedure was performed according to our protocol as described above. Preoperative lymphoscintigraphy showed one axillary and one internal mammary sentinel node, both of which were removed. Histopathologic analysis, including immunohistochemistry, did not reveal metastases. During the $S N$ procedure, a palpable radioactive lymph node was found in the axilla, which was not stained with blue dye. Against protocol this node was judged not to be a sentinel lymph node and was left behind. After secondary removal of this (the same?) node under local anaesthesia pathological examination revealed no metastases. In January 2002, following the development of an axillary recurrence, a complete axillary lymph node dissection was performed. In 7 of the 8 lymph nodes resected, metastases were detected. Locoregional radiotherapy, chemotherapy and hormonal therapy was started. At present, the disease is stable using an aromatase inhibitor.

A second patient, aged 61 years, developed an axillary relapse after a follow up of 17 months. Her medical history mentioned bilateral breast 
reduction surgery in 1985. In August 2000 an excisional biopsy was performed and revealed a grade 3 ductal carcinoma with a diameter of $31 \mathrm{~mm}$. Lymphatic mapping showed an axillary and a parasternal hotspot. Two axillary sentinel nodes were identified and removed, but the internal mammary sentinel node could not be harvested due to its subcostal localisation. Although the axillary sentinel nodes did not contain any metastases, axillary recurrence was confirmed in February 2002 and an axillary lymph node dissection revealed 6 positive lymph nodes, of which two with extracapsular extension, in the axillary basin which contained 22 lymph nodes in all. She received chemotherapy and radiotherapy, but died in 2003 from disseminated disease.

The third patient, 49 years old, developed an axillary recurrence 26 months after initial breast surgery for a grade 2 ductal carcinoma, $12 \mathrm{~mm}$ in diameter. Lymphoscintigraphic images showed, besides 4 axillary hotspots, accessory flow towards one infraclavicular node. All axillary and the

Table 2 Clinical and pathological characteristics of the study population

\begin{tabular}{lll} 
& SN- (344 patients) & SN+(295 patients) \\
\hline Mean Age (yr) & 65.8 & 60.6 \\
\hline Tumour size & & \\
Diameter $<20 \mathrm{~mm}$ & $218(63.4 \%)$ & $115(39.0 \%)$ \\
$20-49 \mathrm{~mm}$ & $121(35.2 \%)$ & $149(50.5 \%)$ \\
$>49 \mathrm{~mm}$ & $5(1.5 \%)$ & $31(10.5 \%)$ \\
\hline Tumour histology & & \\
Ductal & $254(73.8 \%)$ & $215(72.9 \%)$ \\
Lobular & $57(16.6 \%)$ & $71(24.1 \%)$ \\
Other & $33(9.6 \%)$ & $9(3.0 \%)$ \\
\hline Grading & & \\
I & $124(36.0 \%)$ & $62(21.0 \%)$ \\
II & $133(38.7 \%)$ & $131(44.4 \%)$ \\
III & $87(25.3 \%)$ & $102(34.6 \%)$ \\
\hline Lefttright & $179 / 165$ & $168 / 127$ \\
\hline Breast quadrant & & \\
Upper-outer & $162(47 \%)$ & $166(56 \%)$ \\
Upper-inner & $80(23 \%)$ & $39(13 \%)$ \\
Lower-outer & $42(12 \%)$ & $31(11 \%)$ \\
Lower-inner & $32(9 \%)$ & $23(8 \%)$ \\
Central/Paget & $28(8 \%)$ & $36(12 \%)$ \\
\hline
\end{tabular}


infraclavicular sentinel nodes were removed, but these were all negative for metastases. A completion ALND after the diagnosis of the axillary relapse contained 12 nodes, of which 2 contained metastases. She received hormonal therapy, but later on she was diagnosed with pulmonary metastases. Since then metastatic disease has been stable under aromatase inhibitors.

\section{Discussion}

Screening mammography has led to the detection of breast cancer at an earlier stage and consequently more women are diagnosed with breast cancer without axillary lymph node involvement. For this group of patients, routine performance of an axillary clearance induces substantial additional morbidity, but is not beneficial. Nowadays ALND is abandoned in case of a negative SN biopsy and many women are spared the morbidity of ALND. Although the short-term accuracy of the SN technique has been described repeatedly, it remains important to evaluate long-term follow-up results as well, especially with respect to axillary relapse as an indicator of a false-negative $\mathrm{SN}$ procedure.

Axillary recurrence rates after complete ALND range from $0 \%$ to $2 \%{ }^{8-10}$. Subsequently, negative SN biopsy without axillary clearance should at least achieve similar results regarding axillary relapse. Axillary recurrences will be clinically manifest within two years after initial surgery in $75 \%$ of relevant patients". Table 111 summarizes the results of published studies which have investigated axillary recurrence after negative SN biopsy, showing axillary relapse ranging from $0 \%$ to $1.5 \%{ }^{11-35}$. The median follow-up reported was 14 to 57 months. Our own results, with an axillary recurrence rate of $0.9 \%$ after a median follow up of 43 months, support the conclusion of these studies regarding axillary recurrence following negative SN biopsy without ALND: SN biopsy indeed is a reliable procedure to determine the nodal status in breast cancer patients without the morbidity of conventional ALND.

To reduce the chances of a false negative SN biopsy in the future, we reviewed the 3 patients with an axillary relapse in our series. The first patient was found to have a palpable axillary lymph node during SN biopsy. One of the known pitfalls of the SN procedure is massive tumour infiltration of the primary draining lymph node and subsequent rerouting, thereby labelling another lymph node as SN, thus failing to identify the true SN which contains melastases. These lymph nodes can frequently be detected clinically, by preoperative ultrasound or during surgery. Nowadays, we routinely perform an ultrasonographic investigation of the axilla with a fine needle aspiration in case 
of a palpable lymph node or an abnormal lymph node at ultrasound. Hence, palients with increased risk of labelling a false SN can be excluded Additionally, every palpable lymph node, found in the axilla during surgery, should be regarded as a potential sentinel lymph node and therefore should be removed, independent of radioactivity or blue staining ${ }^{9}$.

The second patient with an axillary recurrence had a history of major prior breast surgery, i.e. bilateral breast reduction surgery. Moreover, in this patient $\mathrm{SN}$ biopsy was preceded by a diagnostic excisional biopsy.

As yet, there has been no consensus regarding the accuracy of SN biopsy following prior breast surgery. Several investigators reported that patients with previous excisional biopsy are not eligible for $\mathrm{SN}$ biopsy $4,6,36$, because prior surgery is assumed to alter the lymphatic drainage patterns by disrupting the lymphatic channels. Recently, we published a validation study in 88 patients with previous excisional biopsy, in which SN biopsy proved to be highly accurate, as confirmed by completion ALND (sensitivity $100 \%{ }^{37}$. Also, a large observational study was published concerning this group of patients, in which, after a median follow-up of two years, four nodal recurrences were observed in 543 patients $^{38}$. Both studies confirm the accuracy of the SN procedure following prior excisional biopsy. However, in breast reduction surgery, the anatomy of the subareolar region is altered substantially, which may well explain the false negative result in this patient.

The third patient with an axillary relapse was found to have an infraclavicular hotspot on preoperative lymphoscintygraphy. Axillary and infraclavicular SN biopsy were found to be negative. In retrospective, we could not identify any reason for the false negative result in this patient.

Based on a generally accepted false negative rate of the SN procedure of $5 \%$, Roumen et al. showed that the expected number of patients with residual axillary metastases is $3 \%{ }^{12}$. Our own data, as well as that of the published series shown in Table III, found axillary recurrence to be less than expected. Although, in theory, this could be the result of a relatively short follow-up period, most published studies (Table 3 ) have a median follow up exceeding two years, as the period in which axillary relapse generally becomes manifest Our own results showed axillary recurrence 26, 21 and 17 months after initial treatment. Another possible explanation for these low rates of axillary relapse is the scrupulous pathologic examination for (micro)metastases within the sentinel node procedure. Finally, the use of more effective adjuvant systemic therapy in many patients nowadays may result in remission or down staging of residual axillary metastases. This may even delay or prevent axillary recurrence to become clinically manifest. 
Axillary recurrence in $S N$ negative patients

Table 3 Axilllary recurrence after negative SN biopsy without ALND

\begin{tabular}{|c|c|c|c|c|c|}
\hline Author & Year & Patients & $\begin{array}{l}\text { Median follow up } \\
\text { (months) }\end{array}$ & Axillary recurrence & $\begin{array}{l}\text { Axillary recurrence } \\
\text { after (months) }\end{array}$ \\
\hline Giuliano"11 & 2000 & 67 & 39 & 0 & \\
\hline Roumen ${ }^{12}$ & 2001 & 100 & 24 & $1(1 \%)$ & 14 \\
\hline Schrenk ${ }^{13}$ & 2001 & 83 & 22 & 0 & \\
\hline Veronesi $1^{14}$ & 2001 & 285 & 14 & 0 & \\
\hline Chung ${ }^{15}$ & 2002 & 208 & 26 & $3(1.4 \%)$ & $4,11,40$ \\
\hline Meijer ${ }^{16}$ & 2002 & 100 & 47 & $1(1 \%)$ & 24 \\
\hline Hansen ${ }^{17}$ & 2002 & 238 & 39 & 0 & \\
\hline Loza $^{18}$ & 2002 & 168 & 21 & $1(0.6 \%)$ & 30 \\
\hline Reitsamer ${ }^{19}$ & 2003 & 116 & 22 & 0 & \\
\hline Ponzone ${ }^{20}$ & 2003 & 150 & 15 & 0 & \\
\hline Blanchard21 & 2003 & 685 & 29 & $1(0.1 \%)$ & 41 \\
\hline Badgwel||22 & 2003 & 159 & 32 & 0 & \\
\hline Veronesi $^{23}$ & 2003 & 167 & 46 & 0 & \\
\hline Jeruss $s^{24}$ & 2005 & 592 & 27 & $1(0.2 \%)$ & 22 \\
\hline Smidtt25 & 2004 & 439 & 26 & $2(0.5 \%)$ & 4,27 \\
\hline Naik $^{26}$ & 2004 & 2340 & 31 & $3(0.13 \%)$ & $18,29,38$ \\
\hline Langer ${ }^{27}$ & 2005 & 149 & 42 & $1(0.7 \%)$ & 14 \\
\hline $\mathrm{Kokke}^{28}$ & 2005 & 113 & 37 & $1(0.9 \%)$ & 29 \\
\hline Wessem $^{29}$ & 2004 & 82 & 28 & $1(1.2 \%)$ & 24 \\
\hline Torrenga $a^{30}$ & 2004 & 104 & 57 & $1(1.0 \%)$ & 24 \\
\hline Verones $j^{31}$ & 2005 & 953 & 38 & $3(0.3 \%)$ & $20,30,38$ \\
\hline Zavagno $^{32}$ & 2005 & 479 & 36 & 0 & \\
\hline Sanjuàn ${ }^{33}$ & 2005 & 158 & 21 & $1(0.6 \%)$ & 19 \\
\hline Swenson ${ }^{34}$ & 2005 & 612 & 33 & $3(0.5 \%)$ & $11,24,36$ \\
\hline De Kanter ${ }^{35}$ & 2006 & 149 & 65 & $4(2.6 \%)$ & $10,12,14,56$ \\
\hline Current study & 2006 & 344 & 43 & $3(0.9 \%)$ & $17,21,26$ \\
\hline
\end{tabular}

\section{Conclusion}

Our results in this follow-up study indicate that adequate staging is achieved by SN biopsy in breast cancer patients. This procedure does not lead to an increased incidence of axillary recurrence, as compared to ALND. Although longer follow-up is required, these midterm follow-up data support the current opinion that ALND can be safely abandoned in case of a negative SN biopsy. 


\section{REFERENCES}

1. Consensus conference. Adjuvant chemotherapy for breast cancer. IAMA 1985; 254:3467-3463.

2. Carter $\mathrm{CL}$, Allen C., Henson DE. Relation of tumor size, lymph node status, and survival in 24,740 breast cancer cases. Cancer 1989; 63:181-187.

3. Krag DN, Weaver DL, Alex IC, Fairbank JT. Surgical resection and radiolocalization of the sentinel lymph node in breast cancer using a gamma probe. Surg Oncol 1993; 2:335-339.

4. Albertini Il, L.yman CH, Cox C, Yeatman T, Balducci L, Ku N, Shivers S, Berman C, Wells $K$, Rapaporl D, Shons A, Horton I, Greenberg H, Nicosia S, Clark R, Cantor A, Reintgen DS. Lymphatic mapping and sentinel node biopsy in the patient with breast cancer. IAMA 1996; 276:1818-1822.

5. Giuliano AE, Jones RC, Breman $M$, Statman R. Sentinel lymphadenectomy in breast cancer. I Clin Oncol 1997; 15:2345-2350.

6. Veronesi U, Paganelli G, Galimberti V, Viale G, Zurrida S, Bedoni M, Costa A, De Cicco C, Geraghty JG, Luini A, Sacchini V, Veronesi P. Sentinel-node biopsy to avoid axillary disseclion in breast cancer with clinically negative lymph-nodes. Lancet 1997; 349:1864-1867.

7. van der Ent FWC, Kengen RAM, van der Pol HAG, Hoofwijk AGM. Sentind node biopsy in 70 unselected patients with breast cancer: increased feasibility by using $10 \mathrm{mC}$ radiscolloid in combination with a blue dye tracer. Fur J Surg Oncol 1949; 25:24-29.

8. Recht A, Pierce SM, Abner A, Vicini F, Osteen RT, Love SM, Silver B, Harris JR. Regional nodal failure after conservative surgery and radiotherapy for early-stage breast carcinoma. I Clin Oncol 1991; 9:988-996.

9. Fisher B, Redmond C, Fisher FR, Bauer M, Wolmark N, Wickerham DL, Deulsch M Montague E, Margolese R, Foster R. Ten-year results of a randomized clinical trial comparing radical mastectomy and total mastectomy with or without racliation. $N$ Engl I Med 1985; 312:674-681.

10. Fowble B, Sulin L.J, Schultz DJ, Goodman RL. Frequency, sites of relapse, and oulcome of regional nocle failures following conservative surgery and radiation for early breast cancer. In I Radial Oncol Biol Phys 1989; 17:703-710.

11. Giuliano AE, Haigh PI, Brennan MB, Hansen NM, Kelley MC, Ye W, Glass EC, Tumer RR. Prospective observational study of sentinel lymphadenectony without further axillary dissection in patients with sentinel node-negative brenst cancer. J Clin Oncol 2000; 18:2553-2559.

12. Roumen RM, Kuijt GP, Liem IH, van Beek MW. Treatnent of $T 00$ patients with sentinel node-negative breast cancer without further axillary dissection. Br J Surg 2001 ; 88:1639-1643. 
13. Schrenk $P$, Halzl-Griesenhofer $M$, Shamiyeh $A$, Waynad W. Follow-up of sentinel node negative brcast cancer patients without axillary lymph node dissection. I Surg Oncol 2001; 77:165-170.

14. Veronesi U, Galimberti $V$, Zurrida S, Pigatto F, Veronesi P, Robertson $C$, Paganelli $C$, Sciascia V, Viale G. Sentinel lymph node biopsy as an indicator for axillary dissection in early breast cancer. Eur J Cancer 2007; 37:454-458.

15. Chung MA, Steinhoff MM, Cady B. Clinical axillary recurrence in breast cancer patients after a negative sentinel node biopsy. Am / Surg 2002; 184:310-314.

16. Meijer $S$, Torrenga $H$, van dS, Jr. INegative sentinel node in breast cancer patients a good indicator for continued absence of axillary metastases|

Negatieve schildwachtklier bij borstkankerpatienten goede indicator voor het uitblijven van okselmetastasen. Ned Tijdschr Geneeskd 2002; 146:942-946.

17. Hansen NM, Grube BI, Giuliano AE. The time has come to change the algorithm for the surgical management of early breast cancer. Arch Surg 2002; 137:1131-1135.

18. Loza J, Colo F, Nadal I, Viniegra $M$, Chacon R. Axillary recurrence after sentinel node biopsy for operable breast cancer. Eur I Surg Oncol 2002; 28:897-898.

19. Reitsamer R, Peintinger F, Prokop E, Menzel C, Cimpoca W, Rettenbacher L. Sentinel lymph node biopsy alone without axillary lymph node dissection-follow up of sentinel lymph node negative breast cancer patients. Eur f Surg Oncol 2003; 29:221-223.

20. Ponzone R, Biglia N, Maggiorotto F, Kubatzki F, Elia O, De Rosa G, Sismondi P. Sentinel node dissection as definitive treatment for node negative breast cancer patients. Eur I Surg Oncol 2003; 29:703-706.

21. Blanchard DK, Donohue IH, Reynolds C, Crant CS. Relapse and morbidity in paticnts undergoing sentinel lymph node biopsy alone or with axillary dissection for breast cancer. Arch Surg 2003; 138:482-487.

22. Badgwell BD, Povoski SP, Abdessalam SF, Young DC, Farrar WB, Walker MJ, Yee LD, Zervos EE, Carson WE, III, Burak WE, Jr. Patterns of recurrence after sentinel lymph node biopsy for breasl cancer. Ann Surg Oncol 2003; 10:376-380

23. Veronesi $U$, Paganelli $G$, Viale $G$, Luini A, Zurrida S, Galimberti V, Intra M, Veronesi P, Robertson C, Maisonneuve P, Renne G, De Cicco C, De Lucia F, Gennari R. A randonized comparison of sentinel-node biopsy with routine axillary dissection in breast cancer. N Engl I Med 2003; 349:546-553.

24. Jeruss IS, Winchester DJ, Sener SF, Brinkmann EM, Bilimoria MM, Barrera E Jr, Alwaw E, Nickolov A, Schermerhorn GM, Winchester D). Axillary recurrence after sentincl node biopsy. Ann Surg Oncol 2005; 12:34-40.

25. Smidt ML, Janssen CM, Kuster DM, Bruggink ED, Strobbe LJ. Axillary recurrence after a negative sentinel node biopsy for breast cancer: incidence and clinical significance. Ann Surg Oncol 2005; 12:29-33. 
26. Naik AM, Fey J, Gemignani M, Heerdt A, Montgomery L, Petrek J, Port E, Sacchini V Sclafani L, VanZee K, Wagman R, Borgen PI, Cody HS, III. The risk of axillary relapse after sentincl lymph nude biopsy for breast cancer is comparable with that of axillary lymph node dissection: a follow-up study of 4008 procedures. Ann Surg 2004; 240:462-468.

27. Langer I, Marti WR, Guller U, Moch H, Harder F, Oertli D, Zuber M. Axillary recurrence rate in breast cancer patients with negative sentinel lymph node (SLN) or SLN micrometastases: prospective analysis of 150 patients after SLN biopsy. Ann Surg $2005 ; 241: 152-158$.

28. Kokke MC, Jannink I, Barneveld PC, van der Linden JC, Celderman WA, Wissing IC, Bosscha $\mathrm{K}$. Incidence of axillary recurrence in 113 sentinel node negative breast cancer patients: a 3-year follow-up study. Eur I Surg Oncol 2005; 31:221-225.

29. van Wessem Kl, Meijer WS. Sentinel lymph node biopsy in breast cancer: results of intradermal periareolar tracer injection and follow-up of sentinel lymph node-negative patients. Breast 2004; 13:290-296

30. Torrenga $\mathrm{H}$, Fabry $\mathrm{H}$, van $\mathrm{dS}$, Jr., Van Diest P, Pijpers $\mathrm{R}$, Meijer S. Omitting axillary lymph node dissection in sentinel node negative breast cancer patients is safe: a long term follow-up analysis. J Surg Oncol 2004; 88:4-7.

31. Veronesi $U$, Galimberti V, Mariani L, Gatti $G$, Paganelli G, Viale $G$, Zurrida S, Veronesi P, Intra M, Gennari R, Rita VA, Luini A, Tullii M, Bassani G, Rotmensz N. Senlinel node biopsy in breast cancer: early results in 953 patients with negative sentinel node biopsy and no axillary dissection. Eur J Cancer 2005; 41:231-237.

32. Zavagno G, Carcotoro P, Franchini Z, Renier M, Barulta L, De Salvo Gl., Maravegias K Capitanio $G$, Nitti D, Lise M. Axillary recurrence after negative sentinel lymph node biopsy withoul axillary dissection: a study on 479 breast cancer patients. Eur I Surg Oncol 2005; 31:715-720.

33. Sanjuan A, Vidal-Sicart S, Zanon $G$, Pahisa J, Velasco M, Fernandez Pl., Santamaria $G$, Farrus B, Munoz. M, Albanell I, Pons F, Vanrell JA. Clinical axillary recurrence alter sentinel node biopsy in breast cancer: a follow-up study of 220 patients. Eur I Nucl Med Mol Imaging 2005; 32:932-936

34. Swenson KK, Mahipal A, Nissen MJ, Tuttle TM, Heaton K, Lally RM, Spomer A, Lee MW. Axillary disease recurrence after sentinel lymph node dissection for breas carcinoma. Cancer 2005; 104:1834-1839.

35. De Kanter AY, Menke-P'luymers MM, Wouters MW, Burgmans I, Van Geel AN, Eggermont AM. 5-Year follow-up of sentinel node negative breast cancer patients. Eur I Surg Oncol 2006; 32:282-286.

36. Pijpers R, Meijer S, Hoekstra OS, Collet Gl, Comans EF, Boom RP, Van Diest Pl, Teule G). Impact of lymphoscintigraphy on sentinel node identification with technetium99m-colloidal albumin in breast cancer. J Nucl Med 1997; 38:366-368. 
37. Heuts EM, van der Ent FW, Kengen RA, van der lol HA, Hulsewe KW, Hoolwijk AG. Results of sentinel node biopsy not aifected by previous excisional biopsy. Eur I Surg Oncol 2006; 32:278-281.

38. Luini A, Galimberti V, Galti G, Arnone P, Vento AR, Trifiro G, Viale G, Rolmensz N, Fernandez JR, Gilardi D, Paganelli $G$. The sentinel node biopsy after previous breast surgery: preliminary results on 543 patients treated at the European Instilute of Oncology. Breast Cancer Res Treat 2005; 89:159-163. 


\section{Chapter 5}

Internal mammary lymph drainage and sentinel node biopsy in breast cancer- a study on 1008 patients

EM Heuts, FWC van der Ent, MF von Meyenfeldt, AC Voogd Eur / Surg Oncol 2009; 35:252-257 


\section{ABSTRACT}

\section{Introduction}

Nowadays, axillary sentinel node (SN) biopsy is a standard procedure in the staging of breast cancer. Although the internal mammary (IM) lymph node status is a major independent prognostic factor in breast cancer patients, sampling of IM sentinel nodes (IMSNs) is not performed routinely. The aim of this study was to determine the likelihood of finding IM lymph node metastases in case of IM hotspots on lymphoscintigraphy and evaluate the relevance of IMSN biopsy as a method to improve staging.

\section{Patients and methods}

Between April 1997 and May 2006, a total of 1008 consecutive patients with clinically node-negative operable primary breast cancer were enrolled in a prospective study on SN biopsy. Both axillary and IMSNs were sampled, based on lymphoscintigraphy, intraoperative gamma probe detection and blue dye

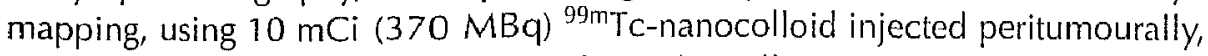
and $0.5-1.0 \mathrm{ml}$ Patent Blue $\mathrm{V}$ injected intradermally.

\section{Results}

Lymphoscintigraphy showed axillary sentinel nodes in 98\% (989/1008) and IMSNs in 20\% of the patients (196/1008). Sampling the IM basin, as based on the results of lymphoscintigraphy, was successful in $71 \%$ of the patients (139/196) and revealed metastases in 22\% (31/139). In $29 \%$ percent of the patients with positive IMSN's (9/31) no axillary metastases were found.

\section{Conclusion}

Evaluation of IMSNs improves nodal staging in breast cancer. Patients with IM hotspots on lymphoscintigraphy have a substantial risk (22\%) of metastatic involvement of the IM chain. In addition, true IM node-negative patients can be spared the morbidity associated with adjuvant radiotherapy. 


\section{INTRODUCTION}

The sentinel lymph node (SN) procedure has become the standard of care for staging clinically node negative patients with breast cancer ${ }^{1-3}$. However controversy exists about the management of extra-axillary nodes, especially those located in the internal mammary (IM) chain.

In addition to the axillary Jymph node status, the $I M$ lymph node status provides important prognostic information in breast cancer patients ${ }^{4}$. If positive prognosis is less favorable. However, when lymphatic mapping reveals IM drainage, staging of these nodes is not performed routinely, thus discarding additional staging information.

Most authors do not perform IMSN biopsy, because the clinical importance of $I M$ lymph node metastases is unclear. Results of ongoing trials are needed to formulate treatment guidelines for these patients.

The aim of this study was to determine the risk of $1 \mathrm{M}$ lymph node metastases in case of IM hotspots on lymphoscintigraphy and evaluate the relevance of IMSN biopsy as a method to improve staging, as based upon the results of a 9 years period, in which IMSN biopsy was performed on a routine basis in patients with primary breast cancer.

\section{Patients AND METHOdS}

From April 1997 until May 2006, having received approval of the local ethical committee, and having oblained informed consent, all conseculive patients with clinically node-negative operable primary breast cancer were included in a prospective study on $\mathrm{SN}$ biopsy. Except for pregnancy and $\mathrm{T}_{4}$-tumours, no patients were excluded.

\section{Sentinel node technique}

Our technique of SN biopsy involves the injection of $10 \mathrm{mCi}(370 \mathrm{MBq}){ }^{99 \mathrm{~m}} \mathrm{Tc}$ nanocolloid, the day before surgery in 3-4 depots around the tumour or in the breast parenchyma surrounding the cavity of a previous excisional biopsy. ${ }^{5}$. In case of non-palpable tumours, the radiocolloid tracer was injected within the relevant quadrant of the breast, without the use of ultrasound guidance. Lymphoscintigraphy was performed on the next day, after a period of 16-18 hours following radiotracer injection, and shortly before surgery. Lymphoscintigraphic images were obtained in three stanclard positions: anterior, anterior oblique and lateral. The location of axillary and non-axillary SNs was marked on the skin. 
After induction of general anaesthesia in the operating room, 10-15 minutes before the incision, 0.8-1.0 ml Patent Blue $\mathrm{V}$ (Laboratoire Guerbet, France) was injected intradermally above the tumour or alongside the scar of the excisiona biopsy. During surgery in all patients attempts were made to harvest both axillary and non-axillary SNs, as visualized on lymphoscintigraphy. The IMN biopsy technique, described by Haagensen ${ }^{6}$, can usually be performed using the mastectomy incision. In breast conserving therapy a small additional horizontal incision $(2.5-3 \mathrm{~cm})$ over the desired interspace was used to sample IMSNs. In case of multiple IM hotspots on the lymphoscintigraphy, the IM lymph nodes were mostly retrieved through the same incision.

Intraoperative identification of the SNs was based both on blue dye mapping and gamma probe detection (1997: RMD $10 \mathrm{~mm}$, Radiation Monitoring Devices USA, 2000: Navigator, Navigator gamma guidance system Watertown, USA and 2006: Europrobe, EuroMedical Instruments Strasbourg, France). Interference from primary site radioactivity of medial tumours, impeding IMSN identification, was managed by using an additionally collimated gamma probe and by narrowing the energy window of the probe, which decreases the influence of scattered radiation from the primary injection site. A postoperative chest $\mathrm{X}$-ray was made routinely following IM node biopsy, to exclude accidental pneumothorax.

In Phase I of this study (137 patients) SN biopsy was followed by completion axillary lymph node dissection in all cases. In Phase II, after validation of the $\mathrm{SN}$ technique in our institute, completion axillary lymph node dissection was performed only in cases of a tumour-positive axillary $\mathrm{SN}$ or nonsuccessful SN procedure. Histopathologic examination of the SNs consisted of rouline hematoxylin and eosin $(H \& E)$ staining, followed by serial sectioning and immunohistochemical staining whenever routine $\mathrm{H} \& \mathrm{E}$ staining did not reveal metastases.

\section{Statistical analysis}

We analyzed three end-points: visualization of the IMSNs, successful biopsy of the IMSNs and the presence of IM lymph node metastases. We used Chi-square tests to compare patient groups with respect to age, tumour localization, tumour size, axillary nodal status, tumour grade and progesterone and estrogen receptor status. A multivariable logistic regression analysis was performed to determine the independent predictive effect of these covariates for each of the three end-points, using a backward stepwise selection of the co-variates. Co-variates were excluded from the model if the probability of the likelihood ratio statistic was larger than 0.05 . Only the results of the final multivariable model will be presented. 


\section{RESULTS}

\section{General characteristics}

A lotal of 1008 consecutive patients with breast cancer were included in this study. All but three patients were women. Their mean age was 59 years (range: 29-96). Preoperative diagnosis was documented by fine-needle aspiration or core biopsy in 823 patients and by previous excisional biopsy in 185 patients. Lymphoscintigraphy visualized axillary hot spots in $98 \%$ of the patients. The axillary SN biopsy was successful in $98 \%$. The axillary basin was tumourpositive in $42 \%$. Of the 427 patients with positive axillary lymph nodes, 328 had 1-3 positive nodes and 99 had $>3$ positive nodes. The mean number of positive axillary lymph nodes was 3.5 (range: $1-37$ ).

\section{Visualization of IMSNs}

In 196 patients additional hot spots were noted in the IM chain. Exclusive drainage to the $I M$ lymph nodes was absent in our series. in 185 patients with previous excisional biopsy, 45 patients had $M$ hotspots and in 823 patients with core biopsy, 151 patients showed IM hotspots $(p=0.06)$. Of the 196 patients with IM hotspots, 115 underwent a masteclomy, compared to 812 patients without $I M$ hotspots, of which 495 underwent ablative treatment $(P=0.82)$.

The proportion of patients in whom the IMSNs could be visualized decreased with age and was also smaller for patients with a tumour in the lateral part of the breast, compared to those with a tumour in the medial or central part of the breast (Table 1). No significant associations were observed with tumour size and grade, axillary nodal status and estrogen and progesterone receptor status. In the multivariable logistic regression analysis, age and tumour localization were the only independent predictors for the ability to visualize the IMSNs (P<0.001).

\section{Biopsy of IMSNs}

IMSN biopsy proved successful in 139 of the 196 of patients showing internal mammary hotspots on the scan. Failure in harvesting the IMSNs was mostly due to insufficient radioactivity uptake $(n=32)$, followed by subcostal location of the SNs $(n=13)$, a shine through effect $(n=6)$, a pleural lesion $(n=3)$ or a mediastinal location of the SNs.

IMSNs were mostly found in the third interspace (36\%), with $26 \%, 25 \%$ and $9 \%$ of IM hotspots in the second, fourth and fifth interspace respectively.

in the 139 patients with a successful IMSN biopsy, the mean number of 
Table 1 Comparisen of characteristics of patients who had visualized internal mammary sentine nodes IMSN's versus those who had no IMSN's visualized on preoperative lymphoscintigraphy $(N=1008)$.

\begin{tabular}{|c|c|c|c|}
\hline Characteristic & $\begin{array}{l}\text { IM SN's not visualized } \\
\quad(N=812)\end{array}$ & $\begin{array}{l}\text { IM SN's visualized } \\
\quad(N=196)\end{array}$ & Prvalue \\
\hline \multicolumn{4}{|l|}{ Age } \\
\hline$\leq 50$ & 202 & 95 & $<0.0001$ \\
\hline 51.70 & 416 & 76 & \\
\hline$>70$ & 194 & 25 & \\
\hline \multicolumn{4}{|c|}{ Period of dianosis } \\
\hline $1997-1999$ & 182 & 61 & 0.03 \\
\hline $2000-2002$ & 318 & 72 & \\
\hline $2003-2006$ & 312 & 63 & \\
\hline \multicolumn{4}{|c|}{ Tumour focalization } \\
\hline Lateral & 468 & 73 & $<0.0001$ \\
\hline Medial & 266 & 98 & \\
\hline Central & 62 & 25 & \\
\hline \multicolumn{4}{|l|}{ Tumour size } \\
\hline$\leq 20 \mathrm{~mm}$ & 449 & 114 & 0.68 \\
\hline$>20 \mathrm{~mm}$ & 337 & 80 & \\
\hline \multicolumn{4}{|c|}{ Axillary nodal status (pN) } \\
\hline Negative & 475 & 106 & 0.26 \\
\hline Positive & 337 & 90 & \\
\hline \multicolumn{4}{|l|}{ Tumour grade } \\
\hline Good & 200 & 54 & 0.61 \\
\hline Moderate & 342 & 76 & \\
\hline Poor & 257 & 64 & \\
\hline \multicolumn{4}{|c|}{ Estrogen receptor status } \\
\hline Negative & 159 & 38 & 0.94 \\
\hline Positive & 594 & 144 & \\
\hline \multicolumn{4}{|c|}{ Progesterone receptor } \\
\hline Negative & 267 & 60 & 0.56 \\
\hline Positive & 486 & 121 & \\
\hline
\end{tabular}


removed SNs was 1.5 (range 1-5). Ninety patients had one IMSN removed, 32 two nodes, 13 three nodes, 3 four nodes and one patient five nodes.

In 10 IMSN procedures a small pleural lesion was noted intraoperatively. Recovery was uneventful following simple vacuum drainage in the first three patients and no additional treatment in the following patients. All patients were checked with chest X-rays to exclude development of a pneumothorax. No bleeding was encountered.

The proportion of patients with a successful biopsy of the IMSNs decreased with age (Table 2). In the univariate analysis, none of the other factors were significantly associated with the likelihood of a successful biopsy of the IMSNs. In the multivariable logistic regression analysis age appeared to be a independent predictor for the success of the IMSN biopsy. The risk of failure of IMSN biopsy was almost five times higher for patients $>70$ compared to those of 50 years or younger (OR: $4.62,95 \% \mathrm{Cl}: 1.74-12.27$ ). The risk of an unsuccessful biopsy of the IMSN biopsy also tended to be lower for patients with a moderately or poorly differentiated tumour than for those with a wel differentiated tumour (OR: $0.36,95 \% \mathrm{Cl}: 0.15-0.89$ ). Twelve of the 57 patients with an unsuccessful IMSN biopsy had a previous excisional biopsy, compared to 33 of the 139 patients with a successful biopsy $(p=0.68)$.

\section{IM lymph node metastases}

IMSN biopsy revealed metastatic involvement in 31 of the 139 patients with a successful biopsy. Of these 31 patients 9 had a negative axillary SN biopsy (AX$/ \mathrm{MN}+$ ) and 3 had micrometastases only. Of the patients with IM lymph node metastases $32 \%$ had a tumour in the lateral part of the breast, $58 \%$ in the medial part and $10 \%$ in the central part of the breast. Eleven of the 31 patients with positive IMSN's had only micromelastatic disease. Of the 31 IM-positive patients, 5 had an excisional biopsy, compared to 28 of the $108 \mathrm{IM}$ negative patients $(p=0.26)$. In the univariate analysis, the chance of finding a positive $I M$ lymph node was significantly higher for patients with a tumour $>2 \mathrm{~cm}$ compared to those with a tumour of $2 \mathrm{~cm}$ or less $(P=0.01)$. The risk of finding a positive $I M$ lymph node was also elevated for patients with a positive axillary lymph node status, as compared to those with a negative axillary nodal status. In the multivariable analysis of the total patient population, axillary lymph node status (OR: 3.40 $95 \% \mathrm{Cl}: 1.45-7.97$ for node-positive versus node-negative patients), tumour location (OR: $2.91,95 \% \mathrm{Cl}$ : 1.33-6.36 for medially versus laterally located tumours) and age (OR: 0.41,95\% Cl: 0.18-0.92 and OR: $0.19,95 \% \mathrm{Cl}: 0.04-0.84$ for patients aged $51-70$ and $>70$ years respectively, as compared to those aged $\leq 50$ years) were independent predictors for IM lymph node metastases. 


\section{Chapter 5}

Table 2 Comparison of characteristics of patients with successiul and unsuccessful biopsy of internal mammary sentinel nodes (IMISNs). Including only patients who had IMSNS visualized on preoperative lymphoscintigraphy $(\mathrm{N}=196)$.

\begin{tabular}{|c|c|c|c|}
\hline Characteristic & $\begin{array}{c}\text { Unsuccessful biopsy } \\
\text { of IMSNs } \\
(\mathrm{N}=57)\end{array}$ & $\begin{array}{l}\text { Successful biopsy } \\
\text { of IMSNs } \\
(\mathrm{N}=139)\end{array}$ & P-value \\
\hline \multicolumn{4}{|l|}{ Age } \\
\hline$\leq 50$ & 21 & 74 & 0.01 \\
\hline $51-70$ & 23 & 53 & \\
\hline$>70$ & 13 & 12 & \\
\hline \multicolumn{4}{|c|}{ Period of diagnosis } \\
\hline 1997-1999 & 22 & 39 & 0.16 \\
\hline $2000-2002$ & 22 & 50 & \\
\hline $2003-2006$ & 13 & 50 & \\
\hline \multicolumn{4}{|c|}{ Tumour localization } \\
\hline Lateral & 23 & 50 & 0.73 \\
\hline Medial & 26 & 72 & \\
\hline Central & 8 & 17 & \\
\hline \multicolumn{4}{|l|}{ Tumour size } \\
\hline$\leq 20 \mathrm{~mm}$ & 30 & 84 & 0.26 \\
\hline$>20 \mathrm{~mm}$ & 27 & 53 & \\
\hline \multicolumn{4}{|c|}{ Axillary nodal status (pN) } \\
\hline Negative & 74 & 32 & 0.71 \\
\hline Positive & 65 & 25 & \\
\hline \multicolumn{4}{|l|}{ Tumour grade } \\
\hline Good & 20 & 34 & 0.32 \\
\hline Moderate & 19 & 57 & \\
\hline Poor & 18 & 46 & \\
\hline \multicolumn{4}{|c|}{ Estrogen receptor status } \\
\hline Negative & 11 & 27 & 0.98 \\
\hline Positive & 42 & 102 & \\
\hline \multicolumn{4}{|c|}{ Progesterone receptor } \\
\hline Negative & 20 & 40 & 0.40 \\
\hline Positive & 33 & 88 & \\
\hline
\end{tabular}




\section{DISCUSSION}

Many studies on lymphatic drainage of the breast have confirmed the importance of the $I M$ basin as a second draining route in breast cancer $7 ; 8$. As a consequence, $I M$ lymph node dissection was part of the standard surgical treatment in the 1950 s and 1960s. This radical surgical procedure was abandoned in the 1970 s because patient outcome studies showed that radical dissection did not improve survival. However, these studies have clearly shown that patients with documented IM metastases, who did not receive adjuvant therapy, have a worse prognosis. As a consequence, IMSN biopsy can refine staging in breast cancer patients and offers the possibility of providing tailorma de treatment in case of proven metastases to the IM chain.

IM hotspot visualization

In the present study, including more than 1000 breast cancer patients, IM hotspots were seen in $20 \%$ of the patients. This is largely in accordance with the figures reported by other studies (Table 3), which range from 14 to $22 \%{ }^{9-13}$

Differences between studies in the proportion of patients with a successful $v$ is ualization of the IM lymph nodes could be explained by differences in the site of tracer injection and the particle size of the tracers. We use a peritumoural in jection technique, which is associated with a higher visualisation rate of $I M$ hotspots as compared to superficial injection techniques ${ }^{14}$. Differences between sturdies could also be explained by differences in the age distribution of the patients and the location of their tumour. As reported by others, we found that $1 M$ lymph drainage was more common in younger women and in patients with medially located tumours9,10. The influence of tumour localization and age on the $\checkmark$ isualization of IMSN was confirmed in a multivariable analysis. IM visualization

Table 3 Published series concerning visualization and exploration of IMSNs in breast cancer patients

\begin{tabular}{lcccc} 
Author & Year & Number of patients & Visualization of IMSN (\%) & Successful biopsy of IMSN \\
\hline Current study & 2007 & 1008 & $20 \%$ & $139 / 198(70 \%)$ \\
Madsen $^{10}$ & 2007 & 509 & $22 \%$ & $85 / 109(78 \%)$ \\
Leidenius $^{9}$ & 2006 & 984 & $1.4 \%$ & $121 / 138(88 \%)$ \\
Paredes $^{13}$ & 2005 & 323 & $17 \%$ & $32 / 44(73 \%)$ \\
Farrus $^{12}$ & 2004 & 225 & $14 \%$ & $14 / 20(69 \%)$ \\
Estourgie $^{11}$ & 2003 & 681 & $22 \%$ & $130 / 150(87 \%)$ \\
\hline
\end{tabular}


is not influenced by different time intervals between radioactive tracer injection and lymphoscintigraphy i.e. between early and delayed imaging ${ }^{1.4}$

\section{IMSN successrate}

Although the success rate for harvesting SNs in the IM chain is lower than for axillary $S N s, 70 \%$ of the visualized $I M$ nodes were retrieved, which is comparable to other studies (Table 3$)^{4-13.17}$.

Failure was mainly associated with insufficient radioactive uptake. However, since the introduction of SPECT-CT in 2006, it became clear that a substantial number of these vague hotspots are located in the mediastinum, and therefore beyond reach.

\section{Complications of IMSN biopsy}

As reported by others, we found that IMSN biopsy has few complications ${ }^{15.16}$. Morbidity was limited as a result of the small incisions over the intercostal space, leading to good cosmetic results. Pleural lesions occurred in 10 patients, with uneventful recovery in all of them. We did not encounter any bleeding from the $1 \mathrm{M}$ artery.

\section{IM metastases}

The overall risk of IM lymph node metastases in breast cancer patients is well known and reported to be $18-33 \%$. Metastases exclusively situated in the IMN, without concurrent axillary metastases, occur in $2-11 \%$ of patients ${ }^{15}$.

Important factors predicting the likelihood of IM lymph node metastases are the axillary nodal status, the localization and characteristics of the primary tumour and patients age $e^{4,6,17,18,19}$

Our results also show that $I M$ lymph node metastases are mostly found concomitantly with axillary metastases and are more common in larger tumours. In the multivariable analysis, a positive axillary lymph node status, medial tumour location and decreasing age were independent predictors for a positive IMSN

In the 9 patients with proven metastases to the IM lymph nodes without axillary lymph node metastases, it could be argued that there is an indication to perform an ALND, because their disease has shown that it is not just localised but has a metastatic potential. In our opinion there is no indication to perform axillary clearence in this subgroup of breast cancer patients. One of the reasons is that previous published studies concerning patients with breast cancer who all underwent a radical mastectomy, have shown that indeed there is a small 
group of patients with IM metastases, without axillary metastases in the ALND specimen ${ }^{4}$. Based on the assumption that the SN accurately reflects the nodal status of the axillary basin, there is no need to perform an axillary lymph node dissection, in case of a negative axillary SN. Moreover, we did not encounter any axillary relapse in our own group of patients with negative axillary SN after a median follow-up of 42 month ${ }^{20}$. We therefore feel that there is no indication to perform an ALND in this subgroup of breast cancer patients.

\section{Therapeutic consequences of IMSN biopsy}

It has been suggested that performing IMSN biopsy has little impact on adjuvant treatment. Indeed, only $3 \%$ of our entire study population proved to have IM metastases. However, when focusing on the group of breast cancer patients with proven IM lymph drainage as visualized on iymphoscintigraphy, the risk of IM metastases is substantial $(22 \%)$. As for today, there is insufficient data to determine a positive effect of parasternal radiotherapy on survival in patients with proven IM metastases. However, axillary adjuvant radiotherapy in highrisk subgroups, such as patients with more than 3 axillary metastases, is beneficial in terms of locoregional contro ${ }^{21}$. As a consequence, parasternal radiotherapy was added to the treatment regime in our patients, in case of tumour-positive IMSNs.

An ongoing randomized controlled trial of the European Organization for Research and Treatment of Cancer (EORTC 22922) is currently evaluating the impact of parasternal and medial supraclavicular irradiation on longterm disease-free and overall survival in breast cancer patients with centrally or medially located tumours. In contrast to studies which showed that the primary tumour site correlated with IM metastases, which was the rationale for the EORTC 22922 trial, our data show that the primary tumour site is not an accurate predictor for IM lymph drainage: lymphoscintigraphy showed IM hotspots originating from laterally located tumours in $37 \%$ of patients and internal mammary metastases were associated with lateral tumours in $42 \%$ of patients. In addition, IMSN biopsy in patients with medially or centrally located tumours showed no metastatic involvement in $80 \%(71 / 89)$ in our series. Thus, within the EORTC 22922 study, patients with lateral tumours and possible IM metastases are incorrectly deprived of additional parasternal radiotherapy, while patients with medial or central tumours receive parasternal radiotherapy without proof of internal mammary metastatic involvement. Since radiotherapy of the $I M$ chain carries potential increased morbidity, the appropriate identification of patients who may benefit from adjuvant radiotherapy is 
essential, and should be based on tumour-positive IMSN biopsy, rather than primary tumour site only.

The impact of IMSN biopsy on altering adjuvant systemic therapy was relatively small in our series. It changed the adjuvant systemic treatment regime in 4 of the 31 IMSN positive patients. Micrometastases in axillary and internal mammary sentinel nodes is no indication for adjuvant chemotherapy according to Dutch National guidelines. Therefore, $3 / 31$ patients with micrometastases in the IMSN did not receive adjuvant chemotherapy. Due to the presence of concommitant axillary metastases in 24 patients, 24/31 patients already would have received adjuvant chemotherapy. But considering the high incidence of breast cancer, this limited improvement in staging and treatment, may have an impact on many patients.

\section{Stage migration}

It might be argued that part of the effect of IM sentinel node staging does not really alter the prognosis, but merely results in stage migration. However, the effect of IMSN biopsy changes the AJCC stage distribution in only 9 Ax-/IMN+ patients, since they would have been classified stage I without the results of IMSN biopsy, but as stage IIA in 5 patients and as stage IIB in 4 patients as a result of IMSN biopsy ${ }^{22}$. Moreover, a large study, representing 8422 patients with a median follow up of 11 years, showed that medially located breast tumours are associated with worse prognosis. This suggests that it may be insufficient to rely on axillary staging alone to guide the selection of adjuvant treatment and that additional staging procedures, such as IMSN biopsy, offer the possibility of a more rational use of adjuvant systemic therapies ${ }^{23}$.

\section{CONCIUSION}

IMSN biopsy is feasible with little additional morbidity and improves nodal staging in breast cancer patients. In case of IM hotspots on lymphoscintigraphy, the risk of these nodes harbouring metastases is substantial $(22 \%)$. With respect to the clinical relevance of IMSN biopsy, adjuvant treatment strategies were changed in all patients with IM melastases, by receiving adjuvant radiotherapy of the IM lymph node basin. Besides adjuvant radiotherapy, adjuvant chemotherapeutic regimes were changed in a small group of patients.

Whether these treatment changes will show an improvement on prognosis in this high-risk subgroup of breast cancer patients remains to be awaited. 


\section{RefERENCES}

1. Krag D, Weaver D, Ashikaga $T$, Moffat F, Klimberg VS, Shriver $C$, et al. The Sentinel Node in Breast Cancer--a Multicenter Validation Study. N Engl I Med 1998; 339:941946.

2. Giuliano $A E$, Jones $R C$, Brennan $M$, Statman R. Sentinel Lymphadenectomy in Breast Cancer. J Clin Oncol 1997; 15:2345-2350.

3. Veronesi U, Paganelli G, Galimberti V, Viale G, Zurrida S, Bedoni $M$, et al. SentinelNode Biopsy to Avoid Axillary Dissection in Breast Cancer With Clinically Negative Lymph-Nodes. Lancel 1997; 349:1864-1867.

4. Veronesi U, Cascinelli N, Bufalino R, Morabito A, Greco M, Galluzzo D, et al. Risk of Internal Mammary Lymph Node Metastases and Its Relevance on Prognosis of Breast Cancer Patients. Ann Surg 1983; 198:681-684.

5. van der Ent FWC, Kengen RAM, van der Pol HAG, Hoolwijk AGM. Sentinel Node Biopsy in 70 Unselected Patients With Breast Cancer: Increased Feasibility by Using $10 \mathrm{MCi}$ Radiocolloid in Combination With a Blue Dye Tracer. Fur J Surg Oncol 1999; 25:24-29.

6. Haagensen $C D$. The natural history of breast carcinoma. Diseases of the breast Philadelphia: Saunders WB, 1986:635-718.

7. Hultborn KA, Larsson LG, Ragnhult I. The Lymph Drainage From the Breast to the Axillary and Parasternal Lymph Nodes, Studied With the Aid of Colloidal AU198. Acta Radiol 1955; 43:52-64.

8. Turner-Warwick RT. The Lymphatics of the Breast. Br I Surg 1959; 46:574-82.

9. Leidenius MH, Krogerus LA, Toivonen TS, Leppanen EA, von Smillen KA. The Clinical Value of Parasternal Sentinel Node Biopsy in Breast Cancer. Ann Surg Oncol 2006; 13(3):321-326.

10. Madsen E, Gobardhan P, Bongers V, Albregts $M$, Burgmans J, De Hooge $P$, et al. The Impact on Post-Surgical Treatment of Sentinel Lymph Node Biopsy of Internal Mammary Lymph Nodes in Patients With Breast Cancer. Ann Surg Oncol 2007; 14(4): $1486-1492$

11. Eslourgie SH, Tanis PJ, Nieweg OE, Valdes Olmos RA, Ruigers El, Kroon BB. Should the Hunt for Internal Mammary Chain Sentinel Nodes Begin? An Evaluation of 150 Breast Cancer Patients. Ann Surg Oncol 2003; 10(8):935-941.

12. Farrus B, Vidal-Sicart S, Velasco M, Zanon G, Fernandez PL, Munoz M, et al. Incidence of Internal Mammary Node Metastases After a Sentinel Lymph Node Technique in Breast Cancer and lis Implication in the Radiotherapy Plan. Int I Radiat Oncol Biol Phys 2004; 60(3):715-721

13. Paredes P, Vidal-Sicart $S$, Zanon $G$, Pahisa I, Fernandez P $L$, Velasco $M$, et al. Clinical Relevance of Sentinel Lymph Nodes in the Internal Mammary Chain in Breast Cancer Patients. Eur I Nucl Med Mol Imaging 2005; 32(11):1283-1287. 
14. Heuts EM, van der Ent FW, van der Pol HA, Debets $I M$, Kengen RA, Verkeyn IM, et al Evaluation of Early Versus Delayed Lymphoscintigraphic Imaging in Detecling Internal Mammary Sentinel Lymph Nodes in Breast Cancer: a Multicenter Study Io Establish an Optimal Lymphatic Mapping Protocol. Nucl Med Commun 2006; 27(8):677-681.

15. van der Ent FW, Kengen RA, van der Pol HA, Povel JA, Stroeken HJ, Hoofwijk AG. Halsted Revisited: Internal Mammary Sentinel Lymph Node Biopsy in Breast Cancer. Ann Surg 2001; 234(1):79-84.

16. Galimberti V, Veronesi $P$, Arnone $P$, De Cicco C, Renne $G$, Intra $M$, Zurrida $S$, et al Stage Migration After Biopsy of Internal Mammary Chain Lymph Nodes in Breast Cancer Patients. Ann Surg Oncol 2002; 9(9):924-928.

17. Caccres E. Incidence of Metastasis in the Internal Mammary Chain in Operable Cancer of the Breast. Surg Cynaecol Obstet 1959; 108:715-720.

18. Lacour I, Le M, Caceres E, Koszarowski T, Veronesi U, Hill C. Radical Mastectomy Versus Radical Mastectomy Plus Internal Mammary Dissection. Ten Year Results of an International Cooperative Trial in Breast Cancer. Cancer 1983; 51:1941-1943.

19. Donegan WL. The Influence of Untreated Internal Mammary Metastases Upon the Course of Mammary Cancer. Cancer 1977; 39:533-538.

20. Heuts EM, van der Ent FW, Hulsewe KW, Heeren PA, Hoofwijk AG. Incidence of Axillary Recurrence in 344 Sentinel Node Negative Breast Cancer Patients After Intermediate Follow-Up. A Prospective Study into the Accuracy of Sentinel Node Biopsy in Breast Cancer Patients. Acta Chir Belg 2007; 107(3):279-283.

21. Clarke M, Collins R, Darby S, Davies C, Elphinstone P, Evans E, et al. Fiffects of Radiotherapy and of Differences in the Extent of Surgery for Early Breast Cancer on Local Recurrence and 15-Year Survival: an Overview of the Randomised Trials. Lancet 2005; 366(9503):2087-2106.

22. Singletary SE, Alired C, Ashley P, Bassett LW, Berry D, Bland Kl, et al. Revision of the American Joint Committee on Cancer Staging System for Breast Cancer. J Clin Oncol 2002; 20(17):3628-3636

23. Colleoni $M$, Zahrieh $D$, Celber RD, Holmberg SB, Mallsson JE, Rudenstam CM, et al. Site of Primary Tumor Has a Prognostic Role in Operable Breast Cancer: the International Breast Cancer Study Group Experience. J Clin Oncol 2005; 23(7):13901400. 
Internal Mammary SN biopsy in 1008 patients 


\section{Chapter 6}

Results of tailored treatment for breast cancer patients with internal mammary lymph node metastases 


\section{SUMMARY}

Although the internal mammary (IM) lymph node status is a major prognostic factor in breast cancer, IM nodal staging is not common practice. In order to improve nodal staging, we have routinely performed IM sentinel node (SN) biopsy and have adjusted adjuvant treatment accordingly. We reviewed the outcome of these patients. Data from 764 patients were available for follow-up. A total of 406 patients had no lymph node metastases (group 1), 330 patients had axillary metastases (group 2), 7 patients had IM metastases only (group 3) and 21 patients had both axillary and IM metastases (group 4). Mean follow-up was 46 months. Prognosis did not appear to be worse for patients with IM metastases compared to those with axillary metastases only, which might indicate that they benefit from improved staging and tailored adjuvant treatment algorithms. However, long-term follow-up data, preferably in larger series, are needed to support our findings. 


\section{INTRODUCTION}

Axillary lymph node status is considered to be one of the most important prognostic factors in breast cancer. However, after long-term follow-up 15-30\% of the patients classified as axillary node-negative will experience a treatment failure!.

Since the introduction of the sentinel node ( $\mathrm{SN}$ ) concept for breast cancer in 1993, this technique has evolved into the preferred method for staging the axilla in patients with breast cancer ${ }^{2,3}$. The $\mathrm{SN}$ technique also visualizes sentinel nodes (SNs) outside the axilla, mainly in the internal mammary (IM) basin. Metastatic involvement of the IM nodes (IMNs) has been demonstrated to be associated with a worse prognosis ${ }^{4,5,6}$. Thus, to obtain complete staging information, the SN technique should also be applied to the IMNs ${ }^{7}$. However, IMNs are not routinely harvested. Although several studies have shown that with IMSN biopsy it is possible to identify and selectively remove IMSNs with minimal morbicity ${ }^{7,8}$, controversy remains regarding its clinical relevance and the expected benefit in relation to potential morbidity. To date, no study has been conducted to determine the usefulness of IMSN biopsy in terms of survival benefit.

We have routinely performed IMSN biopsy since the introduction of the $\mathrm{SN}$ technique, in order to improve staging by identifying higher-risk subgroups with internal mammary nodal metastases. Additional adjuvant chemotherapy as well as locoregional radiotherapy is being adjusled accordingly. The aim of this study is to evaluate treatment outcome of patients with $I M$ lymph node metastases, who received tailored adjuvant treatment regimens.

\section{MATERIALS AND METHODS}

\section{Patients}

From April 1997 to July 2004, after approval of the Local Ethical Committee, and after having obtained informed consent, 794 consecutive patients with clinically node-negative operable primary breast cancer were included in a prospective sludy on SN biopsy. No patients were excluded from SN biopsy, except for those who were pregnant or had a $T_{4}$-tumor. For all patients, demographic data and data with respect to diagnostic procedures, treatment and follow up were gathered. Twenty-five patients with synchronous bilateral breast cancer or a diagnosis of invasive breast cancer before April 1997 and 5 patients with incomplete follow-up were excluded from the current study, thus leaving 764 patients available for the analyses. 
Our technique of sentinel node biopsy has been described in detail elsewhere ${ }^{9}$. The lymphatic mapping procedure consisted of a dual-tracer technique. During surgery in all patients attempts were made to harvest both axillary and nonaxillary SNs, as visualized by lymphoscintigraphy. A postoperative chest X-ray was made routinely following internal mammary node biopsy, to exclude accidental pneumothorax.

Histopathologic examination of the sentinel nodes consisted of routine hematoxylin and eosin (H\&E) staining, followed by serial sectioning and immunohistochemical staining whenever routine $H \& E$ staining did not reveal metastases. Patients with solitary tumour cells in the sentinel node (equal to or smaller than $0.2 \mathrm{~mm}$ ) were considered to be node-negative.

During the study period, patients received adjuvant systemic treatment according to the Dutch national guidelines.

Patients with lumour-positive IMSN biopsy, for whom adjuvant systemic therapy was not already indicated as based on tumor size and/or axillary nodal status, received adjuvant chemotherapy and adjuvant hormonal therapy if ERpositive. Additionally, all patients with IMN metastases received adjuvant radiotherapy to the IM chain. Radiation therapy was administered to the IMNs in the three upper intercostal spaces. The intended dose was $50 \mathrm{~Gy}$, given in 25 fractions over 5 weeks.

All patients were seen for follow-up every 3 months during the first year, every 6 months in the second year following surgery and once a year thereafter. Follow-up consisted of physical examination and a yearly bilateral or contralateral mammography.

\section{Statistical methods}

We studied the following end-points: breast cancer related death, for the analysis of breast cancer specific survival, and any relapse of breast cancer (locoregional recurrence, systemic recurrence) for the analysis of disease-free survival. Survival curves were estimated by the Kaplan-Meier method and compared by the logrank-test. A p-value $<0.05$ was considered statistically significant.

To be able to compare treatment outcome in the various subgroups, patients were divided into 8 subgroups as is illustrated in Figure 1.

Breast cancer-specific survival and disease-free survival according to the nodal status was compared for 4 groups. Group 1 (subgroups II+IV+VIII) consisted of patients, who proved to have no lymph node metastases at all (Ax$1 \mathrm{M}$-), group 2 (subgroups I+III+VII) consisted of patients with axillary metastases only (Ax+IM-), group 3 (subgroup $\mathrm{VI}$ ) consisted of patients with solitary IMN 


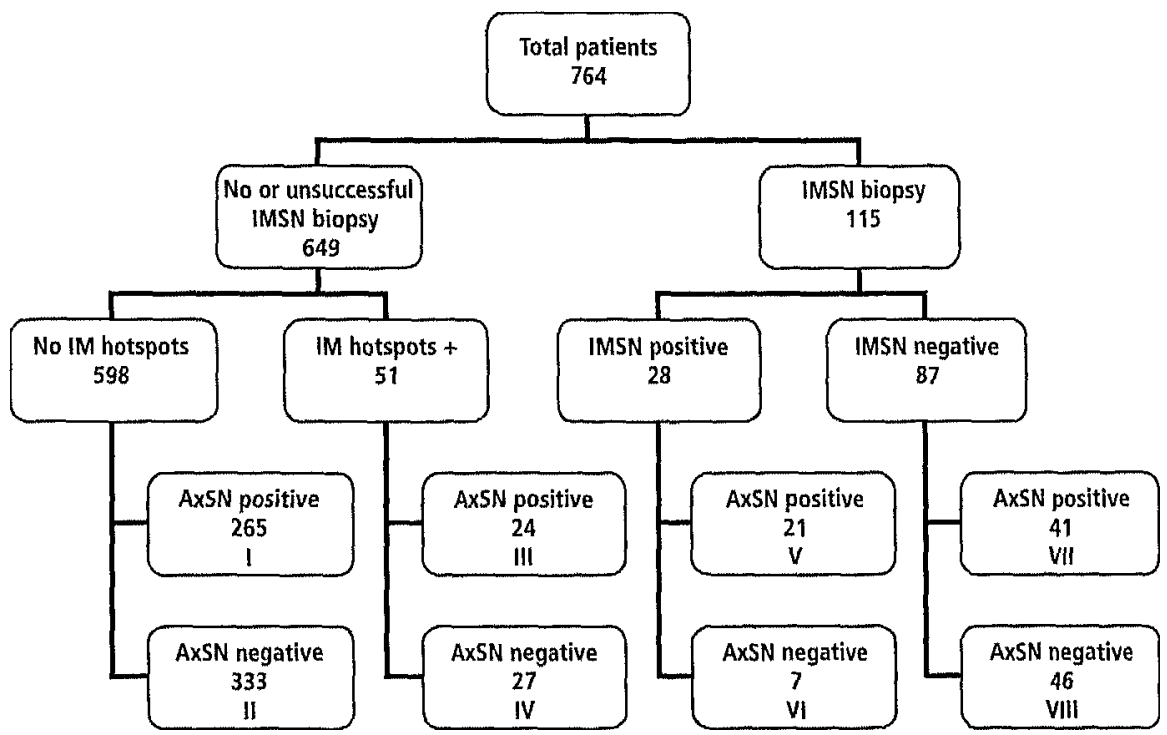

Figure 1 Study population clivided into 8 subgroups according to lymphoscintigraphy and SN biopsy. IMSN=internal Mammary Sentinel node; AxSN=Axillary Sentinel node

metastases $(A x-1 M+)$ and patients in group 4 (subgroup $V$ ) had both axillary and IM metastases $(A x+\mid M+)$. To adjust for potential differences in age, tumor size and tumor characteristics, we performed a multivariable analysis according to the Cox proportional hazards model.

\section{RESULTS}

Of the 764 included in this study, $408(52 \%)$ had a $T_{1}$-tumor, $333(42 \%)$ a $T_{2}$ and $48(6 \%)$ a $T_{3}$-tumor. The preoperative diagnosis was made by fine-needle aspiration or core biopsy in 587 patients $(77 \%)$ and by previous excisional biopsy in 177 patients (23\%).

Lymphoscintigraphy visualized axillary hot spots in 750 patients (98\%). In 166 patients $(22 \%)$ additional hot spots were seen in the internal mammary chain, in $61 \%$ draining from medial or central tumors and in 39\% from lateral tumors. Exclusive drainage to the IMNs was absent in our series. The axillary SN biopsy was successful in $98 \%$ (748/764). The axillary basin was tumor-positive in $46 \%(351 / 764)$ of the patients. Internal manmmary sentinel node biopsy was successful in $69 \%(115 / 166)$ of patients showing parasternal hotspots on the scan and revealed metastatic involvement in $24 \%(28 / 115)$ (Figure 1). Of these, 
$6 \%(7 / 115)$ had a negative axillary $S \mathrm{~N}$ biopsy $(\mathrm{AX}-/ \mathrm{MMN}+)$. In two patients, who were operated during the learning phase of the sentinel node procedure, a completion ALND confirmed this result.

IMN metastases were associated with medial tumors in 14 patients, with lateral tumors in 11 patients and with subareolar tumors in 3 patients.

IM-SN biopsy changed adjuvant systemic treatment in seven IM nodepositive patients $(7 / 28=25 \%)$. Five of these were axillary node-negative. The remaining two patients were axillary node-positive and would initially have had only hormonal therapy, as based on their age over 60 years. Both were given additional chemotherapy, because of proven IM metastases.

In 10 patients $(10 / 166=6 \%$ ) IMSN biopsy resulted in a small pleural lesion. All cases were noted intraoperatively. Initially, this was treated with simple vacuum drainage in 4 patients. The remaining patients received no specific treatment and all patients recovered uneventfully, as was confirmed by chest X-rays.

Median follow-up was 43 months (mean 46 months, range 14-102). For the survival analysis, the total group of 764 patients was divided into four groups, according to the lymph node status. Group 1 consisted of 406 patients, who proved to have no lymph node metastases (Ax-IM-), group 2 consisted of 330 patients with axillary metastases $(A x+(M-)$, group 3 consisted 7 patients with solitary $I M$ metastases (AX-IM+) and patients in group 4, a total number of 21 patients, had both axillary and IM metastases $(A x+I M+)$. The breast cancerspecific survival and disease-free survival rates between group 1 (Ax-IM-) and group $2(A x+I M-)$ differed significantly $(p<0.0001)$, favoring group 1 as can be expected (Table 1 and Figure 2).

Table 1 Five-year breast cancer specific survival (BCSS) and 5-year disease-free survival (DFS), according to nodal status

\begin{tabular}{lccccc} 
& $\mathrm{n}$ & $\begin{array}{c}\text { BCSS (\%) } \\
(\%)\end{array}$ & $(95 \% \mathrm{Cl})$ & $\begin{array}{c}\text { DFS } \\
(\%)\end{array}$ & $(95 \% \mathrm{Cl})$ \\
\hline AX-IM-(group 1) & 406 & 95 & $(92-98)$ & 92 & $(89-95)$ \\
AX+/IM-(group 2) & 330 & 84 & $(79-89)$ & 81 & $(76-86)$ \\
AX-IM-(group 3) & 7 & 82 & $(50-100)$ & 86 & $(60-100)$ \\
AX+IIM+(group 4) & 21 & 89 & $(75-100)$ & 90 & $(77-100)$ \\
\hline
\end{tabular}


No significant differences were observed in breast cancer-specific and diseasefree survival between patients with internal mammary metastases (group 3 and 4) and patients without IM-lymph node metastases (group 2) (Table 1 and Figure 2). The prognostic effect of lymph node status was confirmed by the multivariable analysis (Table 2). Other significant prognostic factors, besides nodal status, were tumor size, histologic grade and estrogen receptor status.

Table 2 Results of multivariable analysis, according to the Cox proportional hazards model, for disease-free survival $(n=693)$

\begin{tabular}{|c|c|c|c|}
\hline Characteristic & $H R$ & $(95 \% \mathrm{Cl})$ & P-value \\
\hline \multicolumn{4}{|c|}{ Age at diagnosis (years) } \\
\hline$<=50$ & 1 (Ref) & & \\
\hline $51-70$ & 0.85 & $(0.52-1.39)$ & 0,522 \\
\hline$>70$ & 0.78 & $(0.42-1.45)$ & 0.427 \\
\hline \multicolumn{4}{|l|}{ Nodal status } \\
\hline$A x+/ / M$ & 1 (Ref) & & \\
\hline$A x-1 M$ & 0.55 & $(0.34 \cdot 0.90)$ & 0.017 \\
\hline$A x+/ / M_{+}$ & 0.61 & $(0.19-1.98)$ & 0.408 \\
\hline$A x-\| M_{+}$ & 1.35 & $(0.18-9.97)$ & 0.771 \\
\hline \multicolumn{4}{|c|}{ Pathological tumor size (mm) } \\
\hline$\leq 20$ & 1 (Ref) & & \\
\hline$>20$ & 3.40 & $(1.92-6.00)$ & $<0,001$ \\
\hline \multicolumn{4}{|c|}{ Estrogen receptor status } \\
\hline Positive & 1 (Ref) & & \\
\hline Negative & 1.67 & $(1.05-2,66)$ & 0.031 \\
\hline \multicolumn{4}{|c|}{ Progesterone receptor status } \\
\hline Positive & 1 (Ref) & & \\
\hline Negative & 1,31 & $(0.75-2.29)$ & 0.348 \\
\hline \multicolumn{4}{|l|}{ Tumor grade } \\
\hline Low & 1 (Ref) & & \\
\hline Intermediate & 3.94 & $(1.19-13.04)$ & 0.025 \\
\hline High & 6.50 & $(2.00-21.16)$ & 0.002 \\
\hline
\end{tabular}




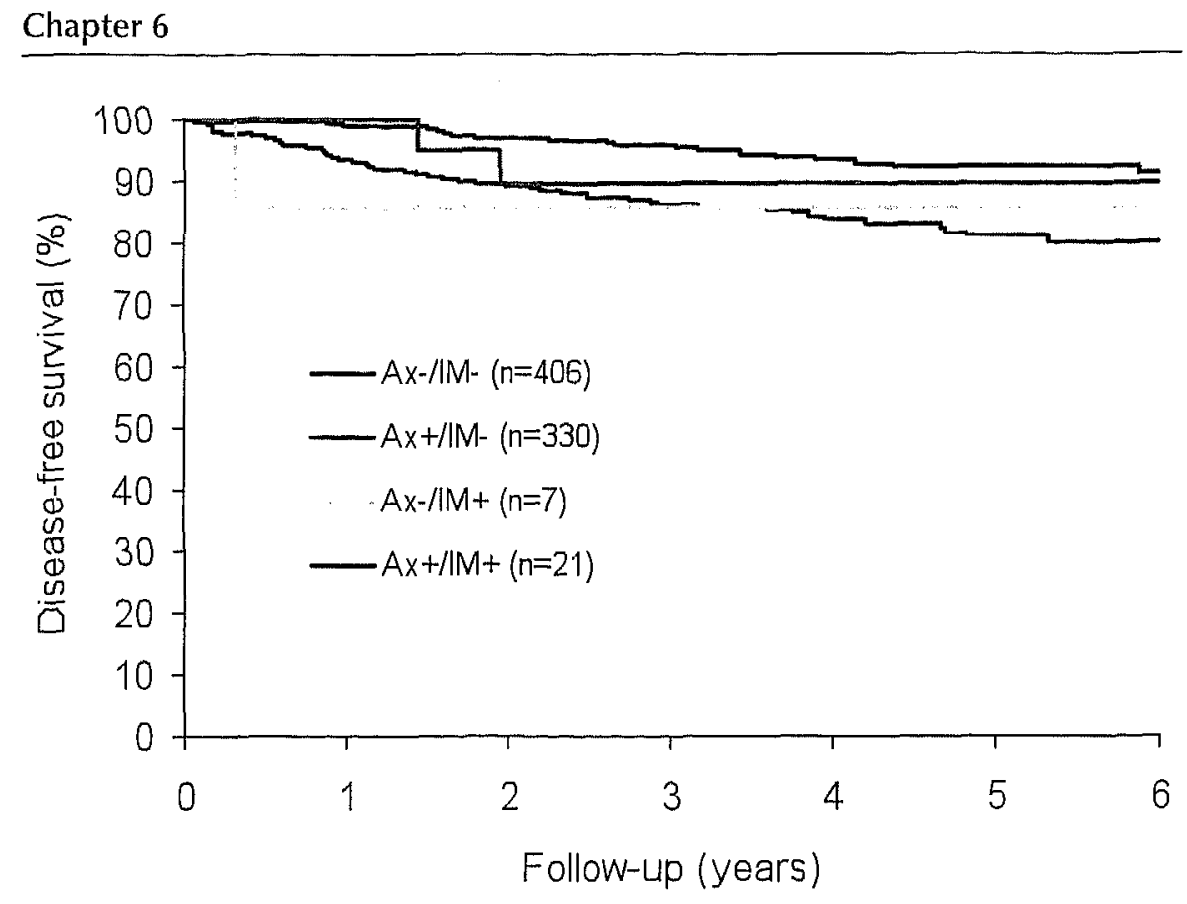

Figure 2 Disease-free survival, according to axillary and internal mammary nodal status. $A x=$ axillary lymph nodes, $I M=$ internal mammary lymph nodes $(+)=$ positive for motastases, $(-)=$ negative for metastases

\section{DISCUSSION}

The importance of the IMNs as a lymphatic drainage pathway from the breast has been confirmed in numerous studies ${ }^{10,11,12,13}$. As a consequence, radica dissection of the internal mammary chain became part of the standard surgical treatment for breast cancer in the 1950s and 1960s. Various studies from that time, concerning this radical surgical treatment, are still the main source of information on the extent of nodal involvement in the internal mammary basin $4,6,14,15,16,17$. The overall prevalence of IMN metastases in these studies varies from 18 to $33 \%$, mostly concomitant with axillary metastases. During the 1970 s internal mammary lymph node dissection was abandoned, based on patient outcome studies, which showed that the procedure did not improve patients' prognosis $5,6,15,16,17$. However, these studies clearly demonstrate that the presence of metastases in the IM chain is associated with a poor prognosis (Table 3). 
Table 3 Overall survival (OS) rates in relation to lymph node status in breast cancer patients.

$n=$ number of patients, $A x=$ axillary lymph nodes, $I M=$ internal mammary lymph nodes, $(t)=$ positive for metastases, $(-)=$ negative for metastases

\begin{tabular}{|c|c|c|c|c|c|c|c|c|c|c|}
\hline \multirow[t]{3}{*}{ Study } & \multirow[t]{3}{*}{ Follow-up } & \multirow[t]{3}{*}{$n$} & \multicolumn{4}{|c|}{$A x-f M-v s . A x-I M+$} & \multicolumn{4}{|c|}{$A x+/ M-v s . A x+/ M+$} \\
\hline & & & \multicolumn{2}{|c|}{$A x-\| M-$} & \multicolumn{2}{|c|}{$A x-\| M+$} & \multicolumn{2}{|c|}{$A x+1 / M$} & \multicolumn{2}{|c|}{$A x+/ M_{+}$} \\
\hline & & & $n$ & 05 & $n$ & OS & $n$ & OS & $\pi$ & OS \\
\hline Càceres, $1967^{14}$ & 5 year & 425 & 175 & $84.6 \%$ & 9 & $55.5 \%$ & 170 & $51.7 \%$ & 71 & $23.9 \%$ \\
\hline \multirow[t]{2}{*}{ Urban, $1971^{18}$} & 5 year & 500 & 228 & $87 \%$ & 36 & $64 \%$ & 124 & $68 \%$ & 112 & $54 \%$ \\
\hline & 10 year & 315 & 144 & $75 \%$ & 23 & $52 \%$ & 73 & $53 \%$ & 75 & $21 \%$ \\
\hline \multirow[t]{2}{*}{ Donegan, $1977^{5}$} & 5 year & 105 & 45 & $67 \%$ & 2 & $0 \%$ & 40 & $35 \%$ & 18 & $28 \%$ \\
\hline & 10 year & 101 & 43 & $40 \%$ & 2 & $0 \%$ & 38 & $21 \%$ & 18 & $6 \%$ \\
\hline Veronesi, $1983^{4}$ & 10 year & 995 & 467 & $82.1 \%$ & 44 & $62.4 \%$ & 346 & $59.6 \%$ & 138 & $37.3 \%$ \\
\hline \multirow[t]{2}{*}{$\overline{\text { Cody }} 1995^{5}$} & 5 year & 195 & 98 & $88.8 \%$ & 22 & $70.2 \%$ & 48 & $86.1 \%$ & 27 & $61.1 \%$ \\
\hline & 10 year & 195 & 98 & $81.3 \%$ & 22 & $58.5 \%$ & 48 & $73.4 \%$ & 27 & $53.0 \%$ \\
\hline Horino, 1991 ${ }^{19}$ & 10 year & 289 & 139 & $92 \%$ & 14 & $67 \%$ & 91 & $67 \%$ & 45 & $40 \%$ \\
\hline Sugg, $2000^{20}$ & 20 year & 286 & 130 & $76 \%^{*}$ & 7 & $28 \% *$ & 84 & $46 \%{ }^{*}$ & 65 & $23 \%{ }^{*}$ \\
\hline
\end{tabular}

* Disease-free survival; $A x=$ axillany lymph nodes, $M=$ internal mammary lymph nodes, $(+)=$ positive for metastases, $(-)=$ negative for metastases 
The wide range of reported survival rates may be attributed to the small sample sizes of some studies and the use of different adjuvant treatment protocols. Survival for patients with metastases exclusive to the $1 \mathrm{M}$ nodes was in most studies comparable to the outcome of patients with solitary axillary metastases, ranging from $50 \%$ to $70 \%$ for $\mathrm{Ax}-\mathrm{IM}+$, compared to $51 \%$ to $86 \%$ for $\mathrm{Ax}+\mathrm{IM}$ - In most studies, the number of patients with both axillary and IM metastases was too small to make comparisons. However, in the largest study, by Veronesi et al., this group has a significantly worse prognosis than the other groups.

In contrast to the studies presented in Table 3, no statistically significan differences in overall survival and disease-free survival were observed in ou study between IM node-negative and IM node-positive patients. Although we are aware that the subgroup of patients with positive IMN's is small and followup still relatively short, this seems to suggest that the tailored adjuvant systemic therapy and additional parasternal radiotherapy has had a beneficial effect on the prognosis of these patients.

The optimal treatment of IM metastases remains controversial. Randomized controlled trials have shown a survival benefit in patients undergoing radiotherapy to the chest wall and locoregional lymph nodes (including the IM chain) after mastectomy $y^{21,22}$. These studies indicate that elimination of locoregional cancer cells by radiotherapy, added to adjuvant chemotherapy, may reduce mortality in selected patients with breast cancer

An ongoing European Randomized controlled trail (EORTC 22922) is currently evaluating the impact of $I M N$ and medial supraclavicular irradiation on longterm disease-free and overall survival in selected breast cancer patients with centrally or medially located tumours.

Although it is true that the primary tumor site correlated with IM metastases, which was the rationale for the EORTC 22922 trial, our data show that tumor site is not a very accurate predictor for IM lymph drainage. In ou study lymphoscintigraphy showed IM hotspots originating from laterally located tumours in $44 \%$ of patients with IM hotspots. These patients may, incorrectly, be deprived of adjuvant radiotherapy. In addition, IMSN biopsy in patients with medially or centrally located tumours showed no metastatic involvement in $76 \%(51 / 67)$ in our series. These specific features of IM lymph drainage, may lower the power of the EORTC trial 22922 to reveal the benefits of IM node irradiation. Since radiotherapy of the IM chain is not without risks, the appropriate identification of patients who may benefit from adjuvant parasternal radiotherapy is essential and should, in our opinion, be based on histological confirmation of nodal involvement, as obtained by IMSN biopsy, and not merely on tumor location or confirmed IM tumour lymph drainage. 
Metastatic involvement of the IM chain is also an indication for adjuvant systemic therapy. However, patients with IM node-positive disease generally already receive adjuvant systemic therapy, based on the concomitant axillary metastases. Therefore alteration in treatment is confined to patients with metastases solely in the IM chain.

Our overall data showed that $\mathrm{IM}$ node status resulted in a change of the adjuvant treatment plans in only $3.4 \%(27 / 789)$ of the patients. One may argue that this proportion is too small to justify the use of IMSN biopsy. However since we found IM-metastases in 16\% (27/169) of patients with visualized lymph drainage to the IM nodes and in 23\% (27/116) of all successful IM-SN biopsies, it can be concluded that the presence of IM drainage patterns on lymphoscintigraphy is associated with a substantial risk of IM-metastases, encouraging removal of these $I M$ sentinel nodes. Thus, optimal nodal staging can be achieved, allowing for tailored treatment strategies, based on individual risk profiles.

\section{CONCLUSION}

Although the presence of IMN metastases indicates advanced locoregional disease, with decreased survival rates, the status of the IM nodes remains unknown in most patients with breast cancer today. IMSN biopsy in breast cancer is technically feasible and improves nodal staging. This technique helps to identify a higher-risk subgroup with $I M$ metastases. Considering the high incidence of breast cancer, by which an improvement in the outcome of treatment, even in limiled subgroups, may result in a substantial contribution to breast cancer therapy, we believe that evaluation of the sentinel nodes in the $I M$ chain should be performed routinely, and proven IM metastases should be treated accordingly. Our results indicate that such a strategy could improve the prognosis of patients with IM metastases. However, long-term follow-up data, preferably in larger series, are needed to support our findings. 


\section{Chapter 6}




\section{REFERENCES}

1. Rosen PP, Groshen S, Saigo PE, Kinne DW, Hellman S. A long-term follow-up study of survival in stage I (TINOMO) and stage II (T1N1MO) breast carcinoma. I Clin Oncol $1989 ; 7: 355-366$.

2. Krag D, Weaver D, Ashikaga T, Moffat F, Klimberg VS, Shriver C, Feldman S, Kusminsky R, Gadd M, Kuhn J, Harlow S, Beitsch P. The sentinel node in breast cancer--a multicenter validation study. N Engl I Med 1998; 339:941-946.

3. Veronesi $U$, Paganelli $G$, Viale $G$, Luini $A$, Zurrida $S$, Galimberti V, Intra $M$, Veronesi $P$, Robertson C, Maisonneuve P, Renne G, De Cicco C, De Lucia F, Gennari R. A randomized comparison of sentinel-node biopsy with routine axillary dissection in breast cancer. N Engl I Med 2003; 349:546-553.

4. Veronesi U, Cascinelli N, Bufalino R, Morabito A, Greco M, Galluzzo D, Delle DV, De Lellis R, Piotti P, Sacchini V. Risk of internal mammary lymph node metastases and its relevance on prognosis of breast cancer patients. Ann Surg 1983; 198:681-684.

5. Donegan WL. The influence of untreated internal mammary metastases upon the course of manmary cancer. Cancer 1977; 39:533-538.

6. Cody HS, Urban JA. Internal mammary node stalus: a major prognosticator in axillary node- negative breast cancer. Ann Surg Oncol 1995; 2:32-37.

7. van der Ent FW, Kengen RA, van der Pol HA, Povel JA, Stroeken HI, Hoofwijk AG. Halsted revisited: internal mammary sentinel lymph node biopsy in breast cancer. Ann Surg 2001; 234:79-84.

8. Estourgie SH, Tanis PI, Nieweg OE, Valdes Olmos RA, Rutgers EJ, Kroon BB. Should the hunt for internal mammary chain sentinel nodes begin? An evaluation of 150 breast cancer palients. Ann Surg Oncol 2003; 10:935-941.

9. van der Ent FWC, Kengen RAM, van der Pol HAG, Hoolwijk AGM. Sentinel node biopsy in 70 unselected patients with breast cancer: increased feasibility by using $10 \mathrm{mCl}$ radiocolloid in combination with a blue dye tracer. Eur J Surg Oncol 1999; 25:24-29.

10. Uren RF, Howman-Giles RB, Thompson JF, Malouf D, Ramsey-Stewart G, Niesche FW, Renwick SB. Mammary lymphoscintigraphy in breast cancer. J Nucl Med 1995; 36:1775-1780.

11. Hulthorn KA, Larsson LG, Ragnhult 1. The lymph drainage from the breast to the axillary and parasternal lymph nodes, studied with the aid of colloidal AU198. Acta Radiol 1955; 43:52-64.

12. Turner-Warwick RT. The lymphatics of the breast. Br I Surg 1959; 46:574-582.

13. Vendrell-Torné E, Setoain-Quinquer J, Doménech-Torné FM. Study of normal mammary lymphatic drainage using radioactive isotopes. I Nucl Med 1972; 13:807-805,

14. Caceres E. Incidence of metastasis in the internal mammary chain in operable cancer of the breast. Surg Ciynaecol Obstet 1959; 108:715-720. 
15. Haagensen $\mathrm{CD}$. The natural history of breast carcinoma. In Diseases of the breast. Philadelphia: Saunders WB; 1986:635-718.

16. Veronesi $U$, Valagussa $P$. Inefficacy of internal mammary nodes dissection in breas cancer surgery. Cancer 1981; 47:170-175.

17. Lacour I, Le M, Caceres E, Koszarowski T, Veronesi U, Hill C. Radical mastectomy versus radical mastectomy plus internal mammary dissection. Ten year results of an international cooperative trial in breast cancer. Cancer 1983; 51:1941-1943.

18. Urban JA, Marjani MA. Significance of internal mammary lymph node metastases in breast cancer. Am I Roentgenol Radium Ther Nucl Med 1971; 111:130-136.

19. Horino T, Fujita $M$, Ueda $N$, Ota J, Ryo $M$, Nakano $Y$, Taguchi T. Efficacy of internal mammary node dissection in the treatment of breast cancer. Ipn J Clin Oncol 1991. 21:422-427.

20. Sugg SL, Ferguson DJ, Posner MC, Heinnann R. Should internal mammary nodes be sampled in the sentinel lymph node era? Ann Surg Oncol 2000; 7:188-192.

21. Overgaard $M$, Hansen PS, Overgaard J, Rose $C$, Andersson $M$, Bach F, Kjaer $M$, Gadeberg CC, Mouridsen HT, Jensen MB, Zedeler K. Postopcrative radiotherapy in high-risk premenopausal women with breast cancer who receive adjuvant chemotherapy. Danish Breast Cancer Cooperative Group 82b Trial. N Engl J Med 1997; 337:949-955.

22. Ragaz J, Jackson SM, Le N, Plenderleith II-I, Spinelli JJ, Basco VE, Wilson KS, Knowling MA, Coppin CM, Paradis $M$, Coldman AJ, Olivotto IA. Adjuvant radiotherapy and chemotherapy in node-positive premenopausal women with breast cancer. $N$ Engl I Med 1997; 337:956-962. 


\section{Chapter 7}

Evaluation of early versus delayed lymphoscintigraphic imaging in detecting internal mammary sentinel lymph nodes in breast cancer

A multicenter study to establish an optimal lymphatic mapping protocol 


\section{AbStract}

\section{Objective}

Metastases in the internal mammary (IM) lymph nodes have an important prognostic value in breast cancer. Lymphatic mapping and sentinel node (SN) biopsy of $I M$ nodes improves staging and permits specific therapeutic strategies, thereby possibly improving final outcome. Therefore, optimal lymphoscintigraphic results are needed. Visualization of IM lymph drainage however is influenced by several factors. We evaluated the effect of different time intervals between radioactive tracer injection and lymphoscintigraphy on visualization of internal mammary sentinel lymph nodes.

\section{Methods}

From February 1997 to August 2001 a total of 682 eligible breast cancer patients underwent sentinel lymph node mapping. The technique involved the injection of $10 \mathrm{mCi}(370 \mathrm{MBq})^{99 \mathrm{~m} T c-n a n o c o l l o i d}$ peritumorally. In 470 patients (group A) the time interval between injection of the radiocolloid and lymphoscintigraphy was 16 hours, compared to 2.5 hours in 212 patients (group B).

\section{Results}

Patient characteristics showed no statistically significant difference between both groups for age and location of the tumour. Axillary hotspots were visualized in $97 \%$ in group $A$ and $96 \%$ in group $B$. Lymphoscintigraphy showed internal mammary hotspots in $21 \%$ in group $A$, compared to $27 \%$ in group $B$. The mean number of $I M$ hotspots per patient was 1.9 in group $A$ and 1.8 in group $B$.

\section{Conclusions}

We found no significant differences between early and delayed lymphoscintigraphic imaging in visualizing internal mammary sentinel lymph nodes. 


\section{INTRODUCTION}

Since the introduction in 1993 of the SN concept, it quickly evolved into a generally accepted and world-wide applied method for staging in breast cancer ${ }^{1}$. Many validation studies confirmed the accuracy of the SN biopsy in predicting the status of the axillary lymph nodes ${ }^{2-6}$. Axillary lymph node dissection is nowadays abandoned in case of negative pathological findings in the axillary $\mathrm{SN}$.

The technique of lymphatic mapping inevitably confronts us with the visualization of non-axillary lymphatic draining patterns, and the question of their clinical relevance. Previous studies showed that the tumour-status of the internal mammary SNs represents a major independent prognostic factor in breast cancer?. Although axillary sentinel nodes are routinely evaluated, IM lymph nodes are not routinely biopsied or included in staging. As for axillary SN biopsy, harvesting of the internal mammary nodes, based on lymphoscintigraphy, will have implications for staging and treatment ${ }^{3}$.

The results of preoperative lymphoscintigraphy therefore should be optimal.

However, the visualization rate of internal mammary nodes on lymphoscintigraphy is influenced by several different factors. In order to establish an optimal IM-imaging protocol within the complex logistics of planning preoperative lymphoscintigraphy and SN surgery, we conducted a study to determine whether different time intervals between injections of a radioactive tracer and performing lymphoscintigraphy affect the visualization rate of internal mammary hotspots.

\section{Methods}

Based on a prospective database, following approval of the local ethics committee and after obtaining informed consent, a cohort study was performed in 682 clinically node-negative T 1-3 breast cancer patients. Afl patients underwent preoperative lymphatic mapping for SN biopsy from February 1997 to August 2001. Data for group A, consisting of 470 consecutive patients, were collected from a single institution. Group $B$ consisted of 223 patients from two other hospitals in the same region. In the latter, insufficient data for analysis were available in 11 patients, resulting in 212 eligible patients in group $B$.

A two day protocol for SN biopsy was administered for both groups. Lymphatic mapping was performed by the same nuclear medicine physicians 
for both groups, preventing bias in individual technical performance. Our technique of SN biopsy has been described in detail elsewhere ${ }^{2}$. The day before surgery, in both groups $10 \mathrm{mCi}(370 \mathrm{MBq})^{99 \mathrm{~m}} \mathrm{TC}$-nanocolloid in $4 \mathrm{ml}$ saline was injected peritumorally in 3-4 depots around the tumour or in the breast parenchyma surrounding the cavity of a previous excisional biopsy. For group A delayed lymphoscintigraphy was performed on the next day, after a mean period of 16 hours (range 16-18 hours) following radiotracer injection, and shortly before surgery. For group $B$ early lymphoscintigraphic images were obtained the same day after a mean period of 2,5 hours (range 2-4 hours) after the injection of the radiocolloid tracer and surgery was performed the next day.

Scintigraphic images in all patients were obtained in three positions: anterior, anterior-oblique and lateral in order to visualize the number of SNs and their axillary and non-axillary position.

Statistical analysis was performed using student $t$ Test for continuous variables and for discrete variables Chi-square analysis was used. $\mathrm{P}$ value < 0.05 was considered statistically significant.

\section{RESULTS}

Lymphatic mapping and SN biopsy was performed in 470 patients in group A and in 212 patients in group B. Patient characteristics are listed in Table 1. Comparing the two groups, no statistical significance was reached for age and location of the tumour. Tumour diameter was also similar, but histology showed more lobular tumours in group $A$ and more ductal carcinomas in group B.

The results of preoperative lymphoscintigraphy with visualization of axillary and internal mammary hotspots in both groups are listed in Table 2. Detection of axillary hotspots on lymphoscintigraphy was almost equal in both groups (97\% in group A and $96 \%$ in group B). The lymphoscintigraphic detection of $\mathrm{IM}$ hotspots was $21 \%(99 / 470)$ after delayed imaging (group $\mathrm{A}$ ) and $27 \%(58 / 212)$ after early imaging (group B). Drainage to the IM lymph nodes originated from laterally located tumours in $41 \%$ (41/99) and in 59\% (58/99) for central or medially located tumours in group A. For group B, IM drainage originated from laterally located tumours in $28 / 58(48 \%)$ patients and from central or medially located tumours in $30 / 58(52 \%)$.

The mean number of $I M$ hotspots per patient was 1.9 in group $A$ and 1.8 in group B.

The differences in the rate of internal mammary visualization did not reach statistical significance ( $P$ value $>0.05$ ) 
The mean age of patients showing IM drainage was 54 years in group $A$ and 56 years in group $B$.

The detection of internal mammary hotspots was influenced by age, as is shown in Table 3. The proportion of patients with internal mammary hotspots decreases with age. This effect was seen in both groups.

Table 1 Patient characteristics of group A and B

\begin{tabular}{lcc} 
& $\begin{array}{c}\text { Delayed imaging } \\
\text { Group A } \\
\text { (N=470) }\end{array}$ & $\begin{array}{c}\text { Early imaging } \\
\text { Group B } \\
\text { (N=212) }\end{array}$ \\
\hline Mean age (years) & 59 (range 28-96) & $58($ range $30-87)$ \\
& SD 12.0 & SD 12.9 \\
\hline Tumour characteristics & & \\
\hline Diameter & & \\
$<20 \mathrm{~mm}$ & $221(47 \%)$ & $115(54 \%)$ \\
$20-49 \mathrm{~mm}$ & $214(46 \%)$ & $90(42 \%)$ \\
$>49 \mathrm{~mm}$ & $35(7 \%)$ & $7(3 \%)$ \\
\hline Ductal carcinoma & $324(69 \%)$ & $177(83 \%)$ \\
\hline Lobular carcinoma & $112(24 \%)$ & $27(13 \%)$ \\
\hline Other & $34(7 \%)$ & $8(4 \%)$ \\
\hline Left & $262(56 \%)$ & $106(50 \%)$ \\
Right & $208(44 \%)$ & $106(50 \%)$ \\
\hline Breast quadrant & & \\
Upper-outer & $216(46 \%)$ & $99(47 \%)$ \\
Upper-inner & $102(22 \%)$ & $41(19 \%)$ \\
Lower-outer & $58(12 \%)$ & $29(14 \%)$ \\
Lower-inner & $55(12 \%)$ & $17(8 \%)$ \\
Central & $36(7 \%)$ & $22(10 \%)$ \\
Unknown & $3(1 \%)$ & $4(2 \%)$ \\
\hline
\end{tabular}


Chapter 7

Table 2 Lymphoscintigraphic visualization of hotspots in group A and B

\begin{tabular}{|c|c|c|c|}
\hline & $\begin{array}{c}\text { Delayed imaging } \\
\text { Group A } \\
(\mathrm{N}=470)\end{array}$ & $\begin{array}{c}\text { Early imaging } \\
\text { Group } B \\
(\mathrm{~N}=212)\end{array}$ & Pvalue \\
\hline Patients with axillary hotspots & $454(97 \%)$ & $203(96 \%)$ & 0.75 \\
\hline Total axillary hotspots & 629 & 369 & \\
\hline \multirow[t]{2}{*}{ Mean axillary hotspots (range) } & $1.4(1-7)$ & $1.7(1-5)$ & \\
\hline & SD 1.0 & SD 1.0 & \\
\hline Patients with additional IM hotspots & $99(21 \%)$ & $58(27 \%)$ & 0.09 \\
\hline Total IM hotspots & 191 & 107 & \\
\hline \multirow[t]{2}{*}{ Mean IM hotspots (range) } & $1.9(1-6)$ & $1.8(1-5)$ & \\
\hline & SD 1.0 & SD 0.9 & \\
\hline Only IM hotspots & 0 & 0 & \\
\hline
\end{tabular}

Table 3 The correlation between age and internal mammary hotspots on lymphoscintigraphy in group $\mathrm{A}$ and $\mathrm{B}$

\begin{tabular}{ccccc} 
& $\begin{array}{c}\text { Delayed imaging } \\
\text { Group A } \\
(\mathrm{N}=470)\end{array}$ & \multicolumn{2}{c}{$\begin{array}{c}\text { Early imaging } \\
\text { Group B } \\
(\mathrm{N}=212)\end{array}$} \\
\hline Age (years) & $\mathrm{N}$ & IM hotspots & $\mathrm{N}$ & IM hotspots \\
\hline$<40$ & 32 & $12(38 \%)$ & 11 & $4(36 \%)$ \\
$41-50$ & 114 & $40(35 \%)$ & 47 & $19(40 \%)$ \\
$51-60$ & 126 & $19(15 \%)$ & 64 & $18(28 \%)$ \\
$61-70$ & 95 & $15(16 \%)$ & 50 & $8(16 \%)$ \\
$>70$ & 103 & $13(13 \%)$ & 40 & $9(23 \%)$ \\
\hline
\end{tabular}

\section{Discussion}

The lymphatic drainage of the breast has been studied intensively. Halsted identified the internal mammary chain as a route of metastases in breast cancer in 1907. Many subsequent studies have confirmed the importance of the internal mammary basin as a second draining route in breast cancer ${ }^{9,10}$. 
As a consequence, internal mammary lymph node dissection was part of the standard surgical treatment in the 1950s and 1960s. Studies concerning this radical surgical treatment are the main source of information on the extent of nodal involvement in the internal mammary basin. Survival rates proved to be worse in case of internal mammary metastases ${ }^{7,11}$.

During the 1970s internal mammary dissection was abandoned, based on patient outcome studies, which showed unfavourable survival rates, but no improvement on prognosis after radical dissection of the internal mammary chain.

Following the introduction of the $\mathrm{SN}$ technique, however, the internal mammary basin has regained interest. In patients with documented internal mammary lymphatic drainage, IM SN biopsy adds to adequate staging by identifying IM node-tumour positive patients. The less favourable prognosis in these patients thus can be influenced by tailoring their individual adjuvant treatment programs ${ }^{8}$, in order to benefit final outcome.

Optimal visualization of both axillary and non-axillary lymph drainage patterns is mandatory to reach accurate lymphatic mapping and staging.

Whether a one day protocol or a two day protocol is used often is a matter of logistic preference, but neither should have a negative effect on the lymphoscintigraphic results.

In a one day protocol, tracer injection, lymphoscintigraphy and SN biopsy are performed on the same day, thereby avoiding the patient's need for an extra hospital visit.

In a two day protocol, tracer injection can be followed by lymphoscintigraphy on the same day or the next day, i.e. the day of surgery. A two clay protocol has advantages both in scheduling multiple patients for lymphoscintigraphic imaging as well as in planning the operating room (OR) schedule, facilitating the planning of multiple SN procedures at the same day. Moreover, a two day protocol has radiation safety advantages, showing a significantly decreased dosage of radioactivity in the resected specimen ${ }^{12}$ and a smaller absorbed radiation dose to the hands of the medical staff due to radioactive decay ${ }^{13,14}$.

Late lymphoscintigraphic imaging on the day of surgery has the advantage of visualizing the SN without the risk of registering confusing temporary radiocolloid accumulations in lymphatic tracts.

It has been suggested that a longer interval between radioisotope injection and scanning results in a greater number of IM SNs on the lymphoscintigraphy ${ }^{15,16}$. While using a two day protocol in both group $A$ and group $B$, 
we analysed the effect of early lymphoscintigraphic imaging (group B) as compared to delayed imaging (group $A$ ) in visualizing internal mammary SNs.

In this study, we found no statistical significant differences between IM SN visualization in group A (21\%) and group B (27\%)

Hence, we could not demonstrate a correlation between timing of the radiotracer injection and the lymphoscintigraphic detection of IM SNs,

However, there is a wide range of reported visualization of internal mammary hotspots in lymphatic mapping for SN biopsy. Published results differ mainly, because the detection rate is influenced by other several technical, anatomical and biological factors.

The most important factor is the site of tracer injection. While aiming for improved accuracy, various injection sites for the radiocolloid are used, such as intracutaneous, subareolar, peritumoral, intratumoral, subtumoral and periareolar injections. Although axillary lymph drainage patterns are independent of the site of tracer injection ${ }^{5,17}$, internal mammary lymph drainage is not. Visualization of the internal mammary nodes is rarely seen following intra- or subcutaneous, subareolar or periareolar tracer injections, as compared to peritumoral, intratumoral or subtumoral tracer injections. This suggests that the breast parenchyma drains to both the axilla and the internal mammary chain, but the skin overlying the breast only has a lymphatic drainage to the axilla.

Shimazu and Paganelli compared superficial and deep parenchymatous injection of a tracer ${ }^{18,19}$. Internal mammary hotspots were more frequently seen after deep tracer injections. This was associated with more internal mammary metastases found for deep located tumours, compared to superficially located tumours.

A second factor that influences the visualization of IM lymphatic drainage is the localisation of the tumour. Anatomical considerations suggest that medially located intraparenchymatous injections will result in an increased rate of internal mammary hotspots. However, the results in the literature are inconsistent. Early anatomic studies by Hultborn (1955) and Turner-Warwick (1959) conclude that both the medial and lateral halves of the breast show similar drainage rates to the internal mammary chain ${ }^{9,10}$. Our own, previously published, results showed internal mammary drainage in $65(25.3 \%$ ) of 256 patients, in $63 \%$ draining medial or central tumours, and in $37 \%$ draining lateral tumours $^{8}$. These results are in accordance with other studies ${ }^{19,20}$, which confirm that tracer administration in the medial or central quadrants of the breast parenchyma is associated with increased rates of internal mammary hotspots. 
However it is possible that these findings have no relationship with tumour location itself, but can be explained by what Krynyckyi ${ }^{21}$ called a proximityeffect. He noted that in small breasts the chances of detecting IM-SNs were much higher, since the lesion and therefore the tracer injection would be much closer to the chest wall and the deeper lymphatic channels that course to the parasternal IM-SNs. This hypothesis is concordant with the effects of deep subtumoral tracer injection as mentioned by Shimazu ${ }^{18}$.

A third factor influencing parasternal hotspot visualization is the particle size of the different tracers. After injection, a colloid tracer is absorbed into the lymphatics and transported through the lymph channels. Smaller particles flow more easily through the lymphatics and are retained in the macrophages of the lymph node for a relative short period, as compared to larger colloids ${ }^{18,22}$ While using radioactive gold (198Au), which has a small particle size, Hultborn described parasternal radioactive uptake in all patients ${ }^{9}$. Using ${ }^{99 m}$ Tc-antimony sulphide, Uren reported parasternal drainage in $35 \%$ of his patients ${ }^{23}$. In

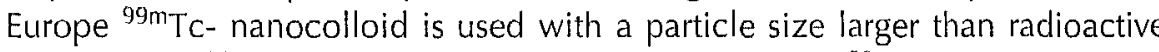
gold and ${ }^{99 m} \mathrm{Tc}$-antimony sulphide colloid. The ${ }^{99 \mathrm{~m}} \mathrm{Tc}$-sulfur colloid, commonly used in the United States, has the largest particle size of the radiocolloid tracers mentioned. Consequently, these differences in particle size contribute in the varying reports regarding lymphoscintigraphic visualization of IM hotspots.

Yet another factor that influences the pattern and speed of lymph drainage is increasing age $e^{24,26}$. It appears that patient age is inversely correlated with the ability to identify axillary SNs. This is related to the induction of fatty degeneration of breast parenchyma in postmenopausal women. The lymphatic capillaries of the breast are confined to the ducto-lobular complexes, in contrast to fatty tissue which contains scarcely any lymphatics.

We evaluated the effect of age on the visualization of internal mammary hotspots. Our results confirmed that, like axillary drainage, internal mammary drainage is affected by increasing age (Table 3 ).

Besides all the above-mentioned issues that influence visualization of parasternal hotspots, it is suggested that the ability to retain radioactivity is different for axillary lymph nodes, as compared to parasternal lymph nodes ${ }^{16}$. Radiocolloid is said to be retained for a shorter time in the internal mammary SN than in the axillary SN. If so, this would suggest that less internal mammary nodes would be seen in group A patients, based on the longer time interval between radioactive tracer injection and lymphoscintigraphy. Indeed, we found less $I M$ hotspots in group $A(21 \%)$ as compared to group $B(27 \%)$, but the difference between both groups was not statistically significant. 
Another variable which could affect IMN visualization is the amount of radioactivity used. However, our results can not distinguish whether increased tracer activity is associated with IMN visualization, since all patients received the same dose of $10 \mathrm{mCi}(370 \mathrm{MBq}){ }^{99 \mathrm{~m}} \mathrm{Tc}$-nanocolloid. Published data of Estourgie et al, using intratumoral injection of $3 \mathrm{mCi} 99 \mathrm{mTC}$-nanocolloid showed IM hotspots in 22\% (150/691), which is comparable to our results ${ }^{27}$.

\section{CONCLUSION}

Internal mammary metastases are increasingly being recognized as having important prognostic significance in breast cancer. Since internal mammary SN biopsy is feasible, and capable of identifying these high-risk IM node-positive patients, factors influencing parasternal hotspot visualization have regained interest.

In search of the optimal logistical and technical protocol for internal mammary lymphatic mapping, we evaluated the effect of different time interval between radioactive tracer injection and lymphoscintigraphy on visualization of internal mammary SNs. We found no statistically significant differences between early and delayed lymphoscintigraphic imaging protocols in this study. 


\section{ReFERENCES}

1. Krag DN, Weaver DL, Alex JC, Fairbank JT. Surgical resection and radiolocalization of the sentinel lymph node in breast cancer using a gamma probe. Surg Oncol 1993; 2:335-339.

2. van der Ent FWC, Kengen RAM, van der Pol HAG, Hoolwijk AGM. Sentinel node biopsy in 70 unselected patients with breast cancer: increased feasibility by using $10 \mathrm{mCi}$ radiocolloid in combination with a blue dye tracer. Eur J Surg Oncol 1999; 25:24-29.

3. Giuliano AE, Kirgan DM, Guenther JM, Morton DL. Lymphatic mapping and sentinel lymphadenectomy for breast cancer. Ann Surg 1994; 220:391-398.

4. Albertini J), Lyman $\mathrm{GH}$, Cox C, Yeatman T, Balducci l., Ku N el al. Lymphatic mapping and sentinel node biopsy in the patient with breast cancer. JAMA 1996; 276:18181822.

5. Borgstein PJ, Meijer S, Pijpers R. Intradermal blue dye 10 identify sentinel lymph-node in breast cancer. Lancet 1997; 349:1668-1669.

6. Tafra L, Lannin DR, Swanson MS, Van Eyk JJ, Verbanac KM, Chua AN et al. Multicenter Trial of Sentinel Node Biopsy for Breast Cancer Using Both Technetium Sulfur Colloid and Isosulfan Blue Dye. Amn Surg 2001; 233:51-59.

7. Veronesi U, Cascinelli N, Bufalino R, Morabito A, Greco M, Galluzzo D et al. Risk of internal mammary lymph node motastases and its relevance on prognosis of breast cancer patients. Ann Surg 1983; 198:681-684.

8. van der Ent FW, Kengen RA, van der Pol HA, Povel $\mid A$, Stroeken HI, Hoofwijk AGi Halsted revisited: internal mammary sentinel lymph node biopsy in breast cancer. Ann Surg 2001; 234:79-84.

9. Hultborn KA, Larsson LG, Ragnhult I. The lymph drainage from the breast to the axillary and parasternal lymph nodes, studied with the aid of colloidal AU198. Acta Radiol. $1955 ; 43: 52-64$

10. Turner-Warwick RT. The lymphatics of the breast. Br I Surg 1959; 46:574-582.

11. Donegan WL. The influence of untreated internal mammary metastases upon the course of mammary cancer. Cancer 1977; 39:533-538.

12. Chok SH, Chow LW, Wong KH, Cheng KC, Ho WY. Breast sentinel lymph node biopsy using radioisotope injection: is one-day botter than Iwo-day protocol? Am Surg 2003; 69:358-361.

13. Nejc D, Wrzesien M, Piekarski, Olszewski I, Pluta P, Kusmierek I et al. Sentinel node biopsy in patients with breast cancer-evaluation of exposure to radiation of nedical staff. Eur J Surg Oncol 2006; 32:133-138.

14. Waddington WA, Keshtgar MR, Taylor I, Lakhani SR, Short MD, Ell P., Radiation safely of the sentinel lymph node technique in breast cancer. Eur I Nucl Med 2000; 27:377391 
Chapter 7

15. Ansari SM, Heiba SI, Mills C, Abdel-Dayem HM. Localization of the breast sentinel node after axillary node dissection with diversion of lymphatic drainage to internal mammary lymph nodes and the importance of delayed imaging. Clin Nucl Med 2001; 26:647-648.

16. Mansel RE, Guyal A, Newcombe RG. Internal mamnary node drainage and its role in sentinel lymph node biopsy: the initial ALMANAC experience. Clin Breast Cancer $2004 ; 5: 279-284$.

17. Zavagno G, Rubello D, Franchini Z, Meggiolaro F, Ballarin A, Casara D et al. Axillary sentinel lymph nodes in breast cancer: a single lymphatic pathway drains the entire mammary gland. Eur J Surg Oncol 2005; 31:479-484.

18. Shimazu $K$, Tamaki $Y$, Taguchi $T$, Motomura $K$, Inaji $H$, Koyama $H$ et al. Lymphoscintigraphic visualization of internal mammary nodes with subtumoral injection of radiocolloid in patients with breast cancer. Ann Surg 2003; 237:390-398.

19. Paganelli G, Galimberti V, Trifiro G, Travaini L, De Cicco C, Mazzarol G et al. Internal mammary node lymphoscintigraphy and biopsy in breast cancer. Q J Nucl Med 2002; 46:138-144.

20. Bevilacqua JL, Gucciardo G, Cody HS, MacDonald KA, Sacchini V, Borgen PI et al. A selection algorithm for internal mammary sentinel lymph node biopsy in breast cancer. Eur J Surg Oncol 2002; 28:603-614.

21. Krynyckyi BR, Chun $H$, Kim HH, Eskandar Y, Kim CK, Machac J. Factors affecting visualization rates of internal mammary sentinel nodes during lymphoscintigraphy. I Nucl Med 2003; 44:1387-1393.

22. Borgstein PJ, Pijpers R, Comans EF, Van Diest PJ, Boom RP, Meijer S. Sentinel lymph node biopsy in breast cancer: guidel ines and pitfalls of lymphoscintigraphy and gamma probe detection. J Am Coll Surg 1998; 186:275-283

23. Uren RF, Howman-Giles RB, Thompson IF, Malouf D, Ramsey-Stewart Ci, Niesche FW et al. Mammary lymphoscintigraphy in breast cancer. J Nucl Med 1995; 36:1775-1780.

24. MCMasters KM, Tuttle TM, Carlson DJ, Brown CM, Noyes RD, Glaser RL et al. Sentinel lymph node biopsy for breast cancer: a suitable alternative to routine axillary dissection in multi-institutional practice when optimal technique is used. I Clin Oncol 2000; 18:2560-2566.

25. Valdes-Olmos RA, Jansen L, Hoefnagel CA, Nieweg OE, Muller SH, Ruigers EJ et al. Evaluation of mammary lymphoscintigraphy by a single intratumoral injection for sentinel node identification. I Nucl Med 2000; 41:1500-1506.

26. Gulec SA, Moffat FL, Carroll RG, Krag DN. Gamma probe guided sentinel node biopsy in breast cancer. Q J Nucl Med 1997; 41:251-261.

27. Estourgie SH, Tanis PJ, Nieweg OE, Valdes Olmos RA, Rutgers EJ, Kroon BB. Should the hunt for internal mammary chain sentinel nodes begin? An evaluation of 1.50 breast cancer patients. Ann Surg Oncol 2003; 10:935-941. 


\section{Chapter 8}

The role of preoperative SPECT/CT for internal mammary sentinel node biopsy in patients with breast cancer 


\section{ABSTRACT}

Introduction

Precise localisation of sentinel nodes (SNs) outside the axilla is a major concern when interpreting lymphoscintigraphy. SPECT/CT is a recent non-invasive technique, providing spatial anatomical information. The purpose of this study was to investigate whether SPECT/CT is beneficial in lymphatic mapping compared to lymphoscintigraphy alone, in patients with internal mammary (IM) hotspots.

\section{Material and methods}

All consecutive patients from 2006 up to 2008 with a cT1-3NO breast carcinoma with $I M$ hotspots on lymphoscintigraphy were prospectively included. Lymphoscintigraphy was followed by SPECT/CT in all patients with IM hotspots. Differences between the lymphoscintigraphy and the SPECT/CT with respect to the number and location of hotspots as well as the surgical and pathological results were analysed.

\section{Results}

Forty-two consecutive patients were included. In 16 patients $(38 \%)$, the SPECT/CT provided no additional information compared to lymphoscintigraphy alone. In 5 patients (12\%) SPECT/CT provided additional information, but without surgical consequences.

In the remaining 21 patients $(50 \%)$ the SPECT/CT results had a substantia impact on the surgical procedure. In 2 patients $(4.8 \%)$, the SPECT/CT showed additional SNs. In 20 patients $(47.6 \%)$ the SPECT/CT results gave substantial reason not to explore the $\mathrm{SN}$ as visualised on the lymphoscintigraphy.

\section{Conclusions}

SPECT/CT has a major impact on surgical decision making compared to lymphoscintigraphy alone in patients with $I M$ hotspots on lymphoscintigraphy. It improves the localisation and increases the number of visualized SNs and more importantly, it reduces the number of non beneficial explorations.

\section{Keywords}

Breast cancer, internal mammary sentinel node biopsy, SPECT/CT, lymphoscintigraphy. 


\section{INTRODUCTION}

Lymphatic mapping and sentinel node (SN) biopsy has become the standard of care for determining disease stage, appropriate therapy, and prognosis in clinically lymph node negative patients with breast cancer ${ }^{1}$. The $5 \mathrm{~N}$ is usually identified using a double tracer technique, combined with preoperative lymphoscintigraphy and a hand-held gamma probe.

The axillary lymph node status is considered the most important prognostic factor in breast cancer. However, in patients classified as axillary node-negative, long-term follow-up shows treatment-failure in $15-30 \%$ of patients. ${ }^{2}$ Previous research has shown that not only the axillary lymph node status but also metastatic involvement of the internal mammary (IM) lymph nodes is an important independent prognostic factor in breast cancer ${ }^{3}$.

Lymphatic mapping visualizes SNs both in and outside the axilla. As for axillary SN biopsy, harvesting of the IM nodes, based on lymphoscintigraphy, will have implications for staging and treatment ${ }^{4-6}$. This procedure is not routinely performed in contemporary surgery, but the prognostic implications of metastatic involvement outside the axilla has led to the conclusion that IM SN biopsy needs to be considered to improve staging. Currently, IM SN biopsy is routinely performed in several institutions.

Precise localisation of hotspots is a major concern when interpreting lymphoscintigraphy. Intra-operative identification of axillary SNs can be achieved in the vast majority of cases. However, with respect to the identification of SNs outside the axilla, the lack of spatial resolution and anatomical detail are a major difficulty. The use of SPECT/CT (Single-Photon Emission Computed Tomography/Computed Tomography) is a recent noninvasive technique that combines the functional information of SPECT with the anatomical information provided by CT and has successfully been used in recent studies. These studies show a higher accuracy of the SPECT/CT in the detection and localization of SNs as compared to conventional lymphoscintigraphy ${ }^{7-11}$. The purpose of this study was to investigate whether SPECT/CT has a significant influence on the surgical decision making, as compared to conventional lymphoscintigraphy alone, in patients with breast cancer with $I M$ hotspots on lymphoscintigraphy. 


\section{MATERIAL AND METHODS}

\section{Patient population}

From January 2006 till January 2008 all consecutive patients with a CT1-3NO breast carcinoma with IM hotspots were prospectively included in a database. Patients with a clinically positive axilla and patients who had received neoadjuvant therapy were excluded.

\section{Imaging and surgical protocol}

Lymphatic mapping and SN biopsy were performed, using a 2-day protocol which has been described previously ${ }^{4}$.

Lymphoscintigraphy was performed 16 to 18 hours (average 16.5 hours) after peritumoral injection of $370 \mathrm{MBq}(10 \mathrm{mCi}) \mathrm{Tc}-99 \mathrm{~m}$ nanocolloid (Nanocoll, Gipharma Srl, Saluggia, Italy) in $4 \mathrm{ml}$ saline $(0.9 \% \mathrm{NaCl}$ ). Lymphoscintigraphic images were obtained in three standard positions: anterior oblique and lateral. Acquisition time was five minutes per view or a minimum of 800 kcounts per image. In case no axilarry hot spot was visualised, an additional tracer injection of $37 \mathrm{MBq}(1 \mathrm{mCi}) \mathrm{Tc}-99 \mathrm{~m}$ nanocolloid was administered intradermally above the tumour. The location of axillary and nonaxillary SNs was marked on the skin. In all patients with hot spots outside the axilla, lymphoscintigraphy was followed by SPECT/CT. SPECT/CT was performed in a supine position with both arms above the head. A non-contrast enhanced low-dose CT of the field of view of the SPECT covering the chest and neck was performed with a slice thickness of 2.5 millimetres. The consecutive SPECT was performed over one field of view (128 x 128 matrix, axial length 512 millimetres) including the chest and neck. The images were obtained in 32 steps $/ 180^{\circ}$ per head, with an acquisition time of 45 seconds per step and reconstructed with filter backprojection Butterworth order 0.35 offset 5 . The $\mathrm{C}$ data were used for attenuation correction and image fusion. The resulting total acquisition time of the SPECT/CT was about 27 minutes. Image analysis of the lymphoscintigraphy and SPECT/CT was performed by two experienced nuclear medicine physicians and five radiologists.

All SN procedures were performed by three experienced surgeons or under their supervision by a senior resident. Shortly before incision, 0.5-0.8 m Patent Blue V (Laboratoire Guerbet, Villepinte, France) was injected intradermally above the tumour. Intra-operative identification of the SNs was based on both blue dye mapping and gamma probe detection (EuroProbe, EuroMedical Instruments, Strasbourg, France). According to local consensus, 
the intended goal was to harvest both axillary and non-axillary SNs, as visualized on lymphoscintigraphy and SPECT/CT. If necessary, additional small incisions were used to harvest non-axillary $5 \mathrm{Ns}$. If the $\mathrm{SN}$ was in an inaccessible position behind the rib, partial ribsesection was not performed, and the $S N$ was left in situ. A postoperative chest $X$-ray was made routinely following IM node biopsy, to exclude pneumothorax, resulting from accidental pleural lesion. In case no axillary hotspot was visualized on the lymphoscintigraphy, the axilla was explored using the blue dye technique.

\section{Analysis}

Patient characteristics and the differences between the lymphoscintigraphy, and the SPECT/CT with respect to the number, and location of the hotspots together with the surgical, and histopathological/immunohistochemical results were recorded prospectively in the database. The concerning specialists were not aware of the current analysis. Data were analysed using descriptive statistics.

\section{REsULTS}

\section{Patient population}

From January 2006 to January 2008 , a total of 42 consecutive patients with a CT1-3NO breast carcinoma with IM hot spots on the lymphoscintigraphy received a SPECT/CT and were prospectively included in the database. The average age was 54.8 years (SD: 10.9 ; range: $30-78$ ).

\section{Imaging and surgical results}

In 13 out of the 42 patients (30.9\%), the SPECT/CT provided no additional information compared to lymphoscintigraphy alone (Figures 1 and 2).

In 5 patients (11.9\%) the SPECT/CT provided a closer determination of the

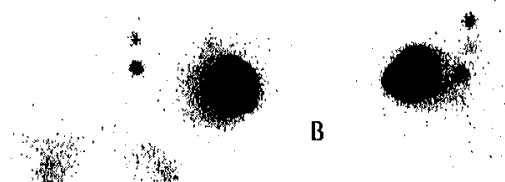

C

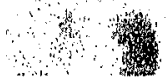

Figure $1 \mathrm{~A}$ : anterior-posterior lymphoscintigraphy showing 1 axillary and 2 internal maminary (IM) hotspots. The lateral view (B) and the oblique view (C), The localion of the most cauclal located (IM) holspot is depicted in figure 2 . 
anatomical location of the hotspot, but this had no consequences for the surgical procedure. In a further 2 patients $(4.8 \%)$ the lymphoscintigraphy turned out to be more accurate than the SPECT/CT. In both cases, the lymphoscintigraphy showed two parasternal hotspots, which on the SPECT/CT appeared to be retrosternal, but revealed to be parasternal nevertheless during surgery. The $\mathrm{SN}$ retrieval in one of the two patients was complicated by a pneumothorax, an indication that a borderline position between retro- and parasternal was probably the case. In 1 patient $(2.4 \%)$ both lymphoscintigraphy and SPECT/CT located the SN retrosternal, but it appeared to be parasternal during surgery.

(1.II
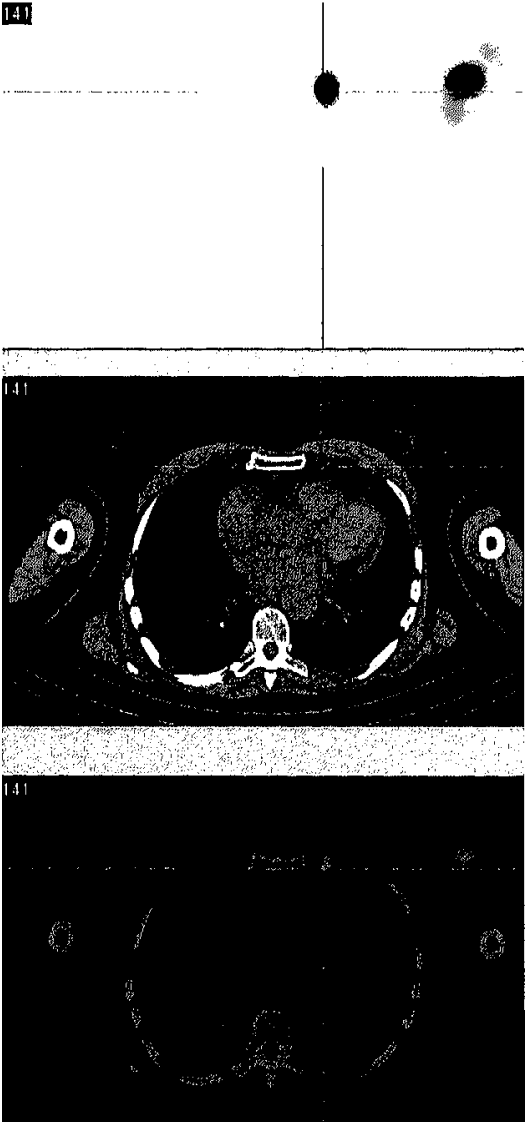

Figure 2 Transaxial SPECT/CT images confirm parasternal location of the internal mammary hotspot.
In the remaining 21 patients $(50 \%)$ the SPECT/CT results had a major impact on the surgical procedure.

In 2 patients (4.8\%), the SPECT/ CT showed additional hot spots. One patient proved to have an additional supraclavicular SN and one patient had an additional axillary hotspot, which was not visualised on the lymphoscintigrap $y$. Bot SNs cou e removed during surgery. Histopathological examination showed no signs of metastasis. Besides the additional hotspots, one of these patients had an IM hotspot on the conventional lymphoscintigraphy, which appeared to be inaccessible on SPECT/CT.

In 20 patients $(47.6 \%)$ the SPECT/ CT results gave substantial reason not to explore the hotspot as visualised on the lymphoscintigraphy. In 13 patients, with a total of $14 \mathrm{IM}$ hotspots on the planar images, due to the finding that one or more IM hotspots on the lymphoscintigraphy could be associad ( 9 hotspots), retrosternal (in 2 hotspots), or retrocostal (in 3 hotspots) position, all with an anatomic substrate on the 


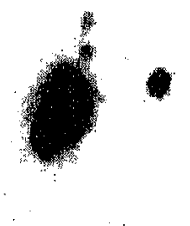

Figure 3 A: anterior-posterior lymphoscintigraphy showing 1 axillary hotspot and 3 internal mammary hotspots. The true location of the IM hotspot in the middle is specified in Figure 4. The lateral position (B) showed one additional axillary holspot, nol visible on the anterior-posterior view. The oblique view $(C)$ showed no additional information.

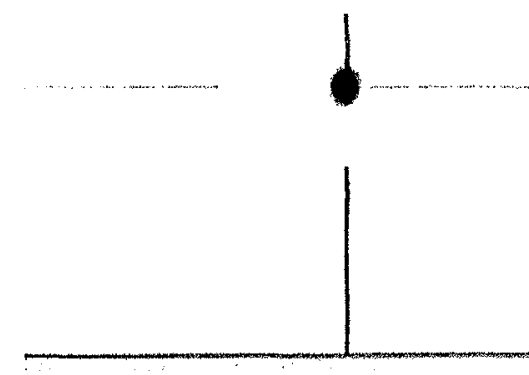

SPECT/CT. An example of this kind of additional information provided by the SPECT/CT is depicted in Figures 3 and 4. in 7 patients the hot spot could not be linked to an anatomic substrate on the SPECT/CT due to non-nodal site of tracer accumulation. These sites of non-nodal

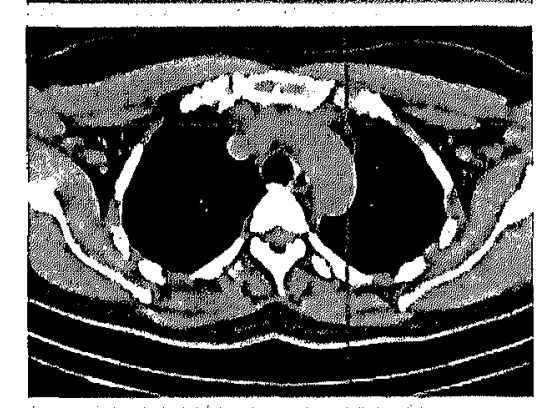
tracer uptake were in the majorit due to contamination of the skin with the radioactive tracer or a lymph tract near the injection site.

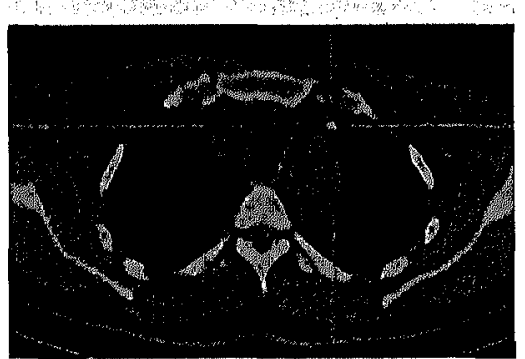

Figure 4 Transaxial SPECT/CT images showing that the location of the holspot in the middle was not parasternal as suggested on the lymphoscinligraphy, but in the mediastinum just anterior to the aortic arch. 


\section{Discussion}

In patients with breast cancer, the IM nodal basin is a relatively common site of metastases. After successful harvesting of IM SNs, 22\% shows metastatic involvement, in about one third without concomitant axillary metastases ${ }^{12}$. The presence of IM metastases represents a poor prognostic factor ${ }^{3}$. Although IM SN biopsy is not performed routinely, it contributes to adequate staging by identifying IM node-tumour positive patients. The less favourable prognosis in these patients thus can be influenced by tailoring their individual adjuvant treatment programs.

The retrieval of IM SNs is often technically more challenging as compared to axillary $\mathrm{SN}$ biopsy and is associated with lower identification rates ${ }^{5}$. Failure in harvesting IM SNs is correlated with their small size, difficult anatomical localization, or limited radioactive tracer uptake ${ }^{4}$. In addition, the visualization rate of internal mammary nodes on lymphoscintigraphy is influenced by several different factors like site of tracer injection, the particle size and amount of the tracer used, the age of the patient and the localisation of the tumour ${ }^{13}$.

Recently, SPECT/CT became available as a diagnostic tool in lymphatic mapping and $\mathrm{SN}$ biopsy. In order to determine its diagnostic value in visualizing and localizing SNs, we analysed our results in the initial 2 years period after introduction of SPECT/CT in our institute. In $50 \%$ of the patients, SPECT/CT resulted in the decision not to explore non-axillary hotspots as visualized on planar lymphoscintigraphic imaging, thereby avoiding surgical explorations that would not benefit the patient.

As such, the additional use of SPECT/CT had a substantial influence on the subsequent surgical procedure. This advantage has not been described in similar research so far.

Surprisingly, the lymphoscintigraphy showed to be more accurate than the SPECT/CT in two cases. In both patients, scanned in the beginning of the study, a parasternal hotspot on the scintigraphic images appeared retrosternal on the SPECT/CT. However, a hand-held gamma-ray detection probe suggested a parasternal location, which was confirmed by surgical exploration. This error of SPECT/CT can be explained by the imaging process. Although the position of the patient does not need to be changed for a SPECT/CT, the timing of the lymphoscintigraphic images and the $C T$ images differs slightly. This can cause possible errors due to respiration and subsequent movement of the thorax. 
The detection of additional SNs is reported as one the advantages of hybrid SPECT/CT in lymphatic mapping in patients with breast cancer $8,11,14,15$. In our patient population this was noted in two patients. The improved visualization rate is not only due to better contrast and resolution of SPECT as compared to conventional lymphoscintigraphy, but also because the CT has the ability to correct the SPECT signal for tissue attenuation. As a result, fused SPECT/CT images can detect hotspots, not visualised by planar lymphoscintigraphy.

Another reported advantage of SPECT/CT is improved anatomical localization of the hotspots ${ }^{8-10}$. Although it is helpful for the surgeon to know the exact location of a hotspot, this will only be beneficial to the patient in case of clinical implications for the surgical procedure. For instance, in one patient the conventional images showed an intramammary $\mathrm{SN}$, which turned out to be an axillary hotspot on SPECT/CT. In another patient, accumulation of radioactivity was seen in the presternal region, which was located parasternal on the SPECT/CT images. This lack of anatomic determination on the conventional images would have been corrected during surgery anyway, once the hand-held gamma probe was used. Therefore, this advantage of SPECT/CT has limited impact on the treatment of breast cancer patients.

Considering the extra costs and time associated with SPECT/CT, we performed SPECT/CT only in case of IM hotspots. Van der Ploeg et al. also performed SPECT/CT selectively in difficult cases, in contrast to the other published studies, in which all consecutive patients were included ${ }^{8,9,11}$.

Another important difference between our study and the available literature lies in the detection of additional axillary sentinel nodes. This can be explained by the technique used for conventional lymphoscintigraphy, since lymphatic mapping is influenced by several different factors like the dosage, volume and particle size of the radiocolloid, the duration of acquisition per view and the time of lymphoscintigraphic imaging post-injection. The reported identification rate for axillary hotspots ranges from $72-94 \%$ in these studies. In a consecutive series of 1008 patients, our visualization rate for axillary hot spots is $98 \%{ }^{12}$. As a consequence, the added value of SPECT/CT to improve the identification rate for axillary SNs is limited in our patients.

\section{ConClusions}

IM SN biopsy contributes to improved staging in breast cancer. The results of lymphatic mapping of axillary and non-axillary SNs, as obtained by lymphoscintigraphy, can be improved by the additional use of SPECT/CT. 
Not only to improve localisation and increase the number of visualized SNs, but foremost, to reduce the number of unnecessary and potentially harmful explorations.

As such, SPECT/CT has a considerable influence on surgical decision making, as compared to lymphoscintigraphy alone, in patients with breast cancer. 


\section{REFERENCES}

1. Mabry $H$, Giuliano AE. Sentinel node mapping for breast cancer: progress to date and prospects for the future. Surg Oncol Clin N Am 2007; 16:55-70.

2. Rosen PP, Groshen S, Saigo PE, Kinne DW, Hellman S. A long-term follow-up study of survival in stage I (T1NOMO) and stage $11(\mathrm{~T} 1 \mathrm{~N} 1 \mathrm{MO})$ breast carcinoma. I Clin Oncol 1989; 7:355-366.

3. Veronesi U, Cascinelli N, Bufalino R, Morabito A, Greco M, Galluzzo D, Delle DV, De Lellis R, Piotti P, Sacchini V. Risk of internal mammary lymph node metastases and its relevance on prognosis of breast cancer patients. Ann Surg 1983; 198:681-684.

4. van der Ent FW, Kengen RA, van der Pol HA, Povel JA, Stroeken HI, Hoofwijk AC. Halsted revisited: internal mammary sentinel lymph node biopsy in breast cancer. Ann Surg 2001; 234:79-84.

5. Estourgie SH, Tanis PJ, Nieweg OE, Valdes Olmos RA, Rutgers EJ, Kroon BB. Should the hunt for internal mammary chain sentinel nodes begin? An evaluation of 150 breast cancer patients. Ann Surg Oncol 2003; 10:935-941.

6. Madsen E, Goharchan P, Bongers V, Albregts M, Burgmans J, De Hooge P, Van Gorp J, van Dalen T. The impact on post-surgical treatment of sentinel lymph node biopsy of internal mammary lymph nodes in patients with breast cancer. Ann Surg Oncol 2007; 14:1486-1492.

7. Maza S, Taupitz M, Taymoorian K, Winzer KJ, Ruckert J, Paschen C, Raber C, Schneider S, Trefzer U, Munz DL. Multimodal fusion imaging ensemble for targeted sentinel lymph node management: initial results of an innovative promising approach for anatomically difficult lymphatic drainage in different tumour entities. Eur I Nucl Med Mol Imaging 2007; 34:378-383.

8. Husarik DB, Steinert HC. Single-photon emission computed tomography/computed tomograplyyfor sentinel node mapping in breast cancer. Semin Nucl Med 2007; 37:29-33.

9. Lerman H, Lievshitz G, Zak O, Metser U, Schneebaum S, Even-Sapir E. Improved sentinel node identification by SPECT/CT in overweight patients with breast cancer, J Nucl Med 2007; 48:201-206.

10. van der Ploeg 1, Valdes Olmos RA, Niewerg OE, Rutgers El, Kroon BB, Hocfnagel CA. The additional value of SPECT/CT in tymphatic mapping in breast cancer and melanoma. I Nucl Med 2007; 48:1756-1760.

11. Lerman H, Metser U, Liovshitz $G$, Sperber F, Shncebaum S, Even-Sapir E. Lymphoscintigraphic sentinel node identification in patients with breast cancer: the role of SPECT-CT. Eur I Nucl Med Mol lmaging 2006; 33:329-337.

12. Heuls EM, van der Enı FW, von Meyenfeldt MF, Voogd AC. Internal mammary lymph drainage and sentinel node biopsy in breast cancer - A study on 1008 patients. Eur I Surg Oncol 2008. 
13. Heuts EM, van der Ent FW, van der Pol HA, Debets IM, Kengen RA, Verkeyn JM, Hulsewe KW, Hoofwijk AG. Evaluation of early versus delayed lymphoscintigraphic imaging in detecting internal mammary sentinel lymph nodes in breast cancer: a multicenter study to establish an optimal lymphatic mapping protocol. Nucl Med Commun 2006; 27:677-681.

14. Valdes Olmos RA, Vidal-Sicart S, Nieweg OE. SPECT-CT and real-time intraoperative imaging: new tools for sentinel node localization and radioguided surgery? Eur I Nucl Med Mol Imaging 2009; 36:1-5.

15. Pecking AP, Wartski M, Cluzan RV, Bellet D, Alberini JL. SPECT-CT fusion imaging radionuclicle lymphoscintigraphy: potential for limb lymphedema assessment and sentinel node cletection in breast cancer. Cancer Treat Res 2007; 135:79-84. 


\section{ChAPTER 9}

General Discussion 


\section{General Discussion}

Sentinel lymph node (SN) biopsy has gained widespread acceptance as the preferred method to stage the axilla in breast cancer patients, although several questions have remained unanswered. With regard to the value of the internal mammary sentinel node biopsy there is much less consensus while even more technical issues have remained unresolved.

This thesis has focused on aspects of both axillary and internal mammary $\mathrm{SN}$ biopsy to answer some of the most important questions.

The studies presented in this dissertation are based on a detailed, singlehospital patient registry. Though not level one evidence, research with such databases can provide important information on new diagnostic and therapeutic procedures, long before results from randomized controlled trials (RCT's) will be able to provide definitive answers.

\section{Axillary sentinel node biopsy}

The technique of SN biopsy is not yet standardised. Several studies have shown that performing a preoperative lymphoscintigraphy in combination with the intra operative use of a gamma detection probe and blue dye will achieve the highest identification rates. However, the success rate of the SN procedure is influenced by several other factors and there is still a search for new techniques to optimize the results. Additional tracer injection following initial scan failure (chapter 2) is a simple and effective way to improve the success rate of lymphoscintigraphy, without compromising its accuracy. Besides the study described in this thesis, there is only one other study available which mentions the use of additional tracer injection in case of non visualization of hotspots'. This study, by Cserni and colleagues, was conducted to compare two SN techniques, the blue dye guided lymphatic mapping method and a combination of the blue dye with a radiocolloid tracer. In case the lymphoscintigraghy did not show axillary hotspots after peritumoural injection of $50-60 \mathrm{MBq}$ within 23 hours post injection, a second, lower dose (15-20 MBq) was given subareolarly. The additional tracer was administered in a limited number of 20 patients. It is reasonable to assume that the lymphatic mapping technique used in our patients is superior; the amount of radioactivity of the initial tracer injection was higher $(370 \mathrm{MBq})$ and the timing of lymphoscintigraphy post injection was longer in our lymphatic mapping protocol (12-16 hours). This could explain the improved visualization rate of $98 \%$, as compared to $72 \%$ $(52 / 72)$ in the referred study. However, if lymphatic mapping fails while using our protocol, other factors causing impaired lymphatic drainage seem to be 
responsible, e.g. an increased BMI or advanced age. This can partly be resolved by additional tracer injection, without compromising the accuracy of the $\mathrm{SN}$ procedure. Recently, SPECT/CT came available as a new technique. Both SPECT/CT and an additional tracer injection may be applied in case of initia scan failure in order to identify a SN, thus preventing an unsuccessful SN procedure. However, considering the costs and time associated with SPECT/CT, we advocate the use of additional tracer injection as the preferred method for patients with absent visualisation of axillary hotspots.

Another unresolved issue is the suitability of SN biopsy for certain subgroups of breast cancer patients. Conflicting results have been published for SN biopsy after previous excisional biopsy. Our results have shown that SN biopsy is reliable for these patients (chapter 3), with no false negative result in 87 procedures, confirmed by completion axillary lymph node dissection. At the time these results were published, the eligibility of this subgroup of patients for lymphatic mapping was debated arguing that the lymphatic drainage could be altered with rerouting of the lymphatic flow towards a false "SN"2. This view could be substantiated in a study among 25 patients, showing lymphoscintigraphic images obtained before and after excision biopsy. In 17 of 25 patients a discrepancy in the drainage pattern after surgery was found. The authors therefore questioned the accuracy of SNB after excision biopsy and suggested that investigators performing SN biopsies in this specific group of patients should have long term follow-up data to record definitive axillary recurrence rates as the ultimate proof of accuracy. However, the gold standard for validation of the axillary SN procedure in breast cancer worldwide has been completion axillary lymph node dissection. Accordingly, validation of the SN procedure in this subgroup of patients should also be obtained by performing ALND, as described in chapter 3 of this thesis. One can speculate that the rerouting of lymphatic drainage after a diagnostic lumpectomy ultimately leads to the same. $\mathrm{SN}$, as our results seem to indicate.

In contrast, more recent results from the NSABP B-32 randomised phase III trial, found a false negative rate of $15.3 \%$ in 177 patients with previous incisional or excisional biopsy, compared to a false negative percentage of $8.1 \%(48 / 589)$ in patients with a diagnostic core biopsy ${ }^{3}$. In this study, as well as in our study, a completion axillary lymph node dissection was performed in all patients to determine the accuracy of the SN procedure in this subgroup. However, there are two important differences between the two studies. One is the amount of radioactivity used. We applied $370 \mathrm{mBq}(10 \mathrm{mCi})$ compared to $37 \mathrm{mBq}(1 \mathrm{mCi})$ in the participants of the NSABP B-32 trial. The second, 
probably most important difference is the fact that a preoperative lymphoscintigraphy was not mandatory in this trial. As a result, the true number of SNs may be missed and consequently the "true" SN might not have been identified. These differences in technical aspects may explain the unacceptably high false negative percentage in the NSABP B-32 trial. Based on our observations it is reasonable to conclude that a $\mathrm{SN}$ procedure can safely be performed in the subgroup of patients with a previous excisional biopsy, so that these patients will not be deprived of the advantages of the SN procedure. Special attention should be given to performing preoperative lymphoscintigraphies and to the amount of tracer injected. First and foremost, however, one should aim to establish a histopathologic diagnosis preoperatively using less invasive diagnostic techniques thus avoiding diagnostic surgical breast biopsies

It is generally accepted that an axillary clearance may be omitted in case of a negative SN procedure. However, in a limited percentage of cases SN biopsy fails to identify existing axillary metastases. This may in turn result in axillary recurrences and distant metastases. With long term follow-up results

Table 1 Axilllary recurrence after negative SN biopsy without ALND

\begin{tabular}{lcccc} 
Author & Year & $\begin{array}{c}\text { No. of } \\
\text { Patients }\end{array}$ & $\begin{array}{c}\text { Median follow-up } \\
\text { (months) }\end{array}$ & $\begin{array}{c}\text { Axillary } \\
\text { recurrences }\end{array}$ \\
\hline Blanchard & 2003 & 685 & 29 & $1(0.1 \%)$ \\
Jeruss $^{5}$ & 2005 & 592 & 27 & $1(0.2 \%)$ \\
Smidt $^{5}$ & 2004 & 439 & 26 & $2(0.5 \%)$ \\
Naik' $^{7}$ & 2004 & 2340 & 31 & $3(0.13 \%)$ \\
Veronesi $^{8}$ & 2005 & 953 & 38 & $3(0.3 \%)$ \\
Zavagno $^{9}$ & 2005 & 479 & 36 & 0 \\
Swenson $^{10}$ & 2005 & 612 & 33 & $3(0.5 \%)$ \\
Palesty $^{11}$ & 2006 & 335 & 33 & $2(0.6 \%)$ \\
Heuts $^{12}$ & 2007 & 344 & 43 & $3(0.9 \%)$ \\
Takei $^{13}$ & 2007 & 822 & 36 & $4(0.5 \%)$ \\
Berkvist $^{14}$ & 2008 & 2246 & 37 & $27(1.2 \%)$ \\
Van der Ploeg $^{15}$ & 2008 & 748 & 46 & $2(0.25 \%)$ \\
Van Wely $^{16}$ & 2008 & 392 & 65 & $11(2.8 \%)$ \\
Poletti $^{17}$ & 2008 & 804 & 39 & $7(0.87 \%)$ \\
Veronesi $^{18}$ & 2009 & 3548 & 48 & $31(0.87 \%)$ \\
\hline
\end{tabular}


now becoming available a comparison of the prevalence of axillary recurrences in our study cohort with data from other studies is feasible (chapter 4). More recent literature coniirms our conclusions that the rate of axillary recurrence in patients with a negative $S \mathrm{~N}$ biopsy is low and better than expected. An update of the axillarv recurrences rate after negative $\mathrm{SN}$ biopsy in studies with more than 300 patients is presented in Table 1.

These numbers imply that an axillary lymph node dissection can safely be omitted in case of a tumour negative $\mathrm{SN}$ biopsy.

Internal mammary sentinel node biopsy

The presence of a lymphatic drainage pathway of the breast to the internal mammary nodes, as well as the frequency and prognostic importance of tumour involvement in this lvmphatic basin has been contirmed by numerous studies ${ }^{(1) 21}$. As a consequence, internal mammary lymph node dissection was part of the standard surgical treatment in the 1950s and 1960s. Randomized trials indeed showed unfavourable survival rates for patients with IM metastases, but no improvement of the prognosis after radical dissection of the internal mammary chain. As a consequence, internal mammary dissection was abandoned in the 1970 s.

Following the introduction of the SN technique, the internal mammary basin has regained interest. IMSN biopsy is jeasible and it adds to the adequate staging by identifying IM node tumour-positive patients (chapter 5). The obvious question is whether identification of IMSNs, biopsy of those nodes, the subsequent upstaging, and the change in management will translate into improved survival. We tried to answer this difficult question in chapter ${ }^{6}$. Of the 764 patients studied, only 28 had tumour-positive $I M$ nodes and of them 7 had tumour-negative axillary nodes. Although we were able to demonstrate a tendency to improved survival following adjusted treatment regimens in patients with proven $\mathrm{IM}$ metastases, these numbers were too small to draw definite conclusions about any survival gain by tailored treatment of this group. Much larger series and longer follow-up will be needed to give a final answer to this question. It is questionable whether these studies will ever be achievable, considering the small number of patients with IM metastases and an even smaller part with solitary $I M$ metastases. Meanwhile, the fact that multiple studies have consistently found that medial breast cancers carry a worse prognosis compared to lateral cancers, even after adjusting for other known prognostic factors, seems to indicate some deficiency in staging and subsequent undertreatment. We therefore believe, that IMSN biopsy can 
improve nodal staging by identifying higher- risk patients with IM metastases, who may benefit from adjuvant therapy, which in turn may lead to survival benefit ${ }^{21-23}$. This individualised, tailored adjuvant therapy of patients with $I M$ metastases is in perfect harmony with the current trend of more personalized patient treatment. Performing an IMSN biopsy is dependent on the visualization of $\mathrm{IM}$ hotspots on the preoperative lymphoscintigraphic images. The incidence of IM drainage varies and is affected by several factors. Site of tracer injection particle size and amount of tracer used, age of the patient and localisation of the tumour are all examples of these independent factors. However, increasing the time interval between injection of the radioactive tracer and lymphoscintigraphy does not affect the visualization rate of internal mammary hotspots (chapter 7).

The retrieval of IM SNs is often technically challenging as compared to axillary SN biopsy and is associated with lower identification rates. Failure to harvest IM SNs is correlated with their small size, difficult anatomical localization, or limited radioactive tracer uptake. SPECT/CT (Single-Photon Emission Computed Tomography/Computed Tomography) is currently available to improve the visualization of hotspots and determine their exact anatomical location. The number of reports on the use of SPECT/CT in lymphatic mapping for breast cancer is limited. The reported advantages are the determination of the exact anatomical location of the SNs and the detection of additional SNs. However, the results of our study indicate that the most important advantage of additional SPECT/CT for patients with IM hotspots is the reduction of the number of unsuccessful explorations, because of an unaccessible localization of the IMSN (chapter 8).

\section{Future perspectives}

Whether axillary clearance is of any benefit for node-positive patients in terms of survival is not known yet. The development and more widespread use of chemotherapy, hormonal therapy and monocolonal antibodies have not only reduced the mortality from breast cancer, but also the risk of local recurrence. The role of ALND in node positive patients to achieve these goals is the subject of the American College of Surgeons Oncology Group (ACOSOG) Z0011 trial $^{24}$. This ongoing trial is randomising SN-positive patients between ALND and observation of the axilla.

Other interesting questions that are currently being investigated include besides the suitability of SN biopsy for patients with previous excisional biopsy, which was addressed in this thesis, other questionable exclusion criteria for SN 
biopsy like multicentric or recurrent breast cancer and preoperative radiotherapy to the breast. The accuracy of the $\mathrm{SN}$ procedure in case of recurrent breast cancer is being studied in the SNARB study (Sentinel Node And Recurrent Breast cancer). As a part of this Dutch study, SN biopsy following previous breast radioherapy will be investigated.

Another point of debate is the clinical relevance of micro metastases $(0.2$ $\mathrm{mm}-2.0 \mathrm{~mm})$ and isolated tumour cells $(<0.2 \mathrm{~mm})$ in the $\mathrm{SN}$, since more and smaller metastases are encountered with the use of step-sectioning and immunohistochemical staining. Before the introduction of the SN procedure, these metastases remained undetected. It remains unclear whether these few malignant cells have the potential to grow into palpable nodes and whether they can be the source of distant metastases. The MIRROR study is currently evaluating the impact of adjuvant therapy on disease-free survival for patients with micrometastases and isolated tumour cells. The first results of this study imply that breast cancer patients with isolated tumour cells (ITC) or micro metastases as final $\mathrm{N}$-stage after a $\mathrm{SN}$ biopsy have a worse 5 -year disease free survival as compared to patients having no ITCs or micro metastases, independent of primary tumour characteristics ${ }^{25}$

A new promising development in breast cancer management is the introduction of gene expression profiling using microarray hybridization. The genomic information may be able to refine prognosis, and to improve therapeutic strategies for breast cancer patients ${ }^{26,27}$. For now, whether microarray gene-expression profiling for breast-cancer prognosis is better than our current prognostic markers, including those determined by SN biopsy, remains an open question. Further studies are necessary to develop and improve this new technique.

In the near future new MRI (Magnetic Resonance Imaging) techniques might be able to detect and localise $\mathrm{SNs}^{28}$. Future investigators might produce a contrast agent to determine the metastatic nature of a lymph node in breast cancer patients on MRI images, as is currently evaluated for othe malignancies ${ }^{29,30}$. However, the detection of micrometastases and isolated tumour cells with imaging-techniques seems to be far fetched for now. As a consequence SN biopsy will probably remain an essential part of breast cancer staging. 


\section{CONCLUDING REMARKS}

Sentinel node biopsy has played a significant role in the evolution of breast cancer treatment in the past decade. It has replaced ALND in case of a tumour negative SN biopsy, as the preferred method to stage the axilla, thereby avoiding unnecessary morbidity associated with ALND. The SN procedure is a perfect example of the current trend for more minimally invasive diagnostic and therapeutic procedures. The future will teach us if the prognostic role of SN biopsy will gradually be replaced by a combination of primary tumour characteristics and non-invasive imaging of the axilla. 


\section{REFERENCES}

1. Cserni $G$, Rajtar $M$, Boross $G$, Sinko $M$, Svebis $M$, Baltas B. Comparison of vital dyeguided lymphatic mapping and dye plus gamma probe-guided sentinel node biopsy in breast cancer. World I Surg 2002; 26:592-597.

2. Estourgic $\mathrm{SH}$, Valdes Olmos RA, Nieweg OE, Hoefnagel CA, Rutgers EJ, Kroon BB. Excision biopsy of breast lesions changes the pattern of lymphatic drainage. $\mathrm{Br}$ I Surg 2007; 94:1088-1091.

3. Krag DN, Anderson SJ, Julian TB, Brown AM, Harlow SP, Ashikaga T, et al. Technical outcomes of sentinel-lymph-node resection and conventional axillary-lymph-node dissection in patients with clinically node-negative breast cancer: results from the NSABP B-32 randomised phase III trial. Lancet Oncol 2007; 8:881-888.

4. Blanchard DK, Donohue JH, Reynolds C, Grant CS. Relapse and morbidity in patients undergoing sentinel lymph node biopsy alone or with axillary dissection for breast cancer. Arch Surg 2003; 138:482-487.

5. Jeruss IS, Winchester DI, Sener SF, Brinkmann EM, Bilimoria MM, Barrera E Jr, et al Axillary recurrence after sentinel node biopsy. Ann Surg Oncol 2005; 12:34-40.

6. Smidı ML, Janssen CM, Kuster DM, Bruggink ED, Strobbe LJ. Axillary recurrence after a negative senlinel node biopsy for breast cancer: incidence and clinical significance. Aon Surg Oncol 2005; 12:29-33.

7. Naik AM, Fey I, Gemignani M, Heerdt A, Montgomery L, Petrek 1, ot al. The risk of axillary relapse after sentinel lymph node biopsy for breast cancer is comparable wilh that of axillary lymph node dissection: a follow-up study of 4008 procedures. Ann Surg 2004; $240: 462-468$.

8. Veronesi U, Galinberti V, Mariani L, Gatti G, Paganelli $G$, Viale G, et al, Sentinel node biopsy in breast cancer: early results in 95.3 patients with negative sentinel node biopsy and no axillary dissection. Eur I Cancer 2005; 41:231-237.

9. Zavagno G, Carcoforo P, Franchini Z, Renier M, Barutta L., De Salvo GL, et al. Axillary recurrence aiter negative sentinel lymph node biopsy without axillary dissection: a study on 479 breast cancer palients. Fur I Surg Oncol 2005; 31:715-720.

10. Swenson KK, Mahipal A, Nissen MI, Tuttle TM, Heaton K, Lally RM, et al. Axillary disease recurrence after sentinel lymph node dissection for breast carcinoma. Cance 2005; 104:1834-1839.

11. Palesty JA, Foster IM, Hurd TC, Watroba N, Rezaishiraz. H, Edige SB. Axillary recurrence in women with a negative sentinel lymph node and no axillary dissection in breast cancer. J Surg Oncol 2006; 93:129-132. 
12. Heuts EM, van der Ent FW, Hulsewe KW, Heeren PA, Houfwijk AG. Incidence of axillary recurrence in 344 sentinel node negative breast cancer patients after intermediate follow-up. A prospective study into the accuracy of sentinel node biopsy in breast cancer patients. Acta Chir Belg 2007; 107:279-283.

13. Takei H, Suemasu K, Kurosumi M, Horii Y, Yoshida T, Ninomiya J, et al. Recurrence after sentinel lymph node biopsy with ur without axillary lymph node dissection in palients with breast cancer. Breast Cancer 2007; 14:16-24.

14. Bergkvist L, de Boniface J, Jonsson PE, Ingvar C, Liljegren G, Frisell 1. Axillary recurrence rate after negative sentinel node biopsy in breast cancer: three-year followup of the Swedish Multicenter Cohort Study. Ann Surg 2008; 247:150-156.

15. van $\mathrm{dP}, 1$, Kroon BB, Antonini N, Valdes Olmos RA, Rutgers El, Nieweg OE. Axillary and extra-axillary lymph node recurrences after a tumor-negative sentinel node biopsy for breast cancer using intralesional tracer administration. Ann Surg Oncol 2008; 15:10251031.

16. van Wely BJ, Smidt ML, de Kievit IM, Wauters CA, Strobbe LJ. False-negative sentinel lymph node biopsy. $\mathrm{Br}$ I Surg 2008; 95:1352-1355.

17. Poletti P, Fenaroli P, Milesi A, Paludetti A, Mangiarotti S, Virotta G, et al. Axillary recurrence in sentinel lymph node-negative breast cancer patients. Ann Oncol 2008; 19:1842-1846

18. Veronesi U, Galimberti V, Paganelli G, Maisonneuve P, Viale G, Orecchia R, et al. Axillary metastases in breast cancer patients with negative sentinel nodes: A follow-up of 3548 cases. Eur J Cancer 2009.

19. Veronesi U, Cascinelli N, Bufalino R, Morabito A, Greco M, Galluzzo D, et al. Risk of internal manmary lymph node metastases and its relevance on prognosis of breasl cancer patients. Ann Surg 1983; 198:681-684.

20. Donegan WL. The influence of untreated internal mammary metastases upon the course of mammary cancer. Cancer 1977; 39:533-538.

21. Lohrisch C, Jackson J, Jones A, Males D, Olivotto IA. Relationship between tumor location and relapse in 6,781 women with early invasive breast cancer. I Clin Oncol 2000; 18:2828-2835.

22. Colleoni M, Zahrieh D, Gelber RD, Holmberg SB, Mattsson JE, Rudenstam CM, et al. Site of primary tumor has a prognostic role in operable breasl cancer: the international breast cancer sludy group experience. J Clin Oncol 2005; 23:1390-1400.

23. Zucali R, Mariani L, Marubini E, Kenda R, Lozza L, Rilke F, Veronesi U. Early breast cancer: evaluation of the prognostic role of the site of the primary tumor. I Clin Oncol 1998; 16:1363-1366.

24. Grube B), Giuliano AE. Observation of the breast cancer paticnt with a tumor-positive sentinel node: implications of the ACOSOG Z0011 trial. Semin Surg Oncol 2001; 20:230-237. 
25. de Boer $M$, van Deurzen $C H$, van Dijck JA, Borm CF, van Diest PJ, Adang EM, Nortier HW, et al. Micrometastases and isolated tumor cells: relevant and robust or rubbish? (MIRROR): preliminary results of the MIRROR study from the Dulch breast cancer trialists' group (BOOG). Abstractbook SABCS 2008. 70s. Alsstracl 23

26. Acharya CR, Hsu DS, Anders CK, Anguiano A, Salter KH, Walters KS, et al. Gene expression signatures, clinicopathological features, and individualized therapy in breast cancer. JAMA 2008; 299:1574-1587.

27. Bueno-de-Mesquita $I M$, van Harten WH, Retel VP, van't Veer L., van Dam FS, Karsenberg K, et al. Use of 70-gene signature to predict prognosis of patients with node-negative breast cancer: a prospective community-based feasibility study (RASTER). Lancel Oncol 2007; 8:1079-1087.

28. Melancon MP, Wang Y, Wen X, Bankson JA, Stephens I.C, Jasser S, et al. Developmen of a macromolecular dual-modality MR-optical imaging for sentinel lymph node mapping. Invest Radiol 2007; 42:569-578.

29. Heesakkers RA, Hovels AM, Jager GJ, van den Busch HC, Witjes IA, Raat HP, cl al. MRI with a lymph-node-specific contrast agent as an alternative to $C T$ scan and lymph-node dissection in patients with prostate cancer: a prospective multicohort study. Lance Oncol 2008; 9:850-856.

30. Lahaye $M J$, Engelen $S M$, Kessels $A G$, de Bruine $A P$, von Meyenfeldt MF, van Engelshoven IM, et al. USPIO-enhanced MR imaging for nodal staging in palients with primary rectal cancer: predictive crileria. Radiology 2008; 246:804-811. 
Chapter 10

Summary 


\section{SUMMARY}

The aim of this thesis was to evaluate technical aspects, clinical implications and outcome several aspects of the sentinel node procedure and determine the clinical implications of axillary and internal mammary sentinel node biopsy in patients with breast cancer.

In Chapter 1, an introduction on sentinel node biopsy in breast cancer is provided as well as the outline of the thesis.

Several studies have shown that lymphoscintigraphy, in combination with the intra operative use of a gamma detection probe, blue dye and radioactive tracer will achieve the highest SN identification rates. However, sometimes lymphatic mapping fails to show a hotspot, because of insufficient or absent radioactive tracer uplake in the lymph nodes. In Chapter 2 we evaluated the use of re-injections of $37 \mathrm{MBq}$ tracer intracutaneously in cases of initial scan failure in order to increase the technical success rate of the sentinel node procedure. A total of 1208 patients with clinically node-negative breast cancer were included in this study. In 93 patients $(7.7 \%)$ visualization of hotspots on initial lymphoscintigraphy was insufficient ( 41 patients) or absent (52 patients). The first 14 patients did not receive additional tracer injection. In 5 patients, additional tracer injection did not result in successful lymphoscintigraphy, which is correlated with massive nodal tumour infiltration. In 33 patients with negative initial lymphoscintigraphy, additional tracer injection resulted in secondary SN visualization. Almost half of these patients had a negative SN and could be spared an unnecessary axillary lymph node dissection (ALND). In 41 patients with faint hotspots on initial lymphoscintigraphy, additional tracer injection, by increasing nodal uptake, simplified an accurate SN biopsy. Decreased radiotracer uptake in this group was associated with older age and high BMI. In conclusion, we demonstrated that additional tracer injection is helpful to visualize hotspots in case of insufficient uptake of radioactive tracer in the sentinel node. However, if lymphatic mapping, even after additional tracer injection, fails to show axillary hotspots, axillary dissection should be performed because of the substantial risk of massive tumour infiltration.

Sentinel node ( $\mathrm{SN}$ ) biopsy has become the standard of care in the treatment of breast cancer, but several controversial issues remain. Scepticism persists about the accuracy of SN biopsy following previous excisional biopsy. It is assumed that the lymphatic drainage pattern is altered in these patients, resulting in less accurate lymphatic mapping and unreliable results of the SN 
biopsy. If this hypothesis is correct, then a number of breast cancer patients will not experience of the advantages of the $\mathrm{SN}$ technique. In Chapter 3, we reviewed the results of $\mathrm{SN}$ biopsy in a total of 88 patients, who had previously undergone diagnostic excisional biopsy followed by complete axillary lymph node dissection. Lymphoscintigraphy visualized one or more axillary hot spots in 84 of the 88 patients. A successful SN biopsy was performed in 87 patients. Complete axillary lymph-node dissection showed no false-negative SN biopsy among the 87 SN procedures. Consequently, the sensitivity of SN biopsy following previous excisional biopsy in this study was $100 \%$. Therefore, these results indicate that patients with previous excisional biopsy are eligible for the sentinel node procedure and can be spared an unnecessary axillary lymph node dissection, if found to be node-negative.

During the learning phase of the sentinel node procedure, false-negative results came to light by confirmatory axillary lymph node dissection. Nowadays, sentinel node negative patients do not receive elective ALND, with acceptance of a false negative rate of $5 \%$. This implies that a number of patients will develop an axillary recurrence. It therefore remains important to evaluate long-term follow-up results, especially with respect to axillary relapse as an indicator of a false-negative SN procedure.

In Chapter 4 we evaluated the results of SLNB with respect to locoregional failures in the axilla in SN-negative patients. Published studies on this subject showed axillary relapse risks ranging from $0 \%$ to $1.5 \%$ after a median followup of 14 to 57 months. Our own results, with an axillary recurrence risk of $0.9 \%$ after a median follow up of 43 months, are in accordance with these studies. Our own data, as well as that of the published series, found axillary recurrence to be less than expected. Although longer follow-up is required, these midterm follow-up data support the current opinion that ALND can be safely abandoned in case of a negative SN biopsy.

In spite of the fact that the preferential lymphatic drainage pathway from the breast is into the axilla, there are other locations to which metastatic tumour cells migrate. The second most important draining route from the breast is towards the internal mammary lymph nodes (IMN). This regional nodal basin has been studied intensively in the 1950's and 1960's. These studies showed that, in addition to the axillary lymph node status, the IM lymph node status provides important prognostic information in breast cancer patients. If positive, prognosis is less favorable. However to date, when lymphatic mapping reveals IM drainage, staging of these nodes is not performed routinely. 
In Chapter 5 we evaluated the relevance of IMSN biopsy as a method to improve staging in a total of 1008 consecutive patients. In this study, both axillary and IMSNs were sampled, based on lymphoscintigraphy, intraoperative gamma probe detection and blue dye mapping. Lymphoscintigraphy showed axillary sentinel nodes in 98\% (989/1008) and IMSNs in 20\% of the patients (196/1008). Sampling of the IM basin, as based on the results of lymphoscintigraphy, was successful in $71 \%$ of the patients $(139 / 196)$ and revealed metastases in $22 \%(31 / 139)$. In $29 \%$ percent of the patients with positive IMSNs (9/31) no axillary metastases were found. With respect to the clinical relevance of IMSN biopsy, adjuvant treatment strategies were changed in all patients with $1 \mathrm{M}$ metastases, by receiving adjuvant radiotherapy of the IM lymph node basin. Besides adjuvant radiotherapy, adjuvant chemotherapeutic regimes were changed in a small group of patients. Thus, IMSN biopsy improves nodal staging in breast cancer patients.

Although several studies have shown that IMSN biopsy enables identifying and selectively removing IMSNs with minimal morbidity, controversy remains regarding its clinical relevance and the expected benefit. We conducted a study to determine the usefulness of IMSN biopsy in terms of survival benefit. The results of this study are presented in Chapter 6. Data from 764 patients with a minimal follow up of one year were available. A total of 406 patients had no lymph node metastases (group 1), 330 patients had axillary metastases (group 2), 7 patients had IM metastases only (group 3) and 21 patients had both axillary and IM metastases (group 4). Mean follow-up was 46 months. Breast cancer specific survival was $95 \%$ for group 1, 84\% for group 2, $82 \%$ for group 3 and $89 \%$ for group 4 . Disease-free survival was $92 \%, 81 \%, 86 \%$ and $90 \%$, respectively, The differences between group 2, 3 and 4 were not statistically significant. Our results suggest that high risk patients with IM metastases benefit from improved staging and tailored adjuvant treatment algorithms. However, long-term follow-up data, preferably in larger series, are needed to support our findings.

There is a wide range of reported success rates of internal mammary hotspot visualization. Results differ mainly, because the detection rate is influenced by several technical, anatomical and biological factors. The aim of the study presented in Chapter 7 was to investigate whether different time intervals between injections of a radioactive tracer and performing lymphoscintigraphy affect the visualization rate of internal mammary hotspots. A total of 682 eligible breast cancer patients underwent sentinel lymph node mapping. The technique involved the injection of $370 \mathrm{MBq}(10 \mathrm{mCi}) \mathrm{Tc}-99 \mathrm{~m}$ 
nanocolloid peritumorally. In 470 patients (group A) the time interval between injection of the radiocolloid and lymphoscintigraphy was 16 hours, compared to 2.5 hours in 212 patients (group B). Axillary hotspots were visualized in $97 \%$ in group $A$ and $96 \%$ in group B. Lymphoscintigraphy showed internal mammary hotspots in $21 \%$ in group $A$, compared to $27 \%$ in group $B$, which is not statistical significant. Thus, in this study, we could not demonstrate a correlation between timing of the radiotracer injection and the lymphoscintigraphic detection of IM sentinel nodes.

Recently, SPECT/CT (Single-Photon Emission Computed Tomography/ Computed Tomography) came available as a new, non-invasive technique that combines the functional information of SPECT with the anatomical information provided by CT. Chapter 8 focuses on the use of SPECT/CT as compared to conventional lymphoscintigraphy alone, in patients with breast cancer with IM hotspots on lymphoscintigraphy. Forty-two consecutive patients were included. In 16 patients $(38 \%)$, the SPECT/CT provided no additional information compared to lymphoscintigraphy alone. In 5 patients (12\%) SPECT/CT provided additional information, but without surgical consequences. In the remaining 21 patients $(50 \%)$ the SPECT/CT results had a substantial impact on the surgical procedure. In 2 patients (4.8\%), the SPECT/CT showed additional SNs. In 20 patients (47.6\%) the SPECT/CT results gave substantial reason not to explore the $\mathrm{SN}$ as visualised on the lymphoscintigraphy. From our results, it can be concluded that SPECT/CT improves the localisation and increases the number of visualized SNs. But foremost, SPECT/CT reduces the number of unnecessary and potentially harmful explorations in patients with alleged IM hotspots on lymphoscintigraphy, which on SPECT/CT proved to be in aberrant positions

Sentinel node biopsy has played a significant role in the evolution of breast cancer treatment in the past decade. It has replaced ALND in case of a negative $\mathrm{SN}$ biopsy, as the preferred method to stage the axilla, thereby avoiding unnecessary morbidity associated with ALND. The SN procedure is a perfect example of the current trend for more minimally invasive diagnostic and therapeutic procedures. 
Chapter 11

Samenvatting 
Chapter 11 


\section{SAMENVATTing}

Het doel van dit proefschrift was om verschillende aspecten van de schildwachtklierprocedure te evalueren en om de klinische consequenties van zowel de axillaire als parasternale schildwachtklierbiopsie bij patiënten met borstkanker vast te stellen.

In Hoofdstuk 1 wordt een introductie over de schildwachtklierbiopsie bij borstkanker gegeven en wordt de opzet van het proefschrift beschreven.

Verschillende studies hebben aangetoond, dat een lymfoscintigrafie in combinatie met een blauwe kleurstof, een radioactieve tracer en het intraoperatieve gebruik van een gamma detectie probe de meest betrouwbare methode is om de schildwachtklier te identificeren.

Soms is er echter geen hot spot zichtbaar op de lymfoscintigrafie, vanwege afwezige of onvoldoende opname van radioactief materiaal in de lymfeklieren.

In Hoofdstuk 2 evalueren we of bijspuiten met een intracutane injectie van $37 \mathrm{MBq}$ in geval van afwezige of onvoldoende visualisatie van hot spots op de lymfoscintigrafie het succespercentage van de schildwachtklierprocedure kan vergroten. In totaal werden $1208 \mathrm{klinisch}$ okselklier negatieve borstkanker patiënten in deze studie geïncludeerd. Bij 93 patiënten $(7,7 \%)$ was de visualisatie van hotspots op de oorspronkelijke lymfoscintigrafie onvoldoende (41 patiënten) of afwezig (52 patiënten). De eerste 14 patiënten werden niet bijgespoten. Bij 5 patiënten leverde bijspuiten geen succesvolle lymfoscintigrafie op, hetgeen correleerde mel de anwezigheid van uitgebreide tumorgroei in de lymfeklier. Bij 33 patiënten met cen aanvankelijk negatieve lymfoscintigrafie resulteerde bijspuiten alsnog in schildwachtkliervisualisatie. Bijna de helft van deze patiënten had een negatieve schildwachtklier waardoor hen een onnodig okseikliertoilet bespaard kon worden. Bij 41 patiënten met vage hot spots op de initiële lymfoscintigrafie, werd door verbeterde opname na additionele tracer injectie, een eenvoudige en betrouwbare schildwachtklierprocedure mogelijk gemaakt. Verminderde opname van de radioactieve tracer was in deze groep geassocieerd met hogere leeftijd en een hoge BMI. In deze studie is aangetoond, dat bijspuiten een zinvolle bijdrage levert bij het visualiseren van hotspots indien er sprake is van onvoldoende opname van tracer in de schildwachtklier. Evenwel, als lymfoscintigrafie, ook na bijspuiten geen axillaire hot spots lat zien, dan is een okselklierdissectie geïndiceerd, omdat er een substantieel risico is op uitgebreide tumorgroei in de oksel. 
De schildwachtklierprocedure is de standaard behandeling geworden bij patiënten met borstkanker, maar er zijn nog verschillende controversiële onderwerpen. Nog steeds worden er vraagtekens geplaatst bij de betrouwbaarheid van de schildwachtklier-procedure na een voorafgaande diagnostische lumpectomie. Er wordt verondersteld, dat bij deze groep patiënten het lymfedrainagepatroon gewijzigd is en dat daardoor het resultaat van de schildwachtklierprocedure minder betrouwbaar zou zijn. Als deze hypothese juist is, zou een aantal borstkankerpatiënten niet kunnen profiteren van de voordelen van de schildwachtkliertechniek.

In Hoofdstuk 3, bespreken we de resultaten van de schildwachtklierbiopsie in een groep van 88 patiënten, die eerder een diagnostische lumpectomie hebben ondergaan, gevolgd door een okselkliertoilet. De lymfoscintigrafie toonde een of meer axillaire hot spots bij $84 / 88$ patiënten. Bij 87 patiënten vond een succesvolle schildwachtklierprocedure plaats. De okseldissectie toonde geen fout-negatieve procedure aan bij deze 87 patiënten. Dientengevolge was de sensitiviteit van de schildwachtklierprocedure na een voorafgaande diagnostische lumpectomie in deze studie $100 \%$. Derhalve komen ook patiënten na een diagnostische lumpectomie in aanmerking voor de schildwachtklierprocedure en kan de klier-negatieve patiënten een onnodig okselkliertoilet bespaard worden.

Tijdens de leercurve van de schildwachtklierprocedure kwamen foutnegatieve resultaten aan het licht door het aanvullend verrichte okselkliertoilet. Tegenwoordig wordt het okselkliertoilet achterwege gelaten bij patiënten met een negatieve schildwachtklier, waarbij $5 \%$ fout-negatieve procedures als acceptabel worden beschouwd. Dit houdt in, dat bij een aantal patiënten zich een okselrecidief zal ontwikkelen. Het blijft daarom belangrijk de lange termijn follow-up te evalueren, vooral omdat een okselrecidief kan duiden op een foutnegatieve schildwachtklierprocedure.

In Hoofdstuk 4 evalueren we de resultaten van de schildwachtklierprocedure met betrekking tot de locoregionale recidieven in de oksel bij patiënten met een negatieve schildwachtklierbiopsie. Gepubliceerde studies over dit onderwerp vermelden okselrecidieven met uiteenlopende percentages van $0 \%$ tot $1,5 \%$ na een mediane follow-up van 14 tot 57 maanden. Onze eigen resultaten, $0,9 \%$ okselrecidieven na een mediane follow-up van 43 maanden, stemmen overeen met deze studieresultaten. Onze eigen gegevens, evenals die van de voornoemde publicaties, laten minder locoregionale recidieven zien, dan men zou verwachten. Hoewel een langere follow-up periode noodzakelijk is, ondersteunen deze middellange follow-up gegevens 
de heersende opvatting, dat een okselkliertoilet veilig achterwege gelaten kan worden bij een negatieve schildwachtklierprocedure.

Ondanks het gegeven, dat de lymfedrainage van de borst bij voorkeur verloopt naar de oksel, zijn er andere locaties, waarnaar tumorcellen kunnen migreren. Lymfdrainage naar de parasternale lymfeklieren is, naast de axilla, de meest voorkomende drainageroute van de borst. Dit regionale klierstation is in de jaren '50 en '60 onderwerp van meerdere studies geweest. Deze studies tonen aan, dat -naast de status van de okselklieren- de lymfeklierstatus van hel parasternale klierstation belangrijke prognostische informatie levert bij patiënten met borstkanker. Bij positieve parasternale lymfeklieren is de prognose ongunstig. Tot op heden is stagering van parasternale lymfeklieren evenwel geen routine.

In Hoofdstuk 5 evalueren we de waarde van de parasternale lymfeklierbiopsie als methode ter verbetering van de stagering in een groep van 1008 achtereenvolgende patiënten. In deze studie, werden zowel axillaire als parasternale schildwachtklieren gebiopteerd op basis van lymfoscintigrafie, intra-operatieve detectie met een gamma probe en een blauwe tracer. Lymfoscintigrafie liet axillaire schildwachtklieren zien in $98 \%$ (989/1008) en parasternale klieren in $20 \%$ van de patiënten (196/1008). Het verrichten van een parasternale schildwachtklierbiopsie op basis van de resultaten van de lymfoscintigrafie, was succesvol in $71 \%$ van de patiënten (139/196) en toonde metastasen aan in 22\% (31/139). In 29\% van de patiënten met positieve parasternale schildwachtklieren (9/31) bleken de axillaire schildwachtklieren negatief. Gezien het belang van de parasternale klierstatus, werd de behandeling van alle patiënten met parasternale metastasen aangepast. Zij kregen aanvullende bestraling op de parasternale lymfeklieren. Behalve aanvullende bestraling, werd bij een kleine groep patiënten ook de chemotherapie aangepast. Derhalve wordt de stagering van borstkankerpatiënten verbeterd door parasternale schildwachtklierbiopsie.

Hoewel verschillende studies hebben aangetoond, dat het verrichten van een parasternale schildwachtklierbiopsie met geringe morbiditeit mogelijk is blijven er controversies bestaan wat betreft de klinische relevantie en het te verwachten voordeel. We onderzochten een groep patiënten om de betekenis van parasternale klierbiopsie met betrekking tot overleving vast te stellen. De resultaten van deze studie worden gepresenteerd in Hoofdstuk 6. Gegevens van 764 patiënten met een minimale follow-up van één jaar waren beschikbaar. Binnen deze groep hadden 406 patiënten geen lymfekliermetastasen (groep 1), 
330 patiënten hadden axillaire metastasen (groep 2), 7 patiënten hadden alléén parasternale metastasen (groep 3) en 21 patiënten hadden zowel axillaire als parasternale metastasen (groep 4). De mean follow-up was 46 maanden. Borstkanker specifieke overleving was 95\% voor groep 1, 84\% voor groep 2, 82\% voor groep 3 en $89 \%$ voor groep 4 . Ziektevrije overleving was respectievelijk $92 \%$, $81 \%, 86 \%$ en $90 \%$. De verschillen tussen groep 2,3 and 4 waren niet statistisch significant. Onze resultaten suggereren, dat patiënten met een hoog risico vanwege parasternale metastasen gebaat zijn bij verbeterde stagering on op maat gesneden adjuvante therapieschema's. Lange termijn follow-up gegevens, bij voorkeur in grotere series, zijn noodzakelijk om onze bevindingen te ondersteunen.

Er is een scala aan publicaties over het succespercentage bij de visualisatie van parasternale hot spots. De resultaten verschillen voornamelijk, omdat de detectie ratio wordt beïnvloed door verschillende technische, anatomische en biologische factoren. Het doel van de studie, welke in Hoofdstuk 7 wordt gepresenteerd, was te onderzoeken of een verschillende tijdsduur tussen he injecteren van de radioaclieve tracer en het tijdstip van de lymfoscintigrafie van invloed zou zijn op mate van visualisatie van parasternale hot spots. Een groep van 682 borstkankerpatiënten onderging de schildwachtklierprocedure. De techniek omvatte het injecteren van $370 \mathrm{MBq}(10 \mathrm{mCi}) \mathrm{Tc}-99 \mathrm{~m}$ nanocolloid rond de tumor. $\mathrm{Bij} 470$ patiënten (groep A) was de tijdsduur tussen injectie van het radiocolloid en de lymfoscintigrafie 16 uur, in vergelijking tot 2,5 uur bij 212 patiënten (groep B). Axillaire hot spots werden zichtbaar in $97 \%$ van groep A and in $96 \%$ van groep B. Lymfoscintigrafie ljet parasternale hot spots zien bi $21 \%$ in groep $A$, vergeleken met $27 \%$ in groep $B$. Dit verschil is niet statistisch significant. In deze studie konden wij derhalve geen correlatie aantonen tussen het tijdstip van de tracerinjectie en de lymfografische detectie van parasternale hot spots.

Onlangs kwam de SPECT/CT (Single-Photon Emission Computed Tomography/Computed Tomography) beschikbaar als een nieuwe, niet-invasieve techniek, die de functionele informatie van SPECT combineert met de anatomische informatie van de CT. Hoofdstuk 8 richt zich op het gebruik van SPECT/CT in vergelijking met de conventionele lymfoscintigrafie, bij borstkankerpatiënten met parasternale hot spots op de fymfoscintigrafie. Tweeenveertig achtereenvolgende patiënten werden geïncludeerd. Bij 16 patiënten $(38 \%)$, verschafte de SPECT/CT geen aanvullende informatie in vergelijking met lymfoscintigrafie alleen. Bij 5 patiënten (12\%) leverde de SPECT/CT additionele 
informatie op, maar dit leidde niet tot chirurgische consequenties. Bij de overige 21 patiënten (50\%) makkten de SPECT/CT resultaten een substantiee verschil uit voor het chirurgisch handelen. In 2 patiënten $(4,8 \%)$, liet de SPECT/CT extra schildwachtklieren zien. In 20 patiënten $(47,6 \%)$ gaven de SPECT/CT resultaten doorslaggevende redenen om de schildwachtklieren, gevisualiseerd op de lymfoscintigrafie niet te biopteren. Op basis van onze resultaten, kan worden geconcludeerd, dat SPECT/CT de lokalisatie en he aantal gevisualiseerde schildwachtklieren verbetert. Maar meer nog, de SPECT/CT vermindert het aantal onnodige en mogelijke morbiditeit verhogende exploraties bij patiënten met zogenaamde parasternale hot spots op de lymfoscintigrafie, die in SPECT/CT zich op een aberrante positie blijken te bevinden.

In de afgelopen 10 jaar heeft de schildwachtklierbiopsie een belangrijke rol gespeeld in de ontwikkeling van de behandeling van borstkanker. De schildwachtklierbiopsie heeft het okselkliertoilet vervangen als de standaard techniek voor de stagering van klier-negatieve patiënten, waardoor onnodige morbiditeit gerelateerd aan het okselkliertoilet kan worden vermeden. De schildwachtklierbiopsie is een goed voorbeeld van de trend richting minimaal invasieve diagnostische en therapeutische procedures. 
Dankwoord 


\section{DANKWOORD}

Het is zover, "het boekje" is af. Het schrijven van dit proefschrift is te vergelijken met de multidisciplinaire behandeling van het mammacarcinoom. Door intensieve samenwerking tussen de verschillende specialismen wordt gestreefd naar een snelle diagnose en adequate behandeling van patiënten met borstkanker. Zowel voor het tot stand komen als voor de afronding van dit proefschrift geldt eveneens dat er meerdere personen met mij hebben samengewerkt om tot dit eindresultaat te komen. Graag wil ik een aantal mensen in het bijzonder bedanken voor hun bijdrage.

Allereerst wil ik Dr. van der Ent, mijn co-promotor van harte bedanken. Fred, je grote betrokkenheid, inspiratie, geduld en je vertrouwen in mij zijn essentiee geweest om dit project af te ronden. Mijn eerste schildwachtklierbiopsie heb ik verricht onder jouw supervisie. Destijds had ik nooit gedacht dat jouw enthousiaste uitleg de basis zou zijn voor deze promotie. Jouw bijdrage is dan ook van onschatbare waarde.

Veel dank ben ik ook verschuldigd aan mijn tweede co-promotor, Dr. Voogd. Beste Adri, jouw statistische kennis zorgde voor onze eerste kennismaking. Daarna heb ik dankbaar gebruik gemaakt van je wetenschappelijke kennis en je nimmer aflatende bereidheid om over verschillende aspecten van het onderzoek mee te denken. Dankjewel voor de vruchtbare en gezellige samenwerking.

Prof. dr. von Meyenfeldt. Maarten, ondanks je overvolle agenda heb je toch de tijd gevonden en de rust genomen om mee te denken over de artikelen en hoofdstukken van het manuscript. Bedankt voor je begeleiding. Daarnaast hoop ik de komende maanden op oncologisch gebied ook nog het nodige van je te leren.

Prof. dr. Tjan-Heijnen, bedankt voor hel aanvaarden van de rol van voorzitter van de beoordelingscommissie van mijn proefschrift. Naast de voorzitter wil ik ook de andere leden van de beoordelingscommissie bedanken. Prof. dr. Teule, Prof. dr. Rutgers en Dr. Boersma, bedankt voor het kritisch lezen en becommentariëren van het proefschrift.

Prof. dr. Cserni, dear Gâbor, I would like to thank you for reviewing my PhD Thesis. 
Mijn paranimfen, Igna en Edith. Igna, het was een logische keuze om jou te vragen als paranimf. Je bent bij alle stadia van het onderzoek betrokken geweest en je hebt de nodige avonden en weekenden zonder je echtgenoot moeten doorbrengen, omdat hij weer eens een artikel moest reviseren. Bedankt voor je tijd, oprechte interesse op alle gebied en gezelligheid. Edith, als chirurgie-maatje hebben we al een aantal jaren samengewerkt. Dit houdt in de praktijk in dat we elkaar soms meer hebben gezien dan onze eigen familie. Bedankt voor je hulp en luisterend oor in de slotfase van het onderzoek.

Ook een woord van dank voor de secretaresse van Maarten, Joyce Haas, die een beetje "mijn" secretaresse is geweest. Zowel afspraken met Maarten als alle formulieren en telefoontjes over de promotie heb je geweldig geregeld.

Ik wil ook al mijn collega's van het Maastricht Universitair Medisch Centrum $(\mathrm{MUMC}+$ ) bedanken voor de geboden gelegenheid het proefschrift af te ronden.

De maatschap chirurgie in Sittard met in hel bijzonder drie chirurgen, Dr. Hoofwijk, Dr. Hulsewé en Dr. Heeren. Ton, dankzij jouw vooruitziende blik en motiverende enthousiasme is er nu toch echt een promotie. Karel en Michiel, bedankt voor jullie medewerking aan het onderzoek en bijdragen aan de diverse manuscripten.

Bijzondere dank ben ik ook verschuldigd aan twee nucleair geneeskundigen, Drs. van de Pol en Dr. Kengen. Beste Harry en Roland, jullie nucleair geneeskundige kennis vormt mede de basis van dit proefschrift. Dank voor jullie inzet en plezierige samenwerking.

Mijn vader en moeder wil ik bedanken voor hun onvoorwaardelijke steun. Zonder jullie was dit boekje er nooit geweest. Mijn drietal mag blij zijn met zo'n opa en oma!

Mijn drie wondertjes: Sterre, Lieve en Melle...eindelijk is het boekje van mamma af....gelukkig wil pappa niet promoveren. 